\title{
Constructability of road pavement layers using New-age (Nano) Modified Emulsions (NME) stabilisation of naturally available granular materials in roads varying from highways to local ac-
} cess roads

\author{
Gerrit J Jordaan ${ }^{1,2, *}$ and Wynand J vdM Steyn ${ }^{3}$
}

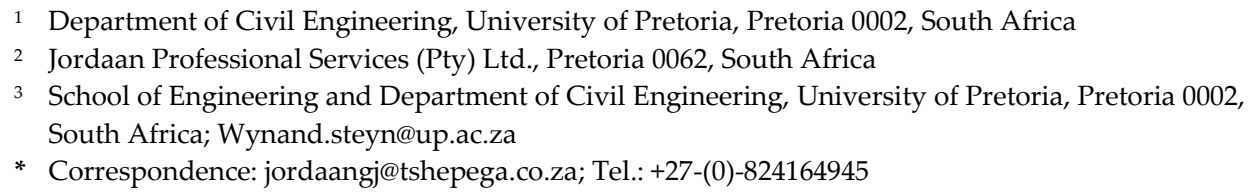

Featured Application: The general use of New-age (Nano) Modified Emulsion (NME) is applicable for the construction of high-order multi-lane highways to lower-order access roads in villages/townships. These nanotechnology solutions are suitable for use with construction equipment ranging from the most sophisticated to the elementary, including labour-enhanced construction methods. NME enhancement/stabilisation of materials for use in roads enable the use of marginal material in all categories of roads. The general acceptance of these new disruptive technologies will be driven by the ease of use, time and cost implications and robustness of the technology during construction in practice, with associated reduction in risks and costs.

\begin{abstract}
The introduction of any new disruptive technology in a traditionally well-established industry, such as the road construction industry, is usually associated with considerable resistance. This is especially relevant when the new technology is based on the use of granular materials traditionally considered to be of an unacceptable quality in combination with relatively new concepts such as New-age (Nano) Modified Emulsions (NME). In such cases, the fact that the material design methods are based on fundamental scientific principles and have been proven in laboratories and through Accelerated Pavement Testing (APT), may be of little influence. However, the general acceptance of new disruptive technologies, e.g. telecommunications and Information Technologies (IT), have been based on the considerable advantages it presented. The same principles are applicable to the general acceptance and use of NME stabilisation/enhancement of materials in the road construction industry. This article is aimed at the practical demonstration of the advantages of the use of nanotechnologies in the construction of the highest order roads (i.e. inter-city multi-lane highways) to lower order access roads (i.e. Low-Volume-Roads (LVR) and even local accesses to farms and in villages/townships). The implementation of NME technologies is directly associated with ease of use, time and cost savings and the addressing and reduction of risks.
\end{abstract}

Keywords: Constructability using nanotechnology applications, nano-silane stabilisation of granular materials, highway construction, central plant mixing; recycling, rehabilitation using nano-silane technologies, materials compatibility, nanotechnology construction related problems, maintenance advantages of nanotechnology solutions

\section{Introduction}

The introduction of any new disruptive technology [1] in a traditionally well-established industry such as the road construction industry, is usually associated with considerable resistance. This is especially relevant when the new technology is based on the use of granular materials traditionally considered to be of unacceptable quality in combination with new relatively new concepts such as New-age (Nano) Modified Emulsions (NME). In combination with fundamental concepts in terms of practical 
pavement engineering, such as Unconfined Compressive Strength (UCS) and Indirect Tensile Strength (ITS), to evaluate the suitability of the use of stabilised granular materials in road pavement layers, nanotechnology advantages may be met with resistance in practice by traditionalists unfamiliar with these material evaluation techniques. In such cases, the fact that the stabilised granular material design method is based on fundamental scientific principles $[2,3,4,5,6,7,8]$, been evaluated and proven in National Research and University laboratories $[4,9,10]$, evaluated in practice through Accelerated Pavement Testing (APT) $[11,12,13]$ and implemented on several roads in southern Africa [14] may have little effect on the construction industry.

In order to be of benefit and to assist in addressing the considerable backlog in transportation infrastructure in (especially) the developing regions of the world, the practical aspects associated with new technologies must be proven to such a degree that all doubts are sufficiently addressed in order to overcome a natural resistance to change. A good transportation infrastructure network forms the backbone and is a pre-requisite to economic development of any country. Hence any potential considerable savings in the unit costs for the provision and maintenance of road infrastructure (without compromising quality and durability), need to be adopted without delay. This can be accomplished through pre-empting any construction related concerns and addressing potential problems and risks for general acceptance to be achieved.

Accelerated acceptance of the introduction of new disruptive technologies, such as in the telecommunications industry (cell/mobile phones) and Information Technologies (IT) (computer technologies), have been based on the considerable advantages these technologies presented to the general population. The same principles are applicable to the general acceptance and successful use of NME stabilisation/enhancement of granular materials in the road construction industry. Proven benefits and risk reductions to the road construction industry will lead to the adoption of nanotechnology solutions despite traditional resistance to change. This article is aimed at the demonstration of the ease of use and the practical advantages of the implementation of NME stabilisation of naturally available granular materials. The applicability of these technologies is demonstrated for the construction of the highest order roads (i.e. inter-city multi-lane highways) to lower order access roads (i.e. Low-Volume-Roads (LVR)) and even local accesses to farms and in villages/townships.

No technology is without risks. However, a rigorous process of risk assessment and the development of a scientifically based material design method [8], laboratory evaluations $[4,9,10]$ and full-sale APT loading assessments $[11,12,13]$, allowed for design risks to be identified and as far as possible, to be addressed in practice. However, contractors often experience unforeseen risks, many of which can be prevented or limited through the timeous identification thereof and the demonstration of the consequences and possible solutions to construction problems through practical examples. Over and above construction procedures, this article also identifies and addresses some of these more subtle (but logical) construction problems that can easily be prevented by following sound construction practices.

NME stabilising agents are highly "forgiving" even in cases where engineering criteria are initially not met due to unforeseen circumstances (e.g. weather conditions or construction equipment problems). In such cases, remedial actions are often possible without major cost implications. These corrective actions are usually associated with a better understanding of the impact and interaction of the NME technology on the granular materials and the basic engineering properties to be achieved in terms of UCS, ITS and durability (Retained UCS (TCS) and Retained ITS (RTS) criteria. Basic principles to construction practices forms the basis for the successful implementation of any technology/procedures and, in some instances, NME stabilising agents may expose unsound practices. Cost-effective solutions to possible construction related problems are crucial to be understood as a function of the inherent characteristics of the NME stabilising agents. Nanotechnology solutions can, in line with the construction and rehabilitation of roads, also contribute significantly to the cost-effective maintenance of the existing surfaced 
road networks, providing water-resistant solutions while creating numerous employment opportunities through improved maintenance (routine as well as periodic) actions of a valuable national asset.

\section{Construction Industry Acceptance of New Technologies}

The introduction and general acceptance of any new technology in an established industry are a function of a number of factors, including:

Primary construction related interest factors influencing new technology introduction:

- Influence on profitability;

- Required equipment and cost thereof;

- Ease of construction;

- Production rates to be achieved;

- Delays caused by slow drying/setting of materials;

- Risk associated with implementation;

- Actions required to reduce risks;

- New skill-set requirements for practical implementation;

- Industry resistance to change as a function of comfort with design approaches and vested interests, and

- $\quad$ Perceived treads to established monopolies.

Secondary interest factors:

- Toxicology (normally addressed through legal requirements),

- Environmental factors (normally addressed by legislation), and

- Addressing the unknown - the fear-factor, by demonstrating safety, opportunities, benefits and addressing scepticism among traditionalists.

Most of these primary and secondary factors have already been discussed in detail in the various publications referred to $[2,3,4,5,6,7,8]$. The practical construction issues, e.g. the use of equipment, identification of and solutions to potential problems and the addressing of opportunities, e.g. maintenance advantages presented through the implementation of nanotechnology solutions, are addressed in this article.

The versatility and ability of anionic NME stabilisation/enhancement of granular materials to address needs at all levels of the road construction industry are of prime importance. It enables the fiscus and authorities to provide more infrastructure at considerably reduced costs without compromising engineering quality. As demonstrated in this article, the implementation of NME technologies will reduce risks to contractors (ease of implementation/operations, generating of opportunities for entering the market space, generation of more projects with the same available funds) and create opportunities to maintain or increase profitability.

\section{Defining Marginal Materials}

The use of marginal materials in road pavement design and construction is usually associated with Low Volume Roads (LVR). This general perception among pavement engineers in terms of the optimum utilisation of granular materials, require a mind-shift in traditional perceptions with the introduction with applicable, proven nanotechnologies. With the enhancement, protection and stabilisation of granular materials using proven nanotechnology applications (organofunctional silane technologies), the traditional perception of marginal or unsuitable granular materials for use in specific pavement layers as a function of design criteria, is far from accurate. It is by far more easy to adjust and enhance the material properties of a relatively good quality granular material (just not meeting the standards of freshly crushed stone), compared to the enhancement/improvement of the quality of very poor-quality materials, containing high percentages of secondary minerals. The definition of "marginal" materials and the use thereof in various road categories is discussed using the basic, easily comparable, relative qualities of the South African granular material classification system [15] as summarised 
Figure 1. For a full understanding of the granular material classification system as well as scientific basis of the nanotechnology solutions, the various references should be studied.

\section{Relative Quality: South African Granular Material Classification}

CBR $\quad$ Material Use in Base/Sub-base pavement layers

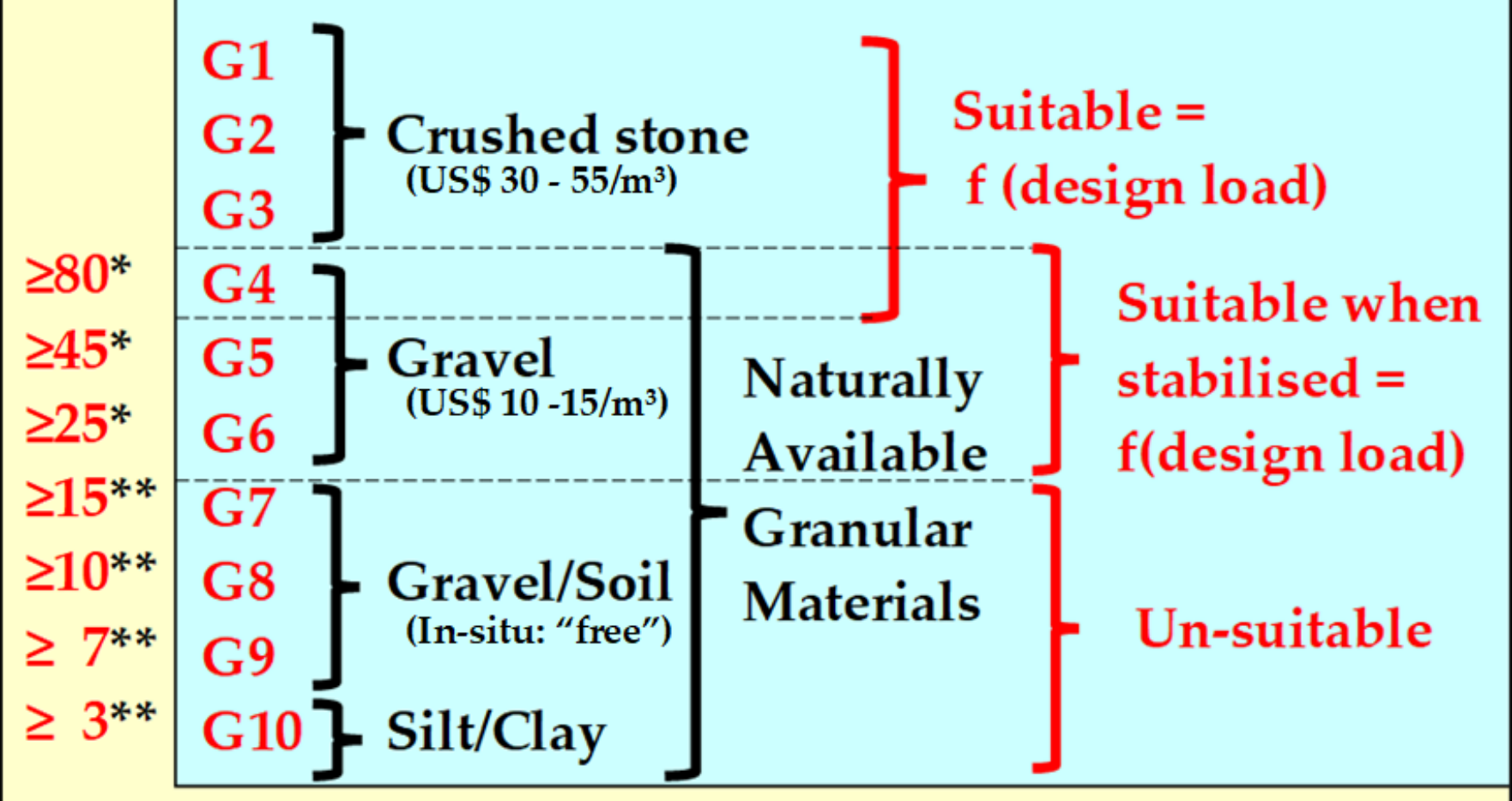

\section{CBR = California Bearing Ratio @ * 95\% Mod. AASHTO; ** 93\% Mod. AASHTO}

Figure 1. Summary of the comparative relative qualities of granular materials as defined using the South African road building material classification system [15] (definition of Mod AASHTO refer [16,17]) - prices associated with the various materials vary depending on the availability from region to region and are based on material costs in South Africa (2021- excluding haulage costs) - depending on the scarcity of high-quality granular materials these prices may vary considerably

The traditional material classification system presented in Figure1 [15] and the use thereof in practice, is, off-cause a function of the design traffic loading, usually expressed in terms of the Equivalent number of dual wheel $80 \mathrm{kN}$ single axle loads [16] (E80s) calculated over the design period [17]. The design E80s are closely associated with the Category of the Road, the expected Level Of Service (LOS) and the number of vehicles (capacity) of the road as per normal new road or rehabilitation design. The Category of road will also determine the accuracy of design [e.g. 8,18,19] as well as the required structural and functional characteristics which must be addressed through the application of normal accepted guideline documents developed and used throughout the world in various countries.

As an introduction to and the understanding of the relevance of the construction techniques, the comparative design catalogue (design pavement structures for design traffic loadings of 1 million standard dual wheel axle loadings (E80s) to 30 million E80s) and the material requirements are repeated in Figures 2 [8], 3 [8] and 4 [19]. It should be noted that the application of the NME technology is not limited to 30 million E80s. The 
APT results (tests performed by the South African CSIR [11,12]) have demonstrated that designs can, with ease, be done for traffic loadings to at least a 100 million E80s. The design of LVR and access roads have also been addressed in more detail in a comprehensive design document applicable to all environmental Climatic Zones of the World [19] with applicable materials criteria summarized in Figure 4 [19].

From the comparative design catalogue (Figure 2), it is seen that for the higher order roads, using conventional designs, a high-quality crushed stone is prescribed for the construction of the base layer (as an alternative to full-depth asphalt designs). This materials are usually only available from commercial sources at a considered cost which, in addition, is also associated with haulage costs that could be substantial, depending on the availability of the material relative to the distance from the construction site. Haulage costs may be a major factor in areas between the Tropics close to the Equator and in desert areas where sources of high-quality crushed stone may be a scarce commodity. In comparison, naturally available materials (gravels of a G5 to G8 quality (refer Figure 1) or sand of various gradings), may be more readability available close to construction sites. The use of the naturally available granular materials together with a material compatible anionic NME stabilising agent, may result in considerable savings in material costs as a basic input into life-cycle cost analyses [18].

Naturally available materials close to, but not meeting the classification criteria/properties of freshly crushed stone, usually still contain a solid core of primary minerals with some presence (relatively small percentages) of secondary minerals which developed as a result of some chemical weathering. The neutralisation of any possible negative effect of these secondary minerals, using applicable nanotechnologies, are relatively easy to achieve by following the recommended materials design method [8].

The opposite is the case with materials of very poor quality as defined for use in road pavement structures (these materials may be classified as very good for purposes such as agriculture). In these cases, the bulk of the naturally available material may consist of secondary minerals with the structure of the particles of the primary minerals already compromised due to the process of chemical weathering [8]. It follows that the crushing strength of the primary minerals present in the naturally available may already have been compromised. Although more complicated, the characteristics of these materials can also substantially be improved using applicable nanotechnologies [8]. In these cases the material may be improved for use in the upper layers (base and/or sub-base of LVR or even roads with design traffic loading up the 3 million E80s, or the supporting layers of pavement structures with higher design traffic loadings.

In terms of traditional designs, G3 to G6 materials are considered marginal or unacceptable for use in roads with a design loading in excess of 10 million E80s. However, in combination with a material compatible anionic NME stabilisation agent, this quality of material is chemically improved to be suitable for use in the base and sub-base layers of these roads. Depending on the mineralogy of the materials and the implementation of a scientifically based materials design approach [8], a material compatible anionic NME stabilising agent can be used with confidence with G3 to G6 materials to meet all engineering specifications for design traffic loadings in excess of 10 million E80s, without compromising quality. In fact, the material compatible anionic NME stabilising agent will protect every particle of the granular material used in the construction of the pavement layers from access to moisture (water) and prevent any possible weathering during the design period of the road [8]. Hence, long term durability is improved with an associated reduction in future periodic maintenance requirements. 

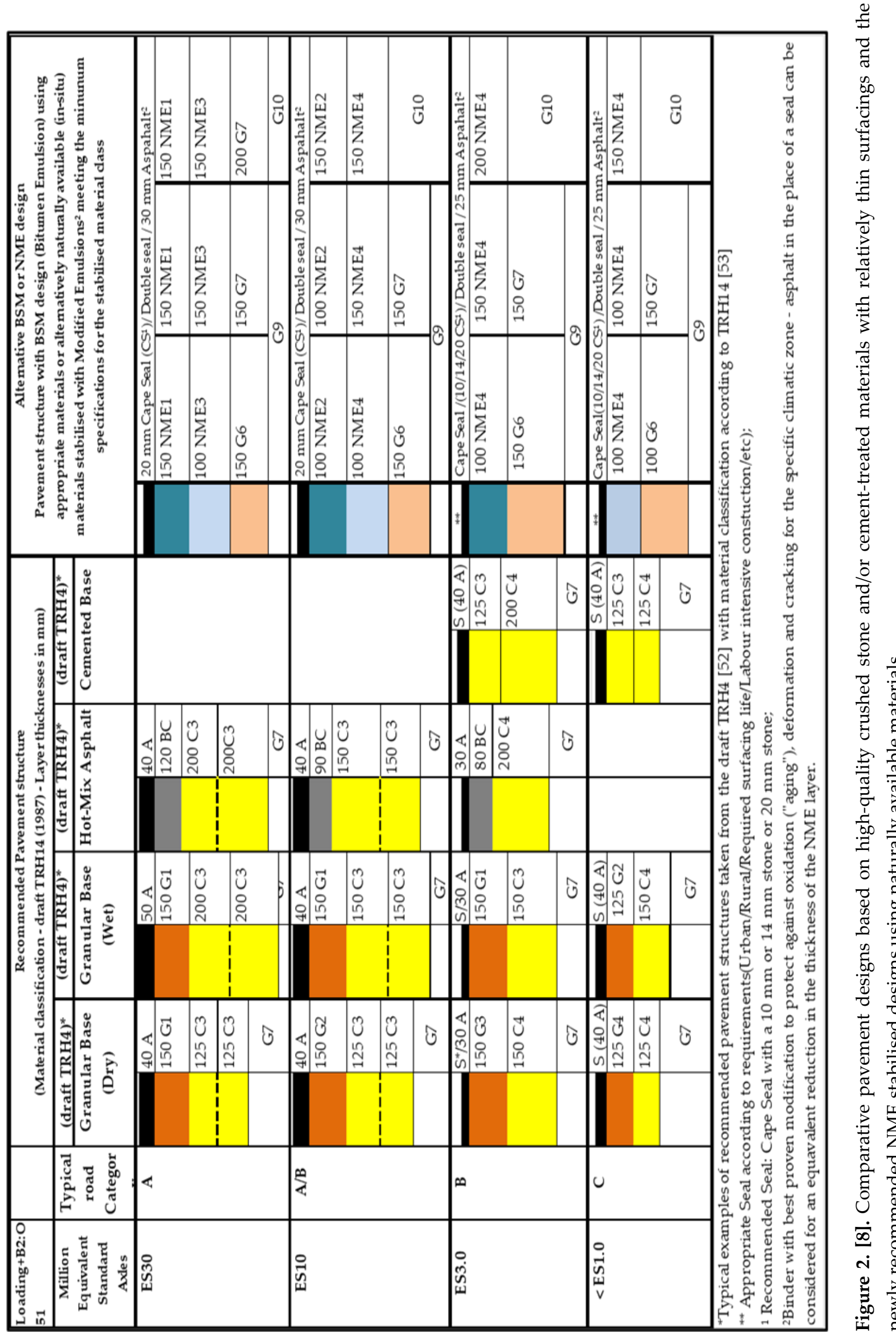


\begin{tabular}{|c|c|c|c|c|c|}
\hline \multirow[b]{2}{*}{ Test or Indicator } & \multirow[b]{2}{*}{ Material $^{1}$} & \multicolumn{4}{|c|}{ Material classification } \\
\hline & & NME1 & NME2 & NME3 & NME4 \\
\hline \multicolumn{6}{|c|}{ Min imum material requirements before stabilisation and/or treatment (Natural materials) } \\
\hline \multirow{2}{*}{$\begin{array}{l}\text { Material spec.(minimum) } \\
\text { Unestablished material: } \\
\text { Soaked CBR }{ }^{2}(\%) \\
\text { (Mod AASHTO) }\end{array}$} & \multirow[b]{2}{*}{ NG /(CS) } & $>45^{2}(95 \%)$ & \multirow[b]{2}{*}{$\begin{array}{l}>25^{2} \\
(95 \%)\end{array}$} & \multirow[b]{2}{*}{$\begin{array}{l}>10^{2} \\
(93 \%)\end{array}$} & \multirow[b]{2}{*}{$\begin{array}{l}>7^{2} \\
(93 \%)\end{array}$} \\
\hline & & $A C V<30 \%$ & & & \\
\hline \multirow{2}{*}{ Grading Modulus (GM) } & NG & $>1.8$ & $>1.5$ & - & - \\
\hline & GS & NA & $>1.5$ & - & - \\
\hline Sieve analysis: $\%<0.075 \mathrm{~mm}\left(\mathrm{P}_{0.075}\right)$ & ALL & $<20 \%$ & $<25 \%$ & $<35 \%$ & $<50 \%$ \\
\hline $\begin{array}{l}\text { XRD scans: } \\
\text { - Total sample } \\
-0.075 \text { mm fraction }\left(P_{0.075}\right)\end{array}$ & $\begin{array}{l}\text { ALL } \\
\text { ALL }\end{array}$ & $\begin{array}{l}\sqrt{ } \\
\sqrt{ }\end{array}$ & $\begin{array}{l}\sqrt{ } \\
\sqrt{ }\end{array}$ & $\begin{array}{l}\sqrt{ } \\
\sqrt{ }\end{array}$ & $\begin{array}{l}\sqrt{ } \\
\sqrt{ }\end{array}$ \\
\hline \multirow{6}{*}{$\begin{array}{l}\% \text { Material passing } 2 \mu \mathrm{m} \text { (Po.002) (e.g. } \\
\text { Clay \& Mica \& Talc) as a \% of Material } \\
\text { (with Talc }<10 \% \text { ) } \\
\text { (XRD-scans of the material passing } \\
\text { the } 0.075 \mathrm{~mm} \text { sieve is used to } \\
\text { determine the \% clay, mica } \\
\text { (muscovite) and talc in the material - } \\
\text { In this case } \mathrm{P}_{0.002}=\mathrm{P}_{0.075} \times \text { (Pday, ex in } \\
\mathrm{P}_{0.075} \text { ) }\end{array}$} & \multicolumn{5}{|c|}{ NME stabilisation with micro-meter $(\mu \mathrm{m})$ emulsion particle sizes } \\
\hline & ALL & $<15 \%$ & $<15 \%$ & $<15 \%$ & $<15 \%$ \\
\hline & \multicolumn{5}{|c|}{$\begin{array}{l}\text { NME stabilisation with emulsion containing micro-scale as well as nano- } \\
\text { scale particles (adjusted according to material grading) }\end{array}$} \\
\hline & $\mathrm{ALL}$ & $\mathrm{NA}$ & $<35 \%$ & $<35 \%$ & $<35 \%$ \\
\hline & \multicolumn{5}{|c|}{$\begin{array}{c}\text { NME stabilisation with emulsion containing nano-scale and pico-scale } \\
\text { particles (grading adjustments) together with technologies addressing } \\
\text { workability of materials on site }\end{array}$} \\
\hline & ALL & NA & NA & $>35 \%$ & $>35 \%$ \\
\hline \multicolumn{6}{|c|}{ Material specifications after s tabilisation and/or treatment } \\
\hline \multirow{2}{*}{$\begin{array}{l}\text { In-situ den sity to be re quired after } \\
\text { stabilisation and compaction (mod } \\
\text { AASHTO) }(\%) \text { (minimum) }\end{array}$} & Base & $>100 \%$ & $>100 \%$ & $>98 \%$ & $>97 \%$ \\
\hline & Sub-base & NA & $>98 \%$ & $>97 \%$ & $>95 \%$ \\
\hline $\begin{array}{l}\mathrm{DCP}(\mathrm{DN} \mathrm{mm} / \text { blow)(Quality } \\
\text { control) } \\
\text { (stabilised and compacted) }\end{array}$ & & NA & NA & $<2.6$ & $<3.5$ \\
\hline $\begin{array}{l}\text { Mod AASHTO density (\%) } \\
\text { (for laboratory testing) }\end{array}$ & & $>100 \%$ & $>100 \%$ & $>100 \%$ & $>100 \%$ \\
\hline \multirow{2}{*}{$\begin{array}{l}\text { *UCS wet (kPa) } \\
(150 \mathrm{~mm} \Phi \text { Sample) }\end{array}$} & Design $^{3}$ & $>2500$ & $>1500$ & $>1000$ & $>750$ \\
\hline & Construction $^{4}$ & $>2200$ & $>1200^{5}$ & $>700^{5}$ & $>450^{5}$ \\
\hline $\begin{array}{l}\text { Retained Compressive Strength } \\
\text { (RCS): (UCS Swed UCSdry) (\%) }\end{array}$ & & $>85$ & $>75$ & $>70$ & $>65$ \\
\hline 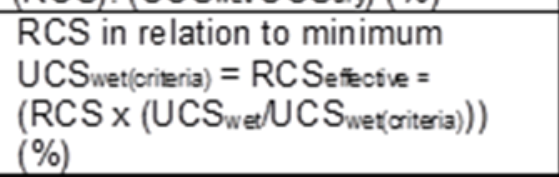 & & $>100$ & $>100$ & $>100$ & $>100$ \\
\hline \multirow{2}{*}{ *|TS $S_{\text {wet }}(\mathrm{kPa})(150 \mathrm{~mm} \Phi$ Sample) } & Design $^{3}$ & $>240$ & $>200$ & $>160$ & $>120$ \\
\hline & Construction $^{4}$ & $>220$ & $>180^{5}$ & $>140^{5}$ & $>100^{5}$ \\
\hline $\begin{array}{l}\text { Retained Tensile strength (RTS): } \\
\text { ITS } \\
\text { werlIT Sdry }(\%)\end{array}$ & & $>85$ & $>75$ & $>70$ & $>65$ \\
\hline 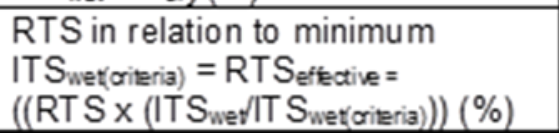 & & $>100$ & $>100$ & $>100$ & $>100$ \\
\hline \multicolumn{6}{|c|}{ 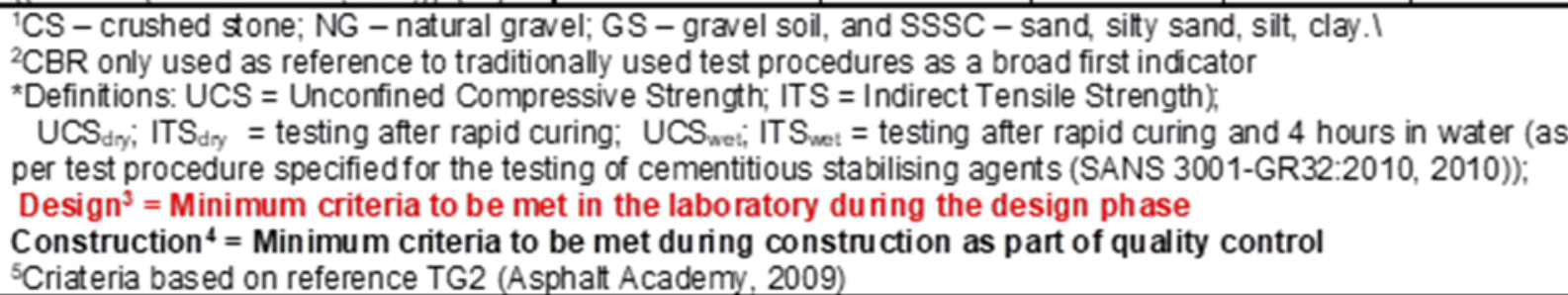 } \\
\hline
\end{tabular}

Figure 3 [8]. Minimum recommended standard specifications for New-age (Nano) Modified (NME) stabilised materials, addressing four different classifications in terms of engineering requirements. 


\section{Basic NME Requirements Meeting the Needs of Constructability in often Difficult Conditions}

Construction operations, especially in the developing regions of the world, often present contractors with severe challenges in terms of various factors unfamiliar to the developing world, including:

- Logistical problems getting materials timeously on site due to infrastructure and climatic conditions and limited production facilities;

- Maintenance problems with regard to construction equipment (limited access to spare parts);

- Uncertainties with regard to sureties and irregular payments;

- Community factors as a result of high unemployment rates and factional (political) influences and related delays due to often unrealistic expectations of employment created in areas with high needs and poverty, etc.

$\mathrm{Al}$ of these challenging conditions require that a basic requirement of any product delivered for stabilisation/enhancement of naturally available granular materials must be resilient in nature in these areas. Suppliers need to guarantee the stability of any NME stabilising agent for lengthy periods of time under extreme climatic conditions, often with minimum ability of regular maintenance of the stabilising agent (e.g. circulation of the stabilising agent stored in flow-bins or tankers in the sun under challenging conditions). These requirements should be addressed clearly in special provisions within contracts, requiring contractors and their suppliers to guarantee the stability of the NME stabilising agent over a period of time (minimum recommended storage time of 4 months), as dictated by local conditions.

Any specified stabilising agent must be able to be applied at ambient temperatures without prior heating and circulation and mixed with the construction water with ease to enable quick and reliant distribution and mixing. Product manufacturing must ensure that particle sizes are minimized to ensure that distribution with construction water can be maintained with a minimum risks of blockages to ensure that nozzles of equipment are staying open (provided equipment is clean at the start of operations) during applications. These requirements will prevent frequent delays caused by blockages which will require frequent cleaning operations, resulting in unnecessary stoppages during construction. Practical experience in southern Africa has shown that high-quality anionic NME stabilising agents are able to meet these conditions with ease.

\section{Construction of NME stabilised pavement layers in practice - basic requirements}

\subsection{Weather conditions}

Weather conditions and limitations to construction as per normal road construction projects are applicable of the construction of road pavement layers using NME stabilising agents. The NME stabilising agents must be added to the construction water prior to the addition thereof to the granular materials that are being stabilised. The in-situ moisture of the materials will determine the total construction water required (together with the stabilising agent), in order to achieve optimum construction compaction conditions. Experience has shown that the best conditions are normally achieved at moisture contents just below Optimum Moisture Contents (OMC). Hence, it is recommended that the total of the added fluid content of the NME stabilising agent be taken into account in the calculation of the required construction water to be added.

For example, if the OMC of the granular material to be stabilised is 8 per cent and the granular material to be stabilised contains 5 per cent moisture, the construction water with the NME stabilising agent to be added is $(8-5) 3$ per cent. In the case where the optimum NME stabilising agent has been established through laboratory testing to be 1 per cent. The 1 per cent NME stabilising agent need to be added to 2 (3-1) per cent construction water prior to the mixing with and stabilising of the granular materials. Some modern recycling equipment allows more than one feed into the recycler. Under no cir- 
cumstances should the NME stabilising agent and construction water be fed into such equipment separately. Water in the carrier of the NME stabilising agent and the separate addition of water and the stabilising agent will not allow for the distribution of the NME stabilising agent with the construction water and result into an unsuccessful stabilisation of the pavement layer.

Depending on local conditions (e.g. very hot days), allowance should be made for the evaporation of water during the stabilising process by increasing the percentage of construction water. The increase of the construction water will also depend on the type of equipment used in the stabilisation process (which will influence the construction time and hence, result in an increase in the evaporation of the water).

\subsection{Delivery and storage of NME stabilising agent to a road construction site}

The NME stabilising agent is normally delivered to site in 1000 litre flow-bins (Figure 5) or using bulk storage tankers varying in size from 15000 to 30000 litres (Figure 6). Although it is often stipulated by supplier to store flow-bins or tankers in shade, experience has shown that high-quantity anionic NME stabilising agents will be stabile with no separation for more than 4 months (recommended minimum required specification) in harsh climatic conditions with daily temperatures exceeding $35^{\circ} \mathrm{C}$ with no shading (Figure 7). In big tankers fitted with a simple circulating pump, a high-quality anionic stabilising agent has been shown to stay stable with no increase in viscosity for periods exceeding 12 months with a once-a-week maintenance (circulation using the fitted circulation pump).

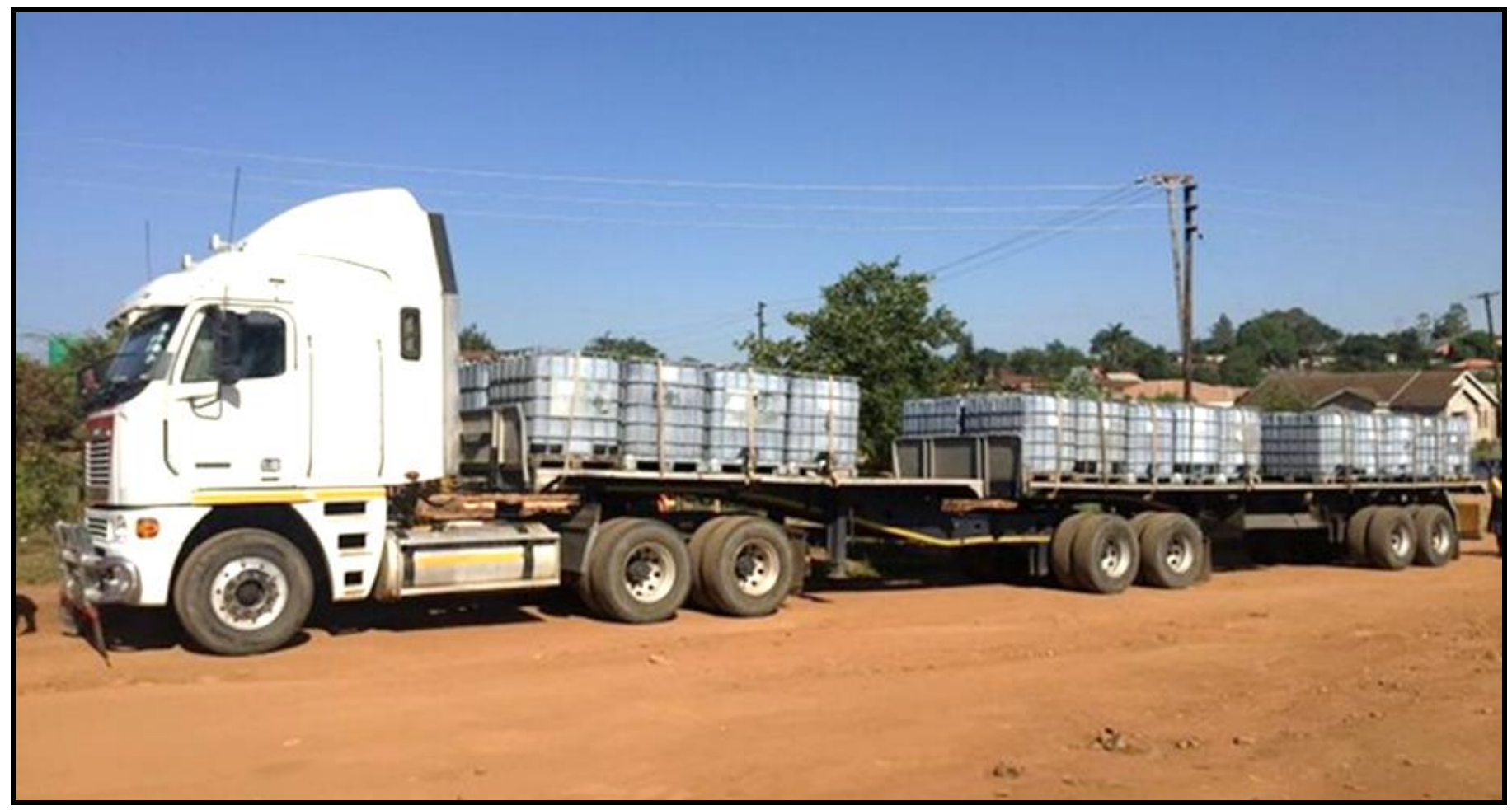

Figure 5. Arriving on site of material compatible anionic NME stabilising agents on site in 1000 litre flow-bins 


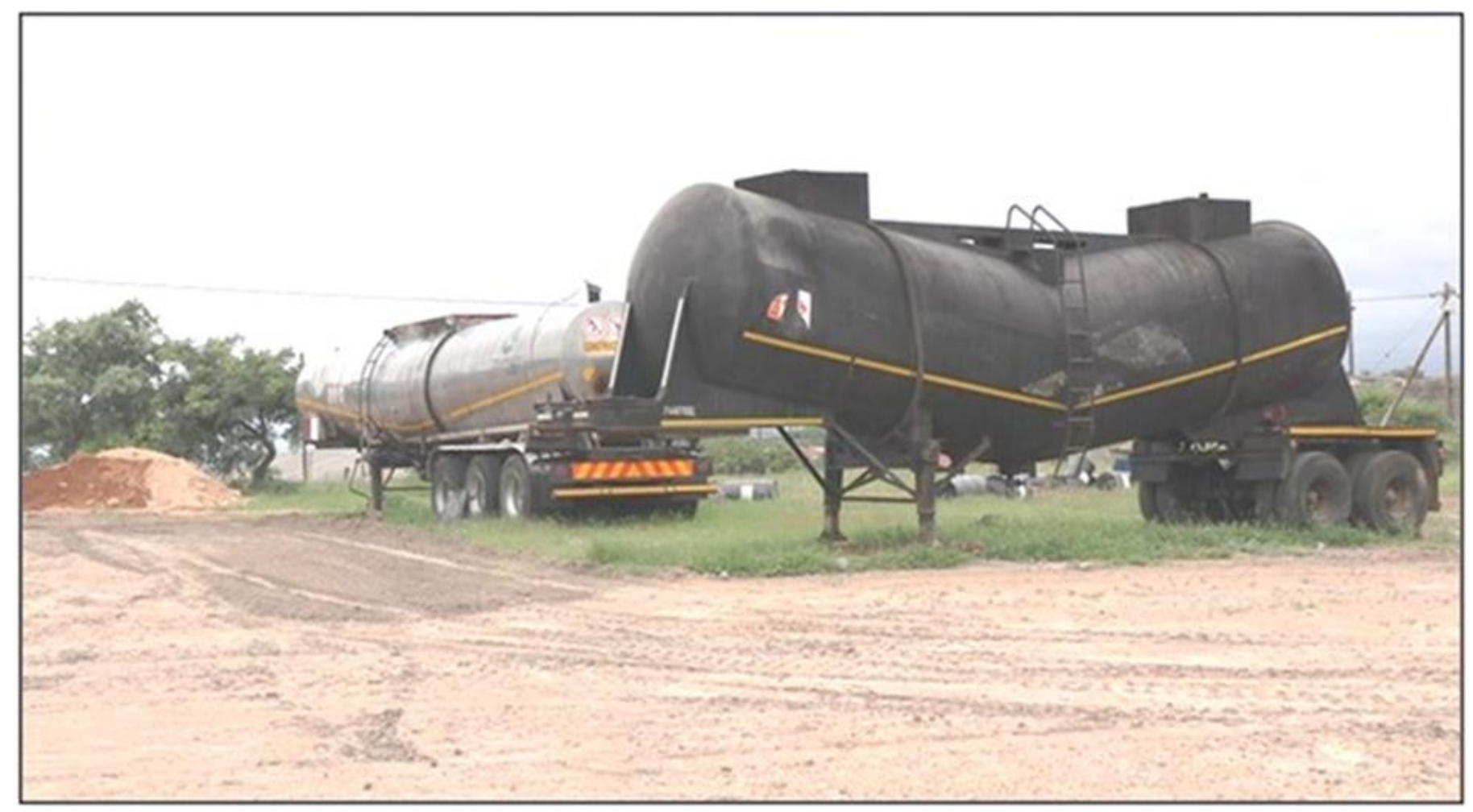

Figure 6. NME stabilising agents delivered to site in bulk storage tankers varying in size normally from 15000 to 30000 litres, depending on the preparation of the contractor

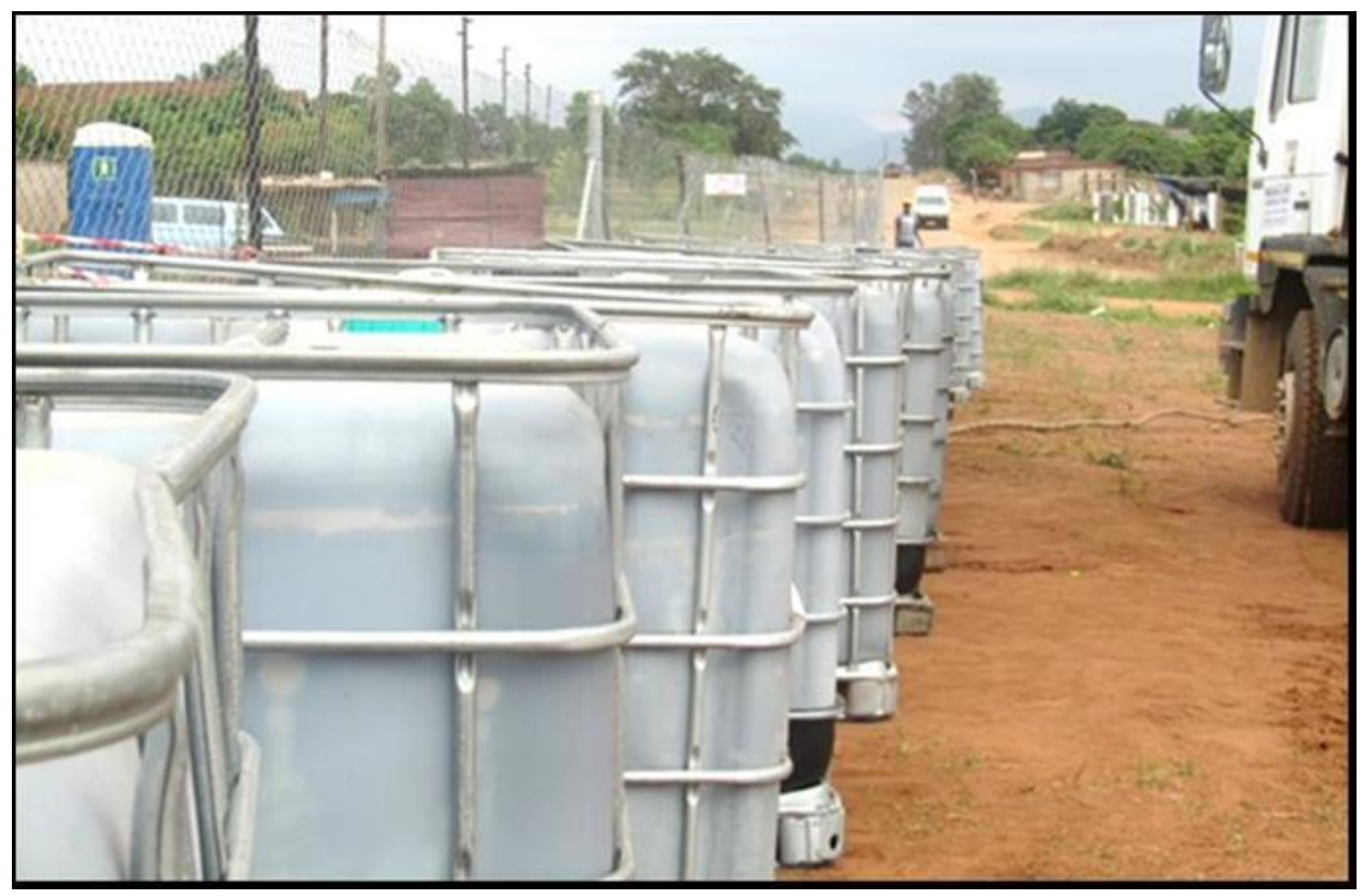

Figure 7. Flow bins containing a high-quality anionic NME stabilising agent exposed to high daily temperature conditions showing no separation or an increase in measured viscosity for periods exceeding 4 months 


\subsection{Clean equipment}

A pre-requisite to the successful application of a NME stabilising agent is the use of thoroughly cleaned equipment. Although contractors are made aware of this aspect, it is almost without exception found that the first day of operation present problems with the use of equipment containing residue from previous operations. The organofunctional silane modification to a stabilising agent is a re-active agent that will react with any residue left in water-bowsers, etc. from previous operations. It has become the norm to expect reactions (as shown in Figure 8) questioning the quality of the stabilising agent when the NME stabilising agent is added to uncleaned water-bowsers resulting in the formation of blobs sticky threads that are unusual. In order to prevent such fist day occurrences it is recommended that equipment be inspected before being used on site for NME stabilisation purposes. Figures 9 ( $a$ and $b$ ) show some results of pre-inspections done on "clean" equipment.

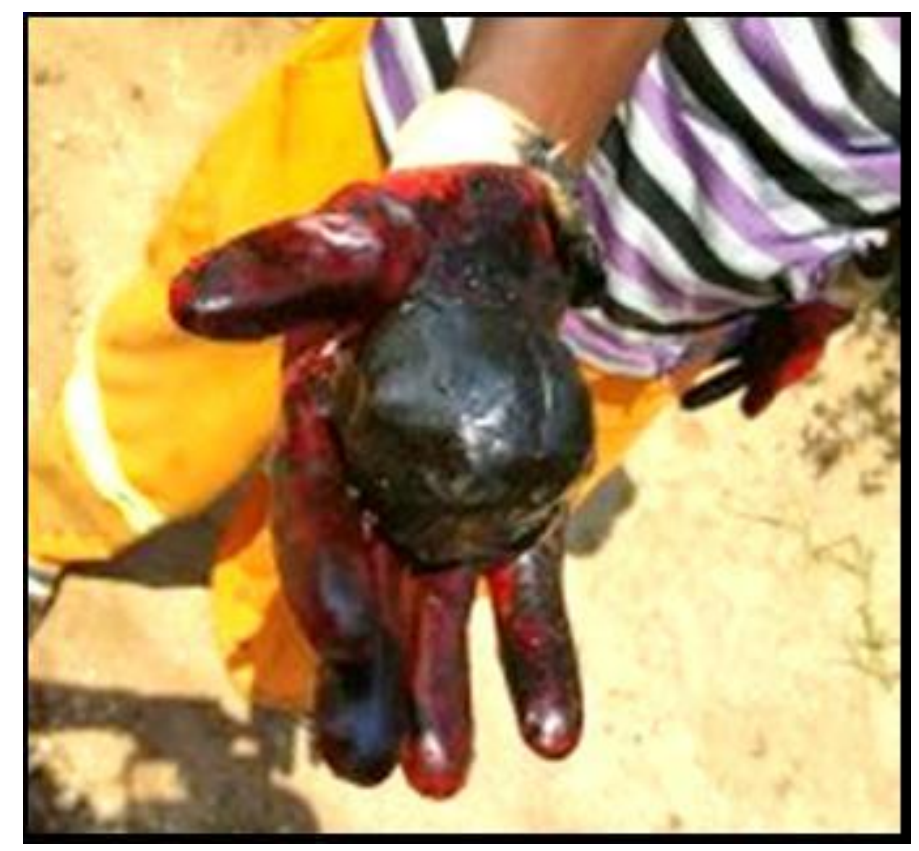

Figure 8. Typical example of an anionic NME stabilising agent that has been added to the construction water bowser containing residue from previous operations

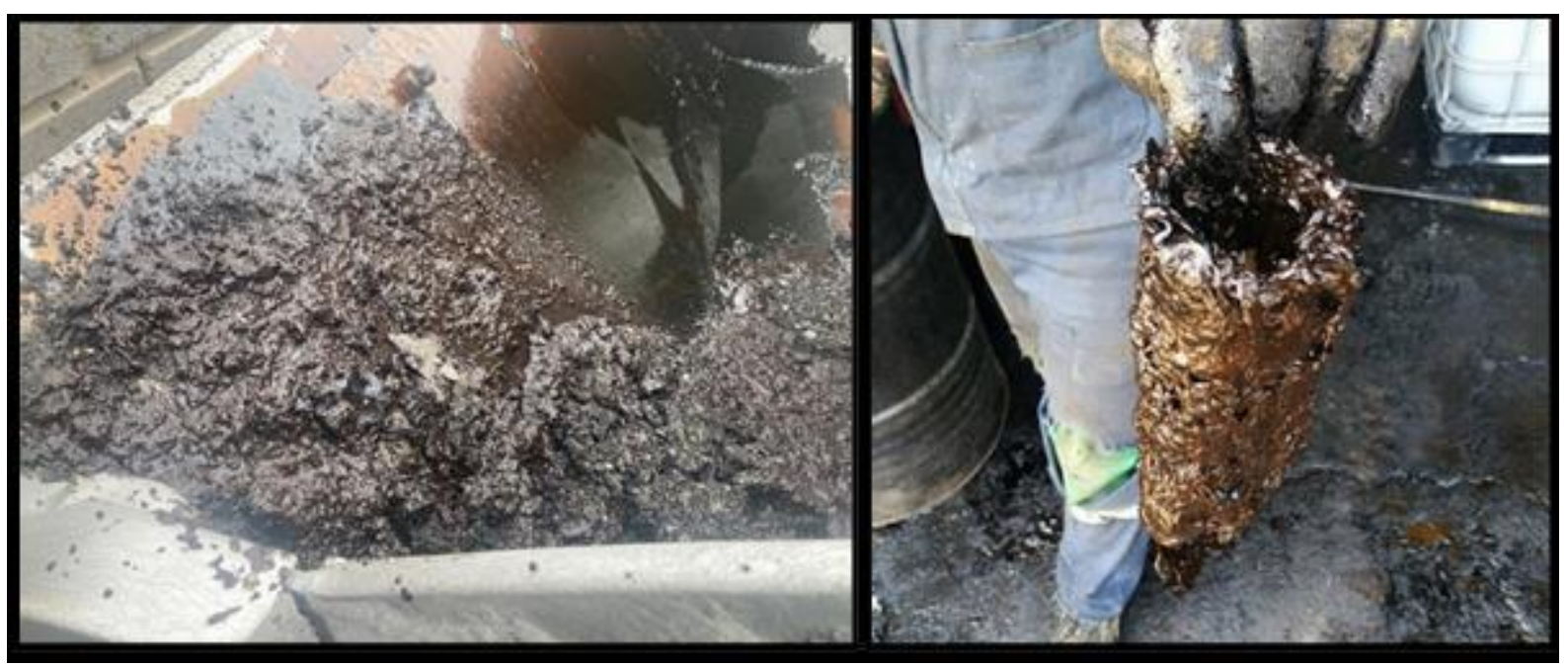

Figure 9. Typical examples of residue and state of equipment found during the pre-inspection of "clean" equipment dedicated by contractors for use for the stabilisation of granular materials using an anionic NME stabilising agent [4] 


\section{Construction Options using NME Stabilising Agents with Granular Materials}

\subsection{General}

The construction of highways, rehabilitation of existing roads or the upgrading of rural gravel roads using in-situ materials stabilised with an anionic NME stabilising agent, lends itself towards the utilisation of a full complement of construction methods. Depending on the specific requirements (over and above the designed material end-product specifications) and needs of the Implementing Agency or the Funding Agency, the pavement structure and surfacing can be done using fully, high-accuracy, mechanised equipment or recyclers or conventional equipment or construction procedures aimed at the maximisation of labour-enhanced construction methods together will suitable compaction equipment. When requiring labour-intensive construction operations, a mixture of suitable equipment with a high labour content together with specific applicable design options (e.g. type of surfacing) usually proves to be the most cost-effective. These requirements are usually a function of external requirements [18].

The applicable construction specifications would have been preceded by a design procedure addressing the technical and non-technical requirements of any specific road [e.g. 18,19] which may or may not influence the construction process to be adopted. Depending on these needs, a life-cycle cost comparison of applicable options [18] will enable the designer to recommend the most cost-effective applicable option, to compile a project-specific Terms of Reference (TOR) and Bill Of Quantities (BOQ) and project-specific special provisions. These documents are used by contractors to determine the most cost-effective equipment to utilise and submit tenders based on the requirements of any specific contract.

With high rates of unemployment in developing countries being a major factor, external influences often require bulk infrastructure programmes to address projects with the emphasis on the provision of opportunities for employment and the creation of small enterprises. In such cases, it is recommended that the Implementing Agency adjust policies in order to sign separate session agreements with material suppliers and equipment rental agencies for direct payment by the Implementing Agency. The BOQ should be adjusted to require emerging contractors to price works based on the execution of the works only. Tenders for material suppliers should be based on end-product specifications, requiring suppliers to meet specified minimum requirements in terms of stability of stabilising agents and meeting minimum engineering criteria, for materials as supplied. Allowance should be made for suppliers to have access to materials to design and optimise material compatible stabilising agents $[8,19]$. In the case of labour enhanced construction methods, adequate provision should be included for experienced supervision of the works, with personnel able to accommodate technology transfer as part of their duties.

Construction equipment suitable for the construction of NME stabilised granular material pavement layers are discussed starting from the use of the most sophisticated equipment. The practical implementation of these construction practical aspects of the use of various types of equipment are shown with some discussions with regard to the advantages and disadvantages. Discussions are done in the following sequence:

- Central plant mixing and construction of base to high levels of accuracy;

- Use of recyclers;

- Using freely available basic conventional equipment (i.e. water -bowser and grader mixing);

- Upgrading of gravel roads using basic equipment, and

- Labour-intensive surfacings. 
6.2 Central plant mixing and construction of pavement layers using paving equipment

As discussed previously, the use of marginal materials and stabilisation/enhancement thereof is not restricted to lower-order roads. The use on crushed stone materials protected by the addition of small percentages of an anionic NME can be beneficial both in terms of durability (prevention of in-situ chemical decomposition) as well as the energy required to achieve high levels of compaction [15]. Naturally available granular materials stabilised with a material compatible anionic NME stabilising agent as per a scientifically based materials design process can also, with relative ease, meet the design requirement for inter-city and other highways, designed to carry relatively high traffic loadings as shown in Figure 1 [15] in association with Figure 2 [8]. These roads are associated with a high required constructed riding quality, ideally suited for the construction using equipment able to deliver these requirements at a low risk to contractors.

The example demonstrated, showed the use of a central computerised mixing planet (Figure 10) to prepare the granular material mixed with the construction water and an anionic NME stabilising agent. The central mixing plant is able to mix the granular material (in this case a G5/6 - refer Figure 1) with a high degree of accuracy with the anionic NME stabilising agent (in the example - 1.2 per cent (containing about 0.7 per cent residual bitumen)) pre-mixed with the construction water to be delivered to trucks for transportation to the road under construction (Figure 10). The water added to the mix should take into account any loss of moisture that may occur during the transportation of the mix to the construction site and the construction of the layer.

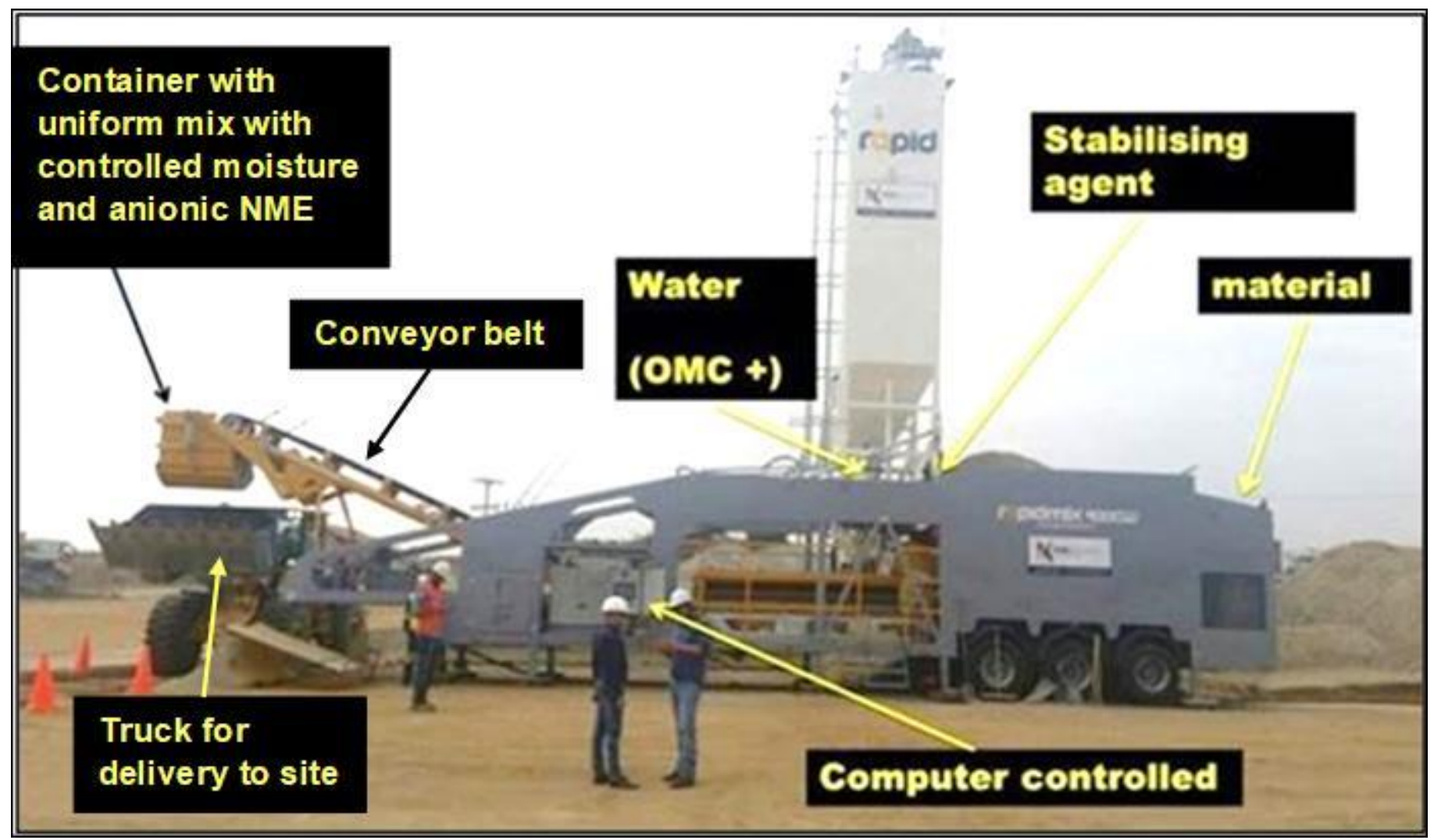

Figure 10. Central mixing plant, mixing the granular material with the required construction water containing the anionic NME stabilising agent, using computerised control for accurate applications

Figure 11 shows the constructed sub-base (in the example - G5/G6 material with 0.7 per cent anionic NME - about 0.4 per cent residual bitumen). Note the curbs put in place for the inter-city freeway that are being constructed. Figures 12 and 13 respectively show the delivery of the mix prepared in the central plant for placement by paver with the various compaction rollers ready for compaction of the $150 \mathrm{~mm}$ thick base layer (small roller for next to curb, smooth drum roller and pneumatic wheel roller) and the base 
material at the back of the paver. Figures 14 to 18 shown the compaction of the base layer and the final finishing of the layer placed to a tolerance of $2 \mathrm{~mm}$ accuracy.

The hydrophobic nature (water repellent characteristics of the anionic NME stabilisation of the base layer was severely tested on site when more than $200 \mathrm{~mm}$ of rain felt during the week following the construction of the layer. Figure 19 show the water with the installed curbs acting as a channel for the flow of the water down a steep ingredient. After drying of the base layer after the severe practical test, no damage was noted (Figure 20) on the layer. It should be noted that in similar experiences with a crushed stone, cement treated or normal emulsion treated unprotected layers, reconstruction of the base layer would, to all expectation, have been required due to water-damage.

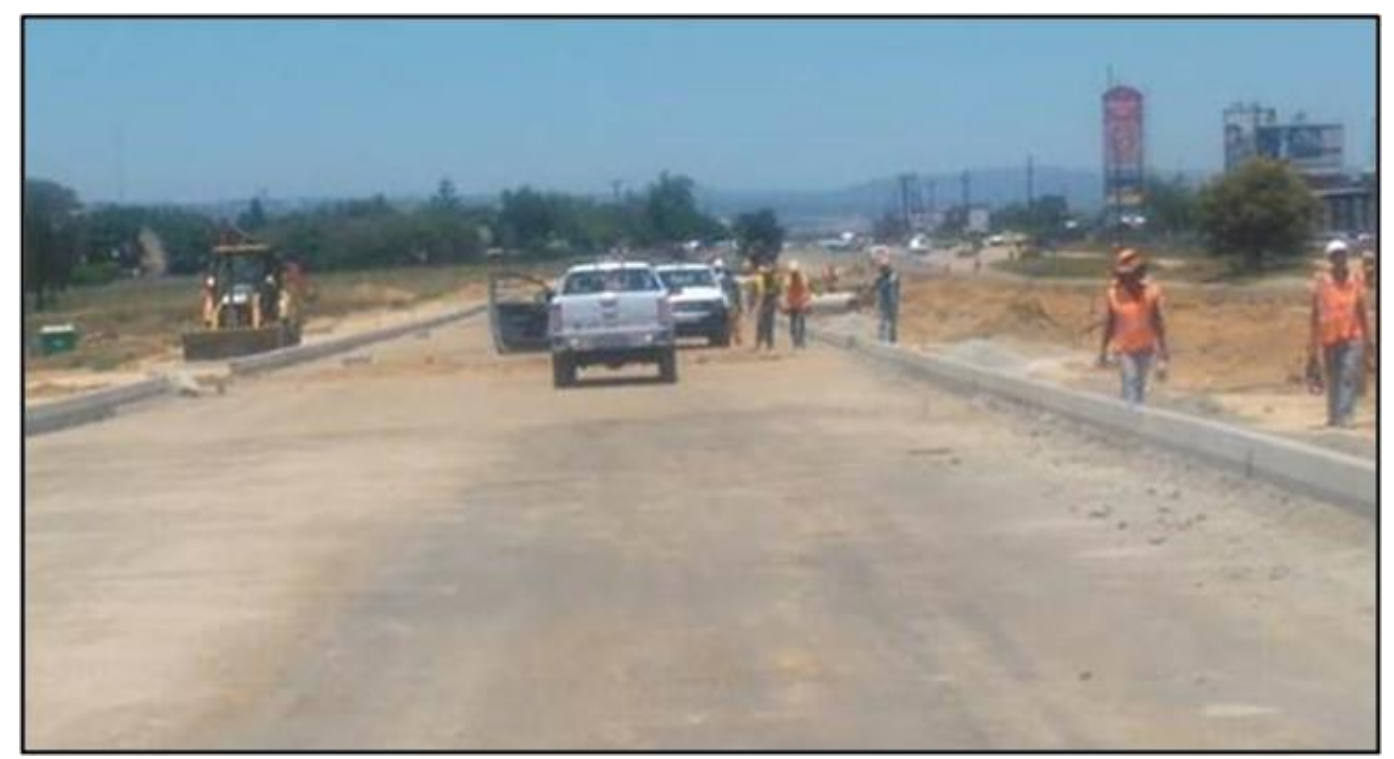

Figure 11. Prepared sub-base with installed curbs for the inter-city freeway under construction

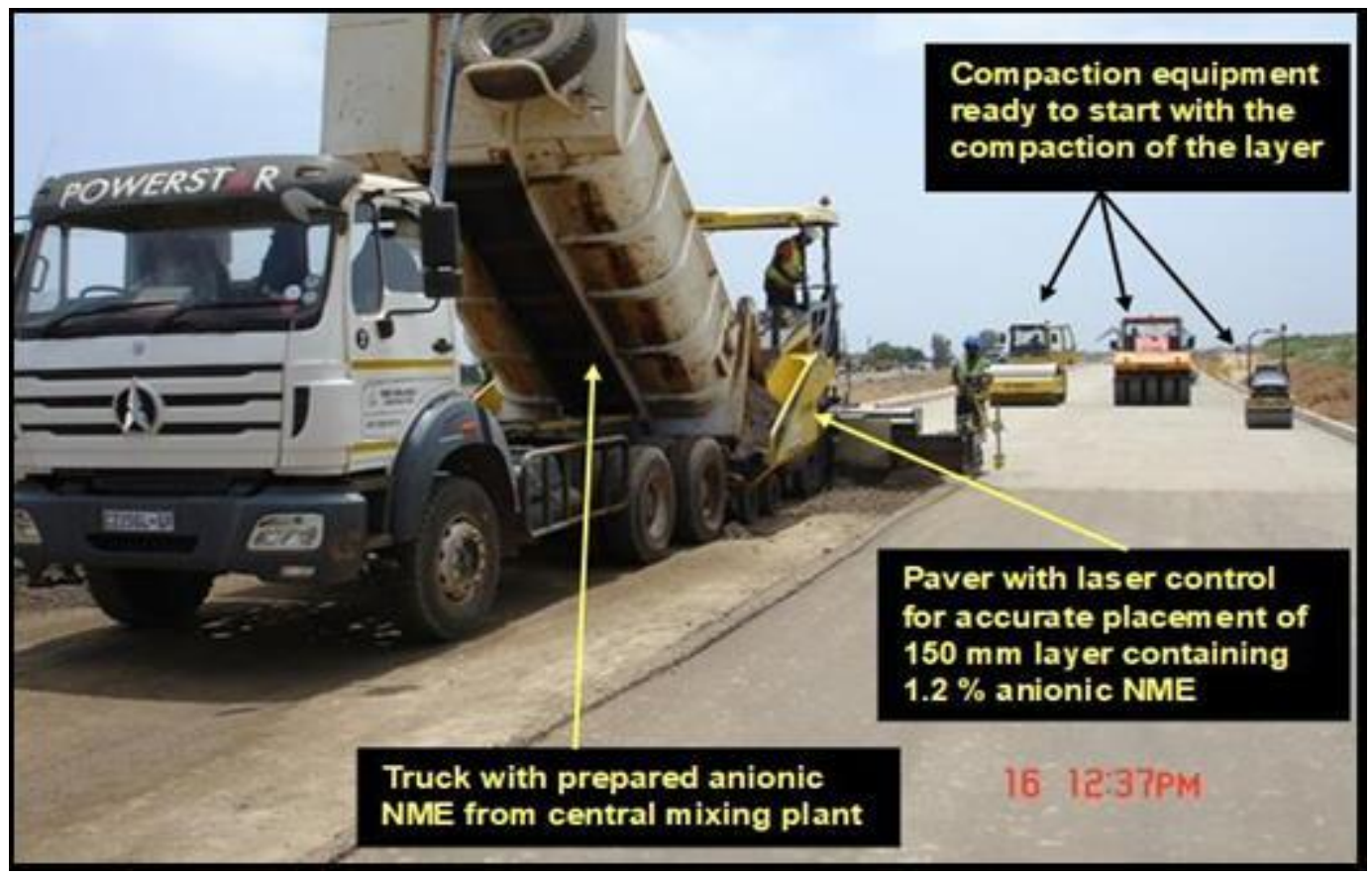

Figure 12. Delivery of anionic NME mix to site for the placement of the $150 \mathrm{~mm}$ base using a high accuracy paver 


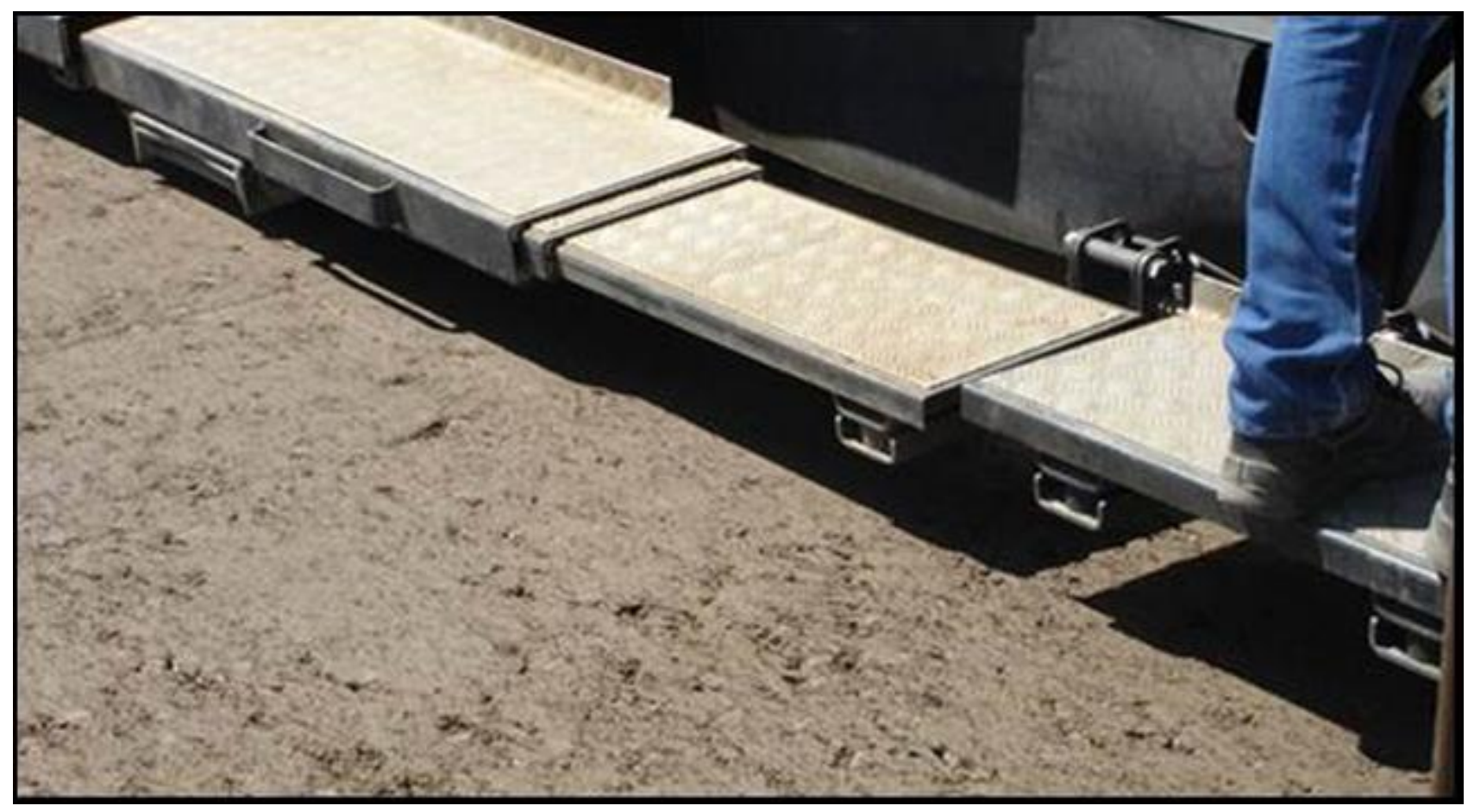

Figure 13. Base layer exiting the paver

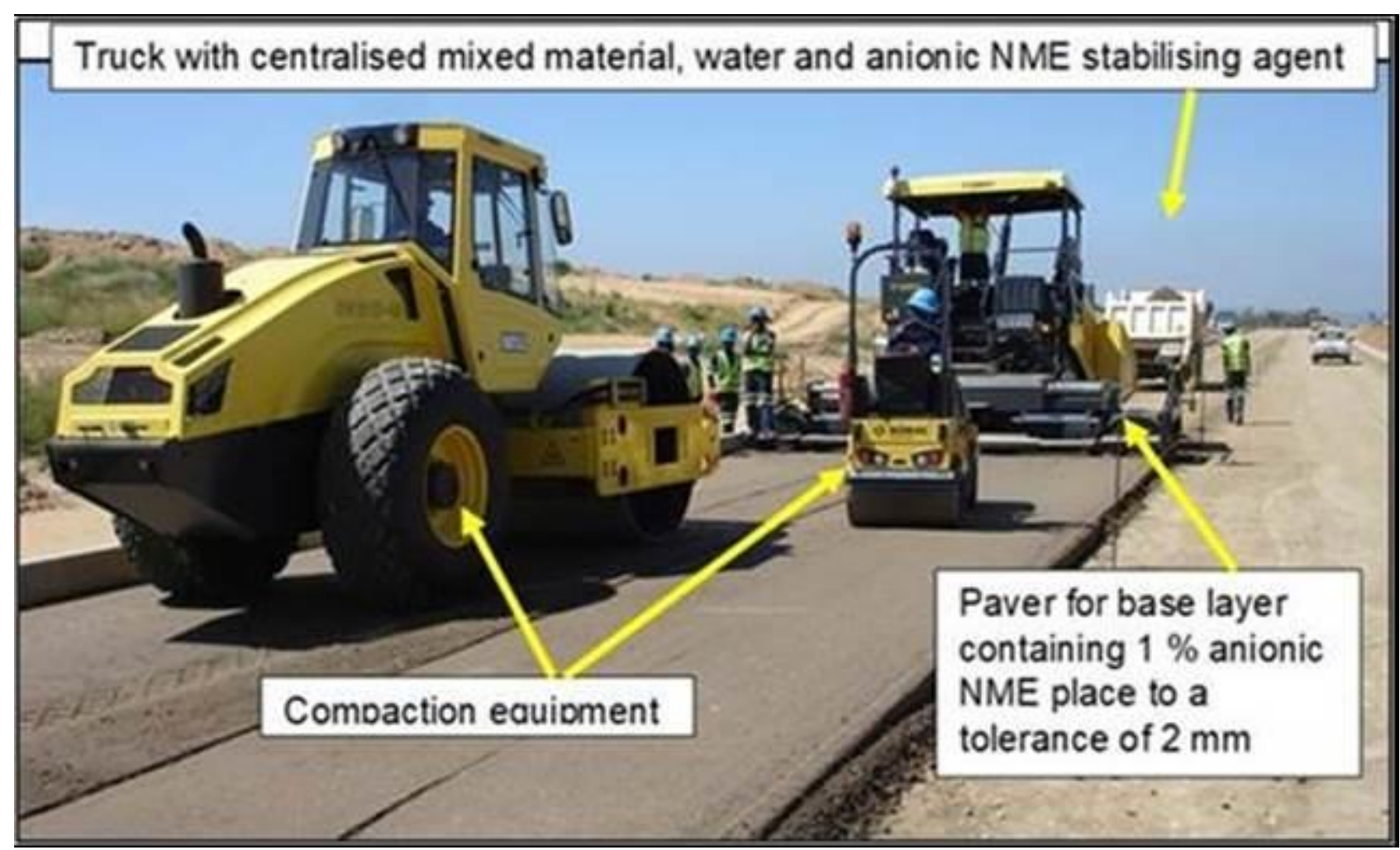

Figure 14. Construction of the base layer of a highway using a 1,2 \% material compatible anionic NME stabilising agent $(\sim 0.7 \%$ residual bitumen) mixed in a centralised batching plant and placed by a paver with a tolerance of $2 \mathrm{~mm}$ 


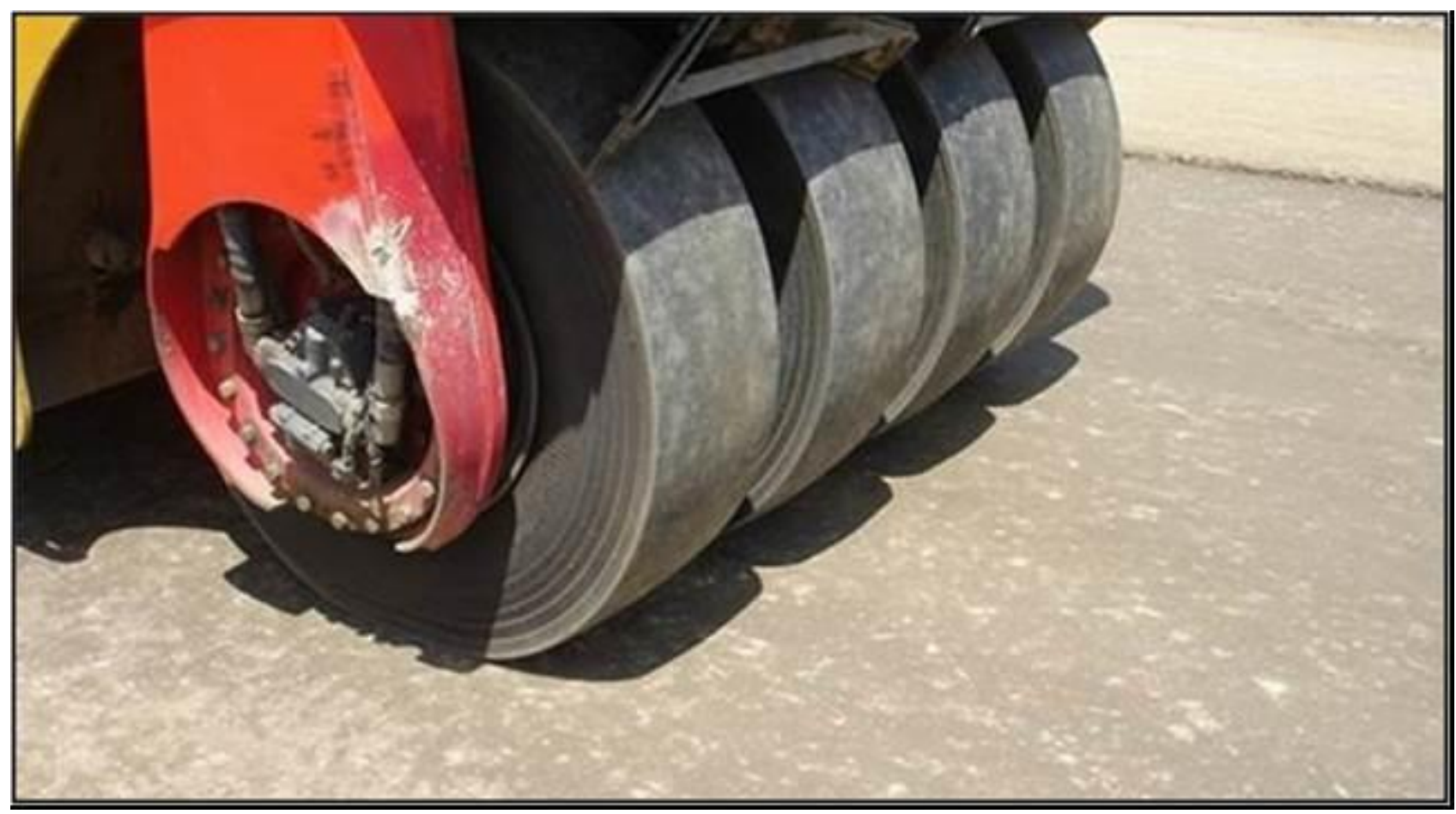

Figure 15. Final compaction of the base-layer constructed with a $1.2 \%$ anionic NME stabilising agent, mixed at a central batching plant and placed with a paver

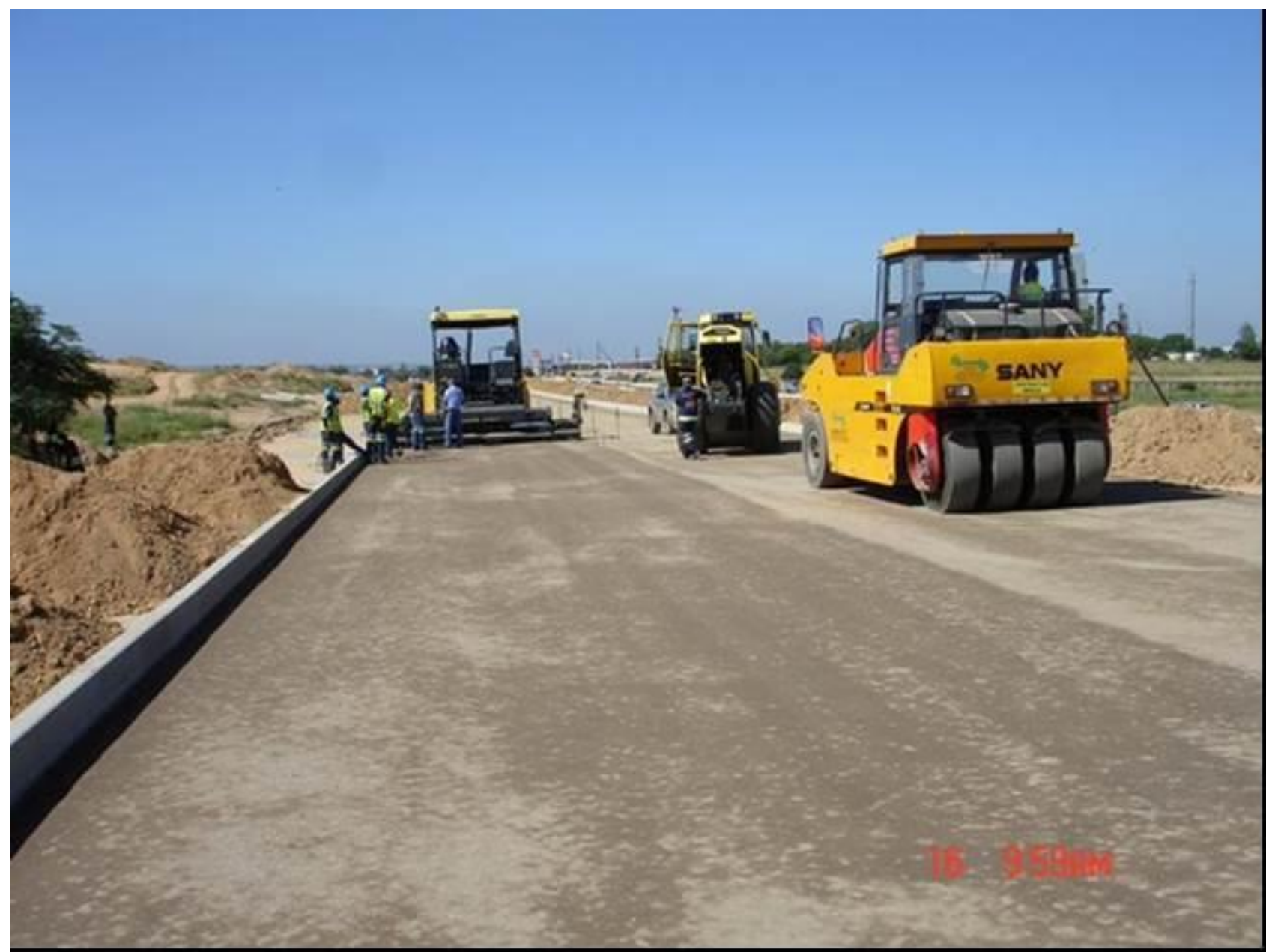

Figure 16. Placing of the $150 \mathrm{~mm}$ anionic NME stabilised base layer - note the quickness to which the layer is drying out 


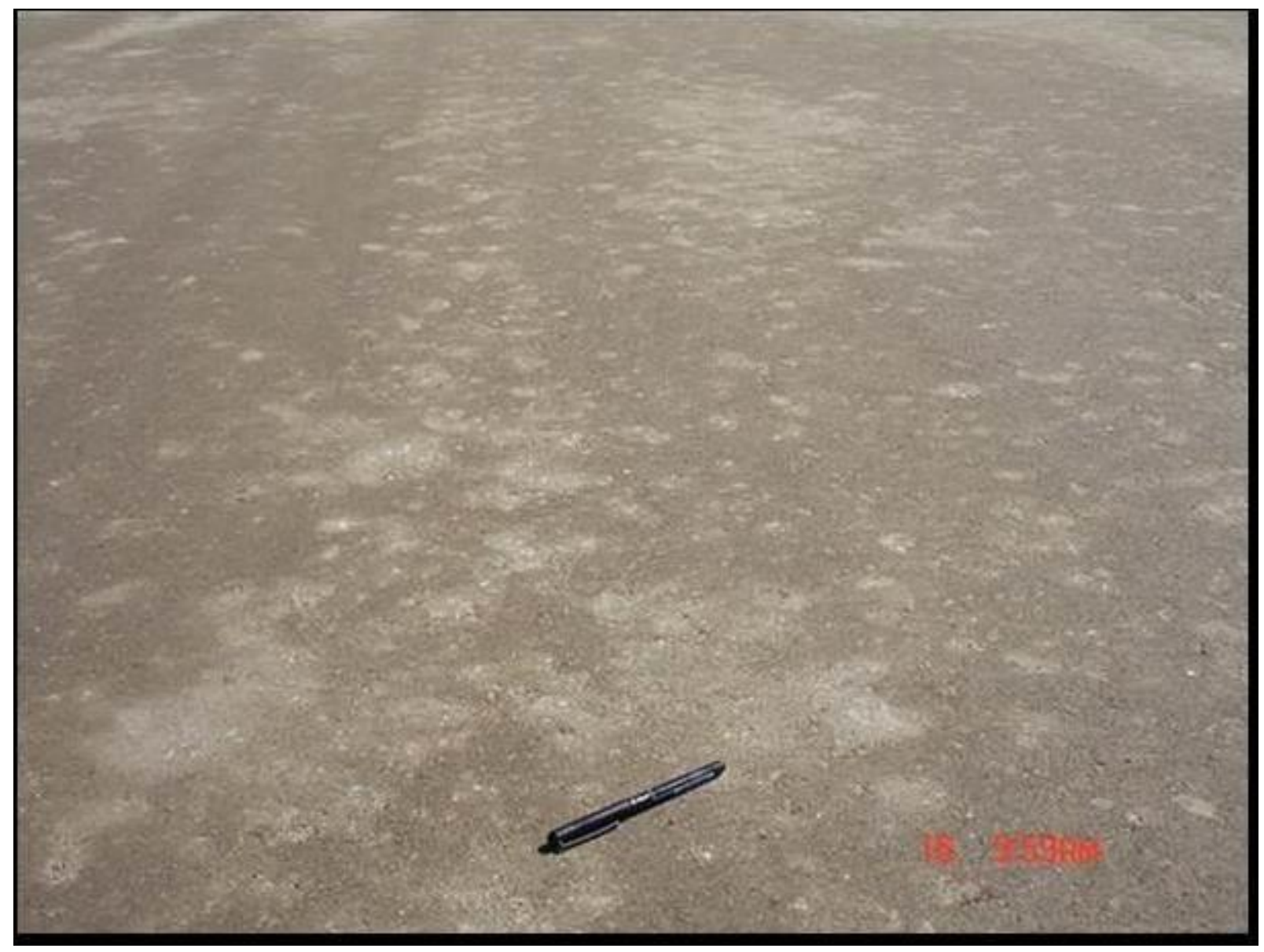

Figure 17. Placement of the $150 \mathrm{~mm}$ base layer by paver after compaction - note the texture of the finishing achieved

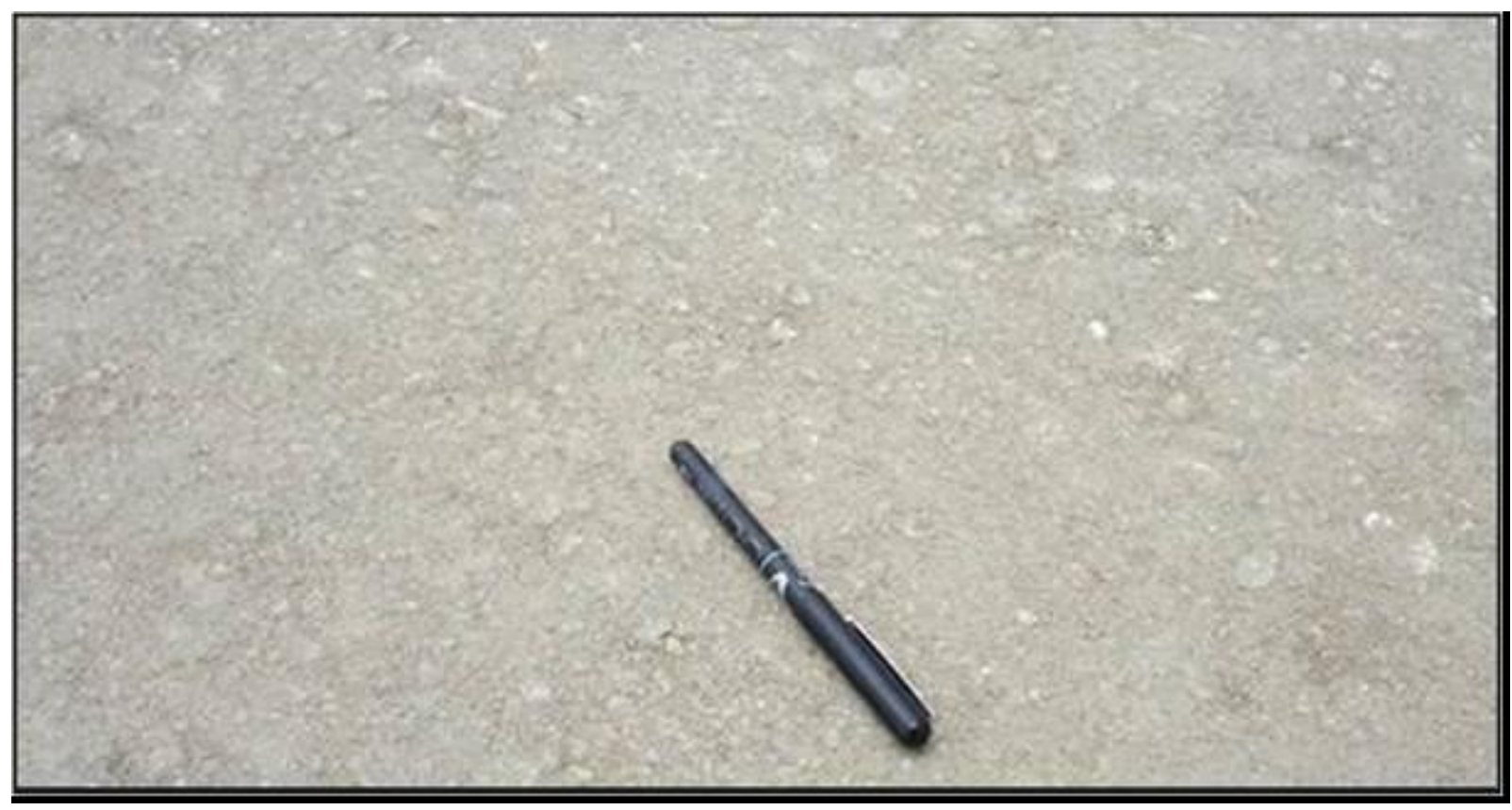

Figure 18. Final surfacing of the base-layer of the highway constructed with a 1,2\% anionic NME stabilising agent ( $0.7 \%$ residual bitumen) which was mixed in a central mixing plant and laid by paver to a tolerance of $2 \mathrm{~mm}$ before any additional protective material was added 


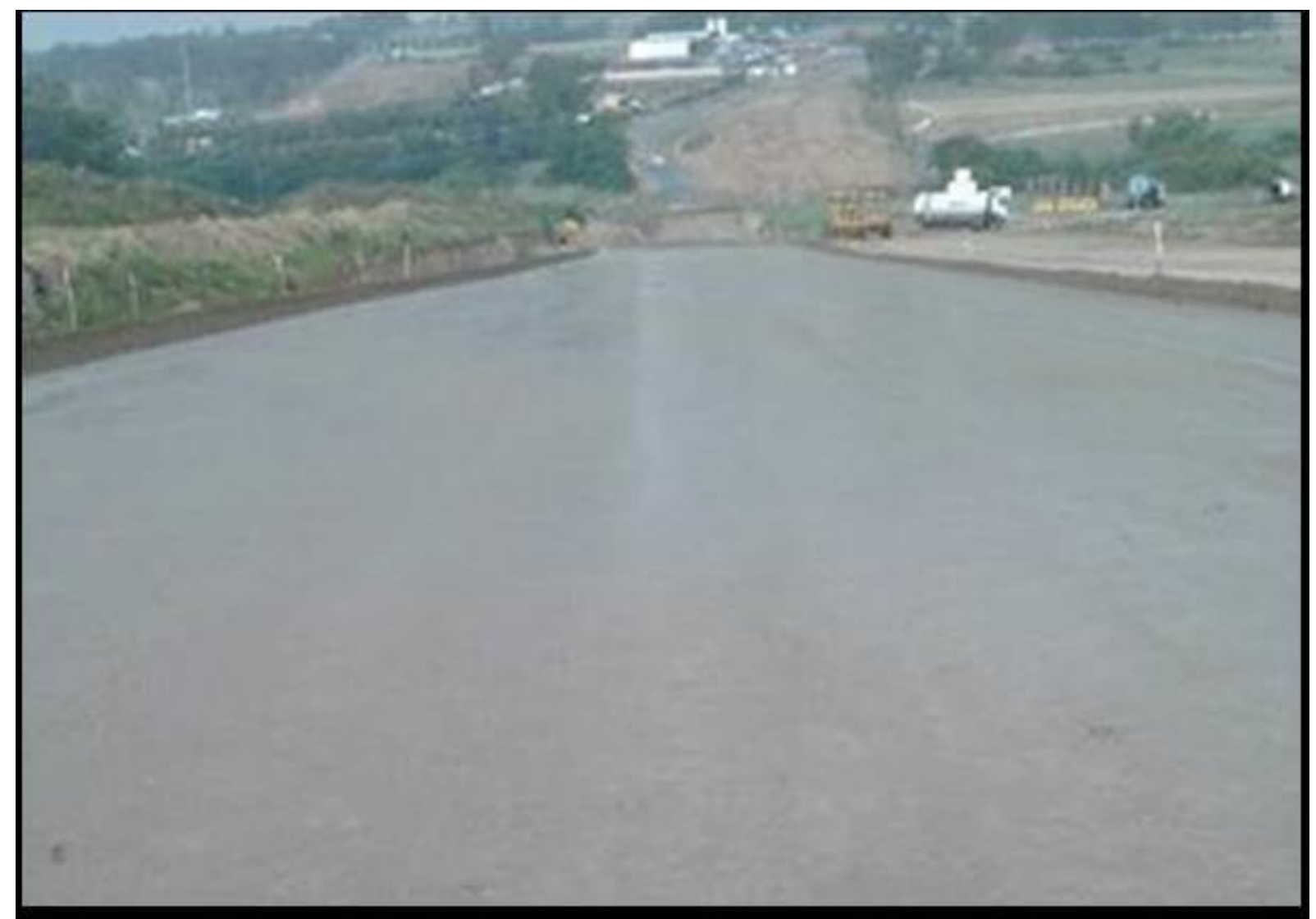

Figure 19. One week after placement of base with no protective later added - $200 \mathrm{~mm}$ of rain with installed curbs acting as a channel

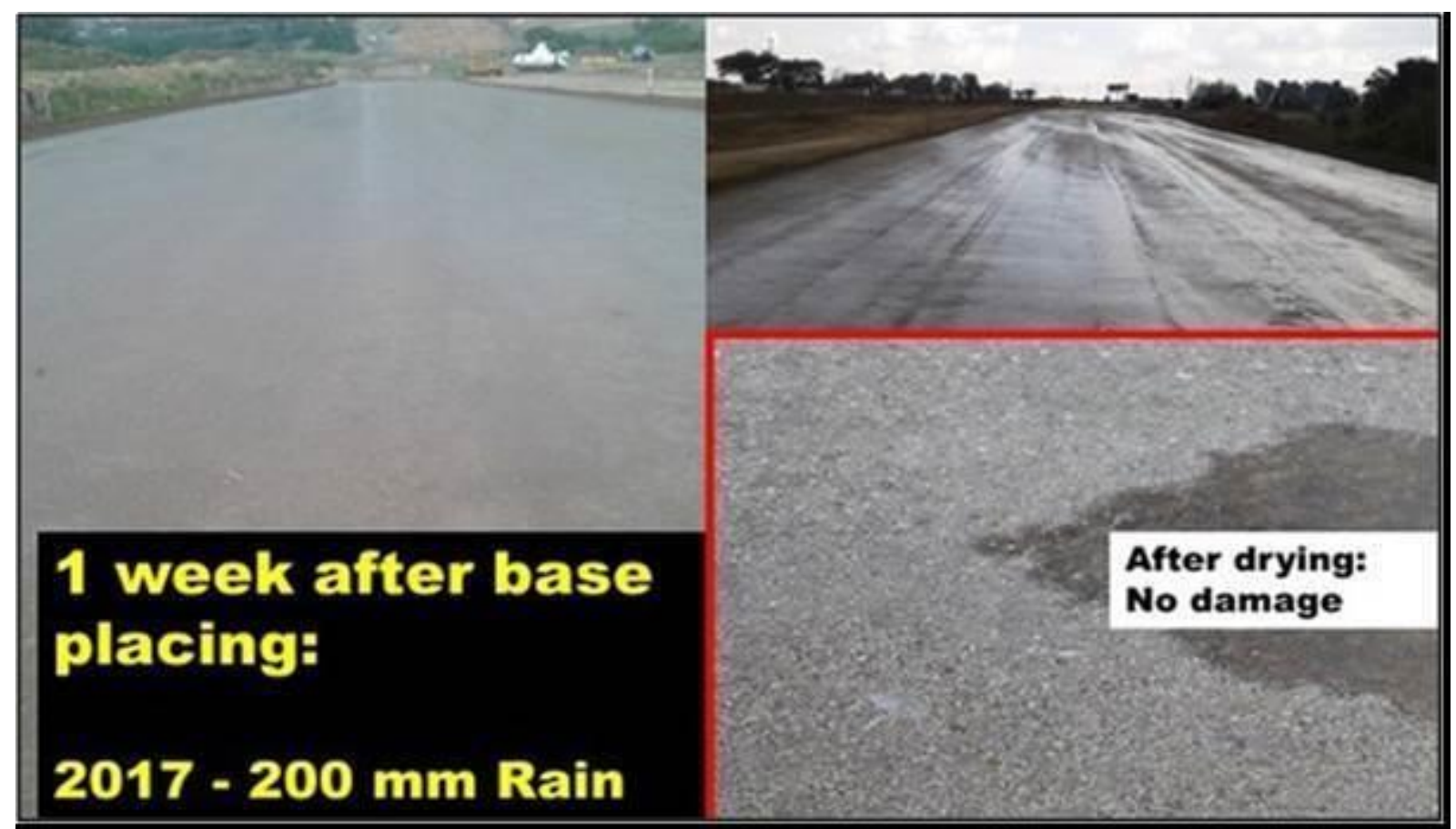

Figure 20. The unprotected base-layer (Figure 18) stabilised with 1,2 \% anionic NME, was severely tested when subjected to $200 \mathrm{~mm}$ of rain the week after placement with no damage to the layer - a practical proof of the water-resistant (hydrophobic) nature of the anionic NME stabilising agent used for the stabilisation of the G5/G6 (refer Figure 1) granular material

\subsection{NME stabilisation using recycling equipment}


Centralised, computerised mixing equipment is generally not reliably available in most countries throughout the world. However, this does not exclude the use of anionic NME stabilised naturally available materials from being used for the construction of highways or, for that matter any other road. NME stabilisation lends it towards road construction using basically any construction equipment. The finishing achieved using basic equipment is normally a function of the training and skills of the operators. The use of sophisticated equipment in road construction normally just simplifies operations and lends itself towards the expedition of road construction projects. The use of recycling equipment also be put in this category. Experience has shown that it is not unusual to stabilise a $1 \mathrm{~km}$ of a $10 \mathrm{~m}$ wide section of road with an anionic NME stabilising agent when the material has already been spread and all equipment and operations well planned.

The NME stabilising agent is easily added to a water-bowser, using gravity as shown in Figure 21. The water-bowser should already contain the required construction water for the section of road, taking the volume of material into account as per previous discussion. The anionic NME stabilising agent will automatically disperse into the construction water to create a uniform mix for immediate use at ambient temperatures. No preheating of a quality NME stabilising agent will be required for temperatures above freezing. The water quality could influence the stabilisation process and normal water construction quality requirement normally specified for any other type of road construction is also applicable to NME stabilisation.

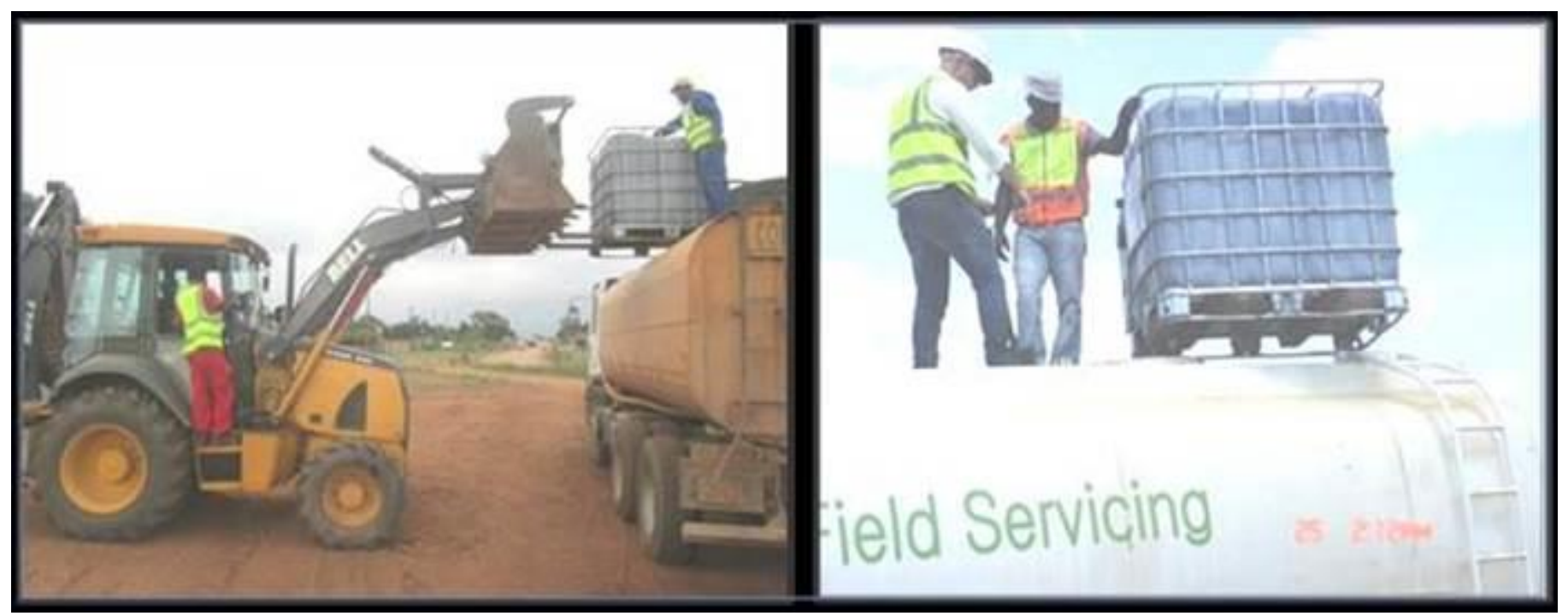

Figure 21. Using basic equipment and gravity to add the anionic stabilising to the construction water already in the water-bowser. The volume of water and that of the stabilising agent would have been calculated on the basis of the volume of granular material to be stabilised

In order to control application rates using recyclers for the mixing of the construction water premixed with the NME stabilising agent, recycler should be equipped with microprocessors which will regulate the application of the stabilising agent with the speed of travelling. These requirement are standard with most modern recyclers makes which also allows for the depth of stabilisation to be controlled with high degree of accuracies. However, very few recyclers used to have this type of automatic control and it is still recommended to include these basic requirements for recyclers into project-specific specifications and prevent any ambiguity as to minimum equipment requirements and prevent construction disputes.

Figure 22 show the use of a recycler for the mixing of stabilising agent and construction water with the granular material on the same highway depicted in Figures 11 to 20. Note the uniformity of the mix at the back of the recycler, showing the good working order of the recycler with all nozzles fully in operation and no problems associated with 
the mixing drum or the supply of the NME stabilising agent pre-mixed with the construction water. Figure 23 show the construction train used in the mixing and compaction of a full width of a secondary road using an anionic NME stabilising agent.

The use of recycles for the in-situ recycling and stabilisation of distressed roads using material compatible anionic NME stabilising agent, are especially a cost-effective procedure for the quick reinstatement of roads with the minimum disruption to traffic and inconvenience to property owners in urban areas. Figures 24 to 31 show the rehabilitation of a severely distressed urban road through the in-situ recycling of the G7-quality base material, mixed with the remainder of the surfacing material. The use of a recycler enabled a total of $6 \mathrm{~km}$ 's to be recycled and stabilised within 2 weeks. With only a quick drying anionic diluted NME prime as protection, the road remained open for almost two months over the summer holidays before placement of a $30 \mathrm{~mm}$ thick 3 per cent Sasobit ${ }^{\circledR}$ modified asphalt was placed onto the rehabilitated road.

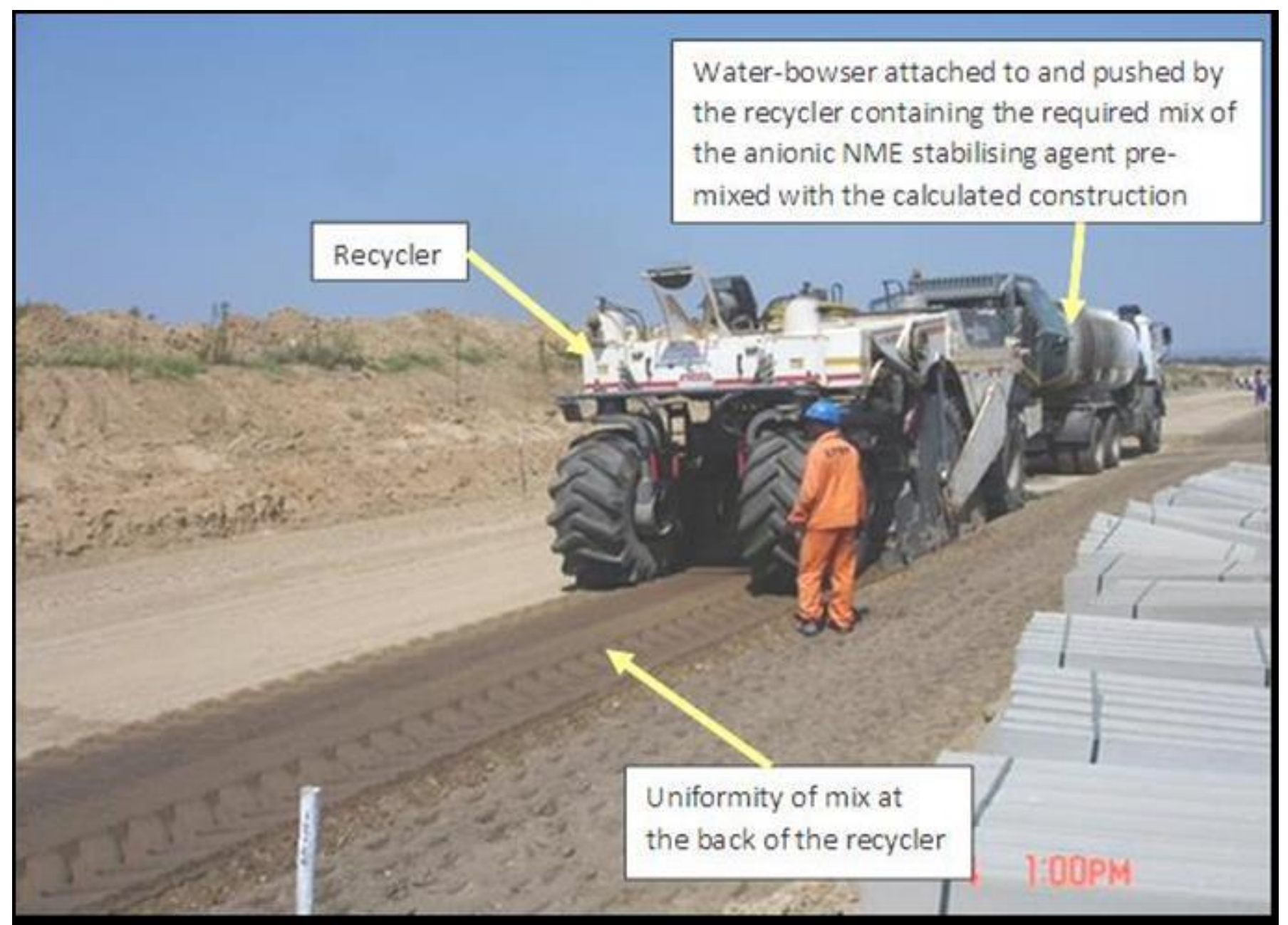

Figure 22. Mixing of the anionic stabilising agent using a recycler with a fitted micro-processor which controls the application of the NME stabilising agent pre-mixed with the construction water 


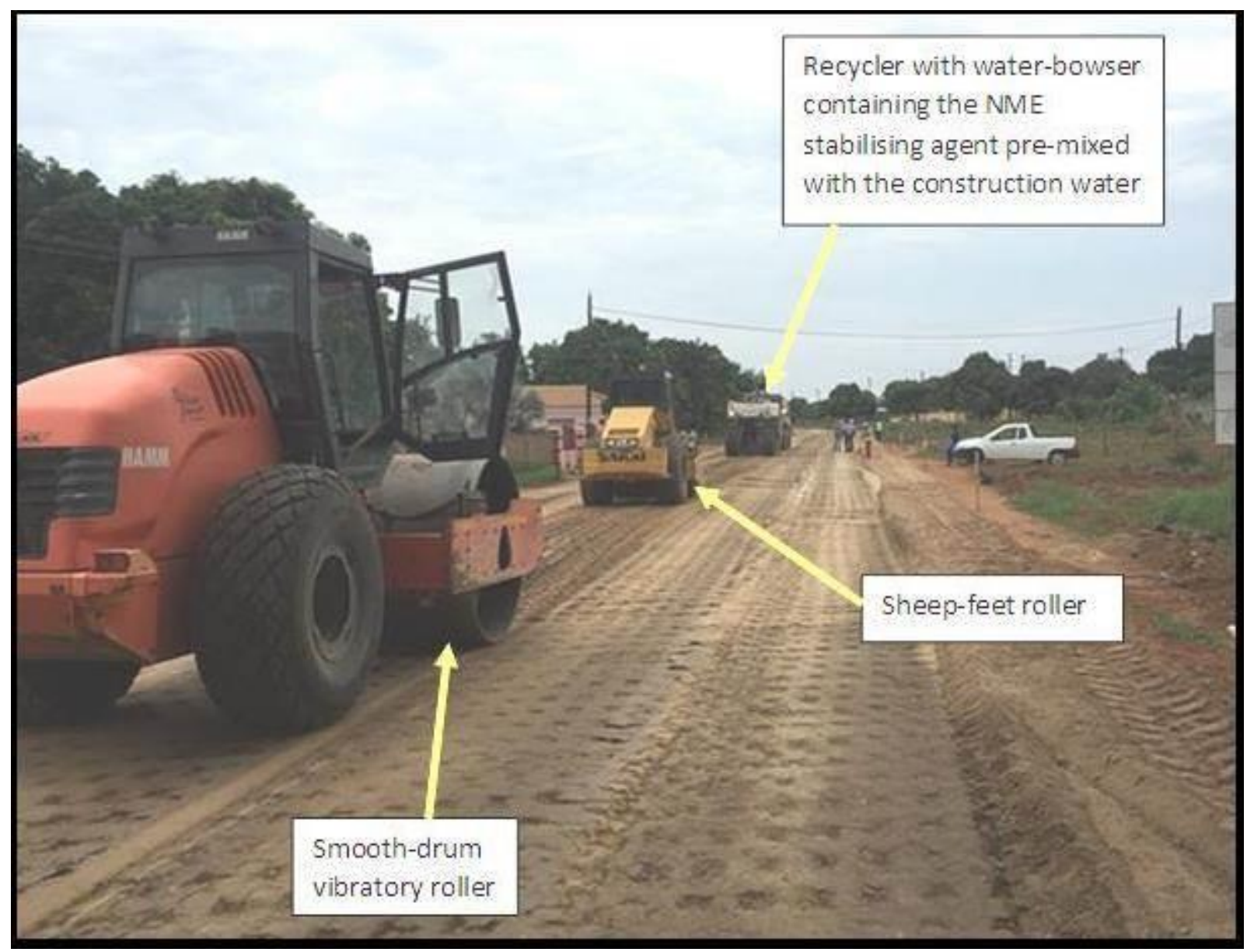

Figure 23. Construction of a full width secondary road using a G7 material (refer Figure 1 ) stabilised with $1 \%$ anionic NME, showing the construction train

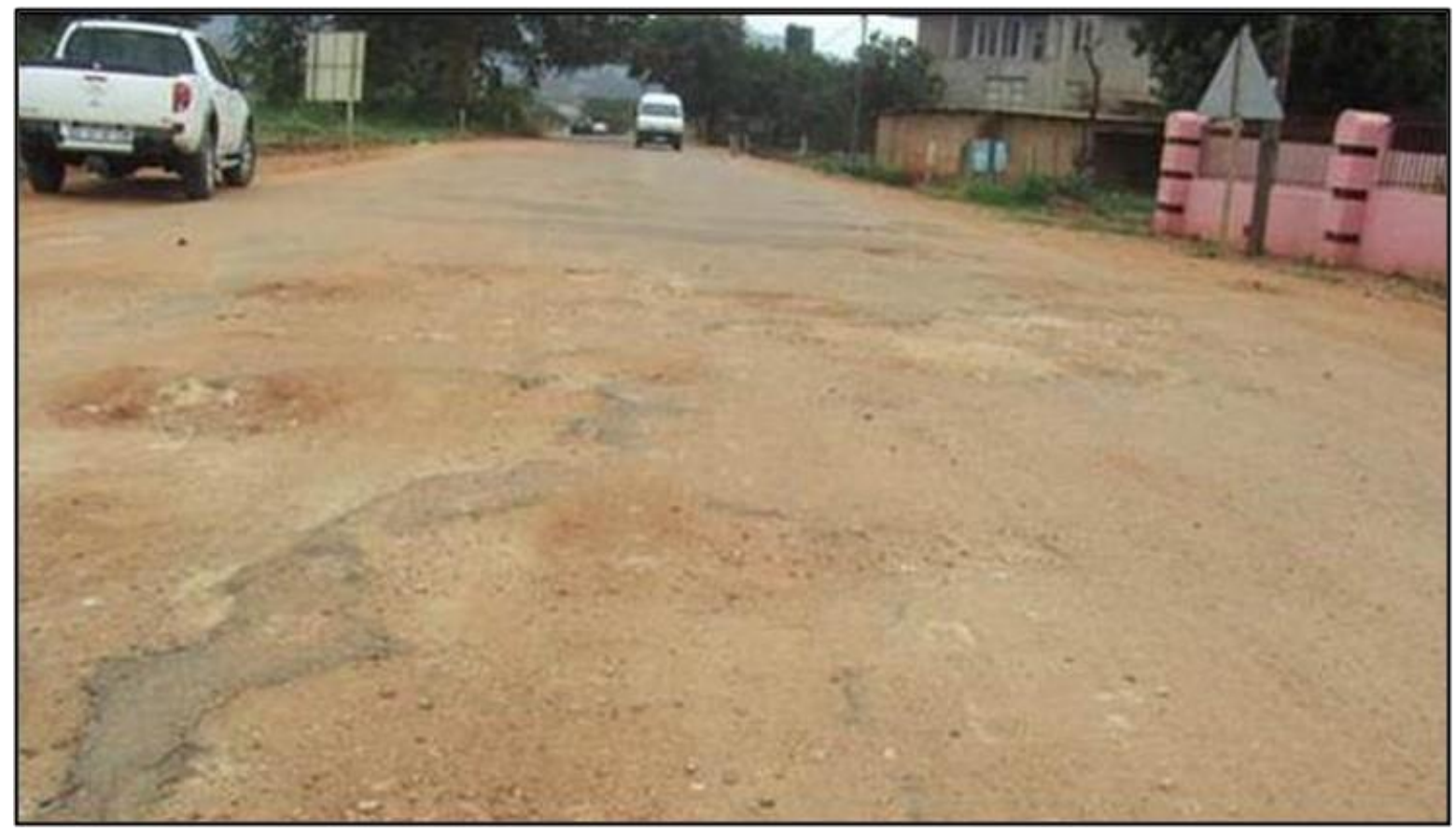

Figure 24. Typical condition of a severely distressed urban road with numerous pot-holes and materials not conforming to traditional standards for in-situ treatment using traditionally used stabilising agents 


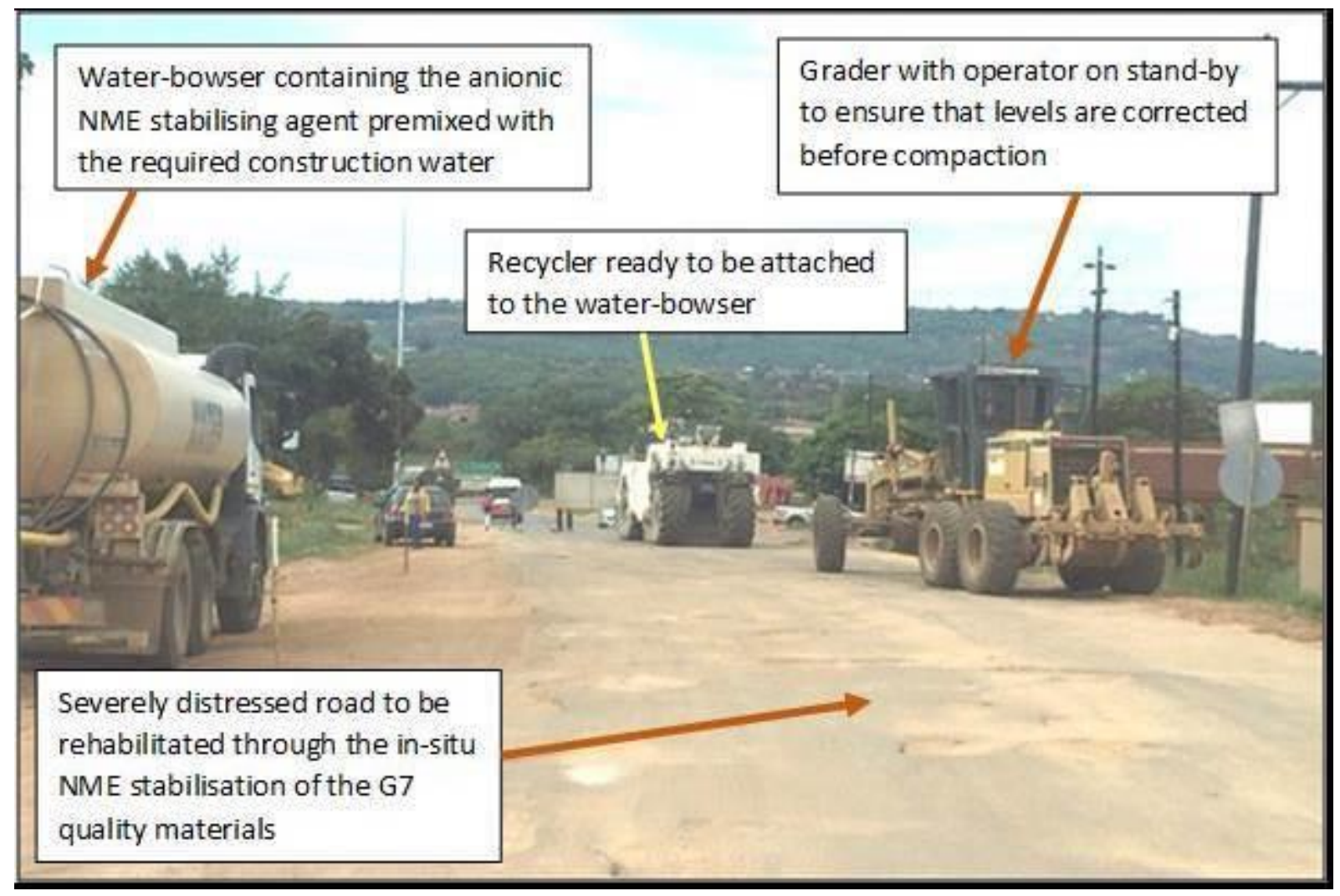

Figure 25. Water-cart, grader and recycler ready for the in-situ rehabilitation through recycling of a highly distressed road containing multiple potholes - The G7 quality material will be mixed with the remaining surfacing material and simultaneously mixed with a material compatible anionic NME stabilising agent

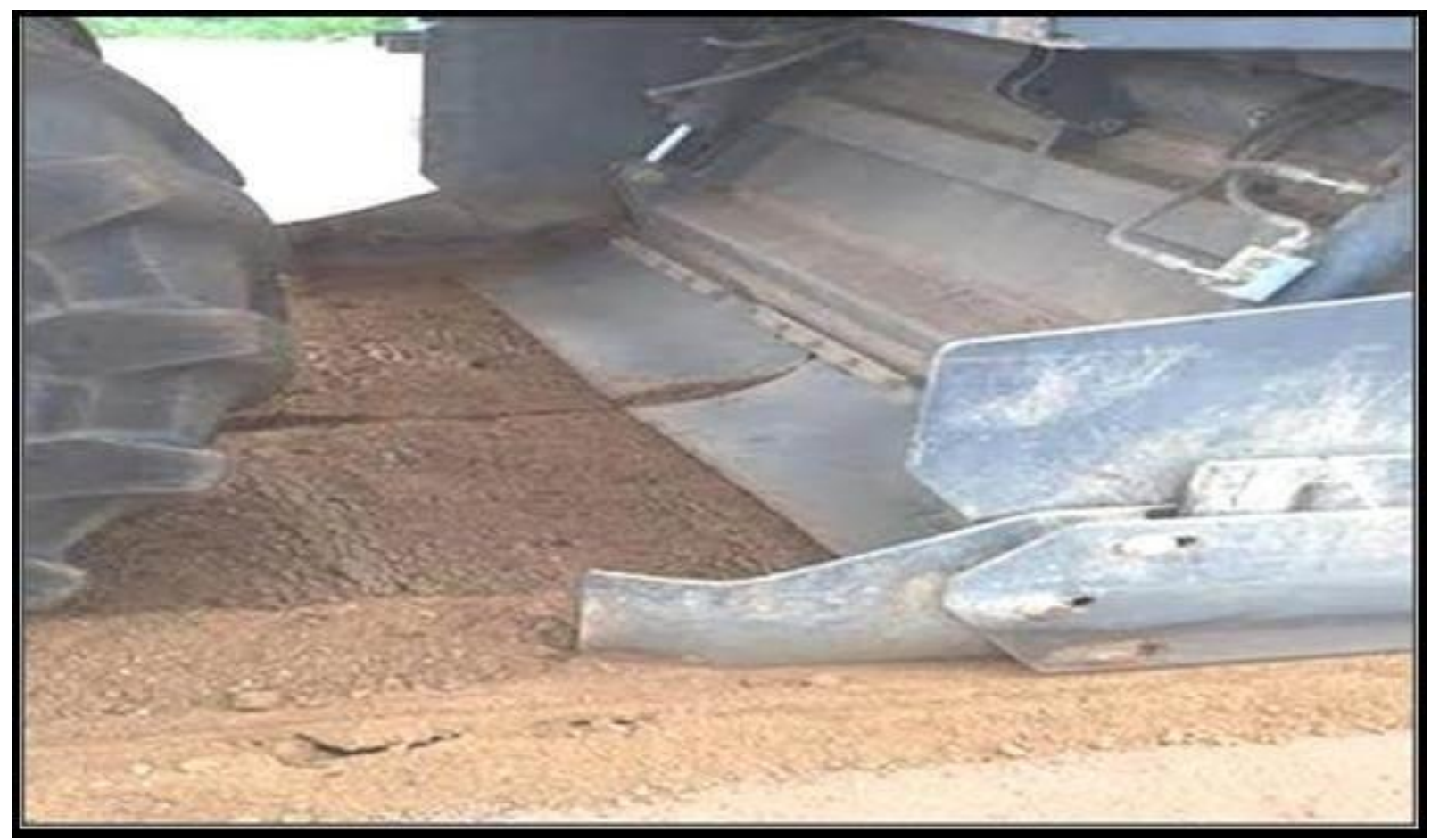

Figure 26. Material directly behind the recycler of the road shown in figure 25, with the NME stabilising agent, pre-mixed with the construction water, already added 


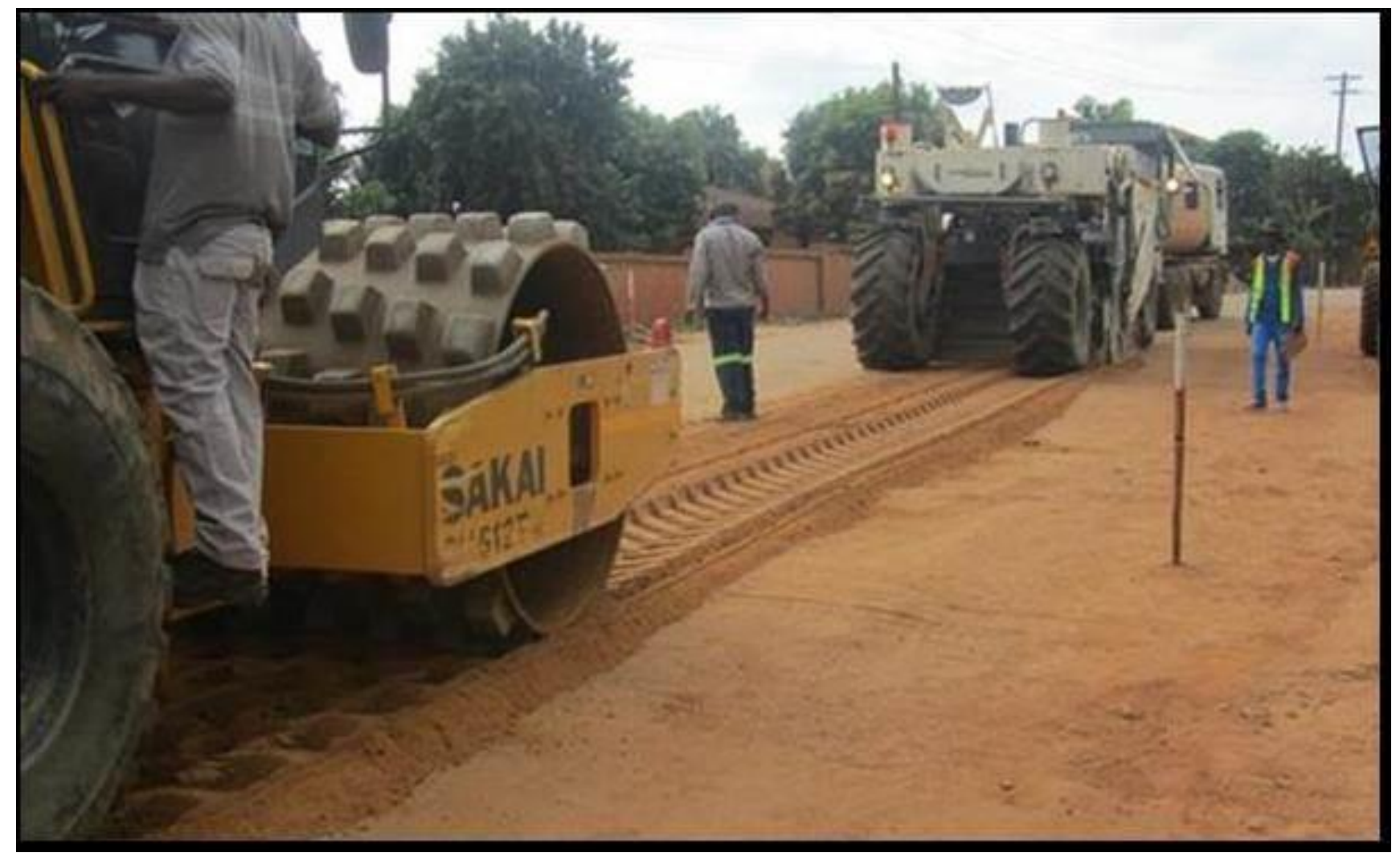

Figure 27. Construction train for the in-situ recycling and NME stabilisation of the severely distressed road.

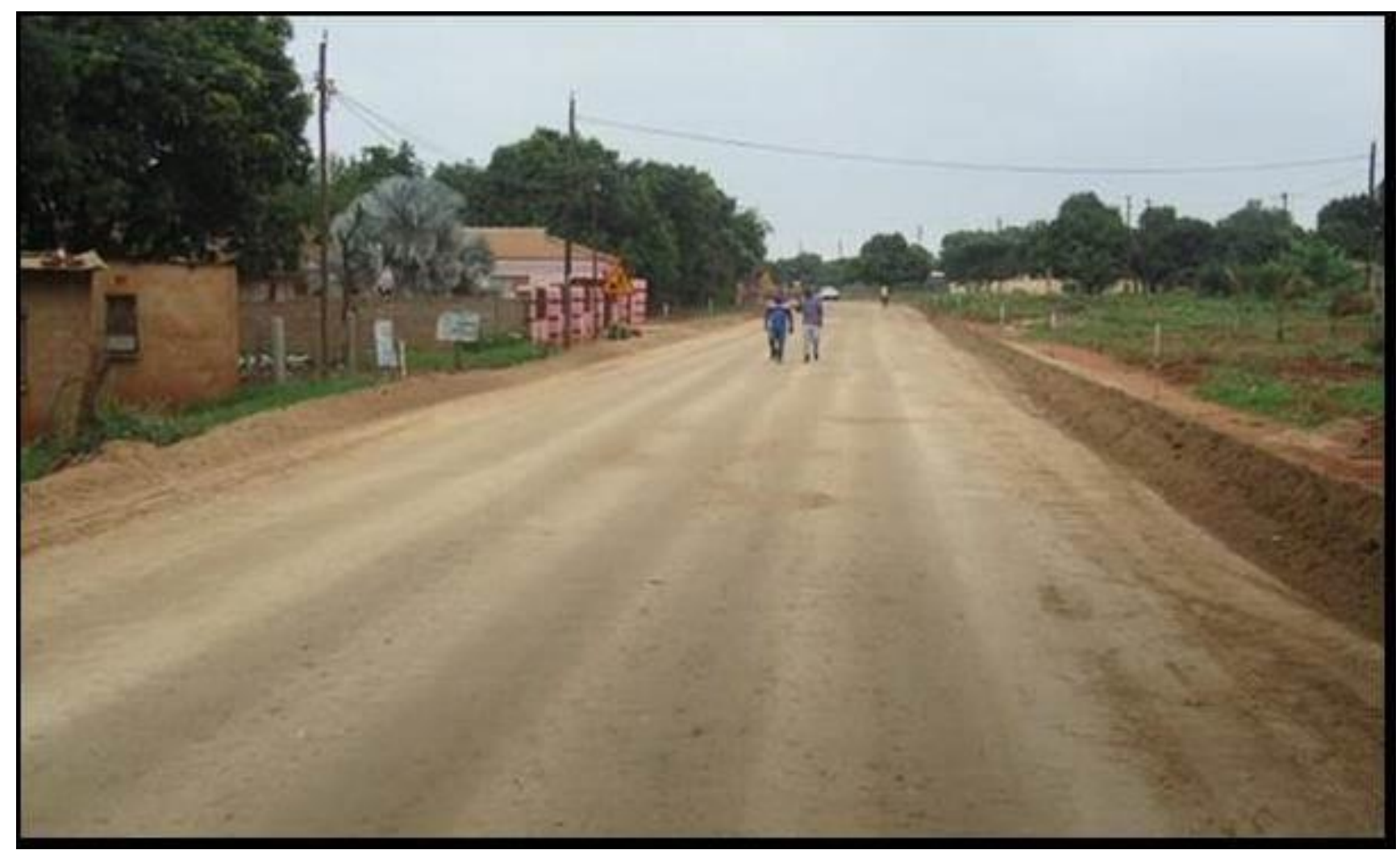

Figure 28. Recycled road with NME stabilisation opened to local traffic to provide access to houses - with no protective prime or surfacing added (note the same pink painted façade of the same house shown in Figure 24) 


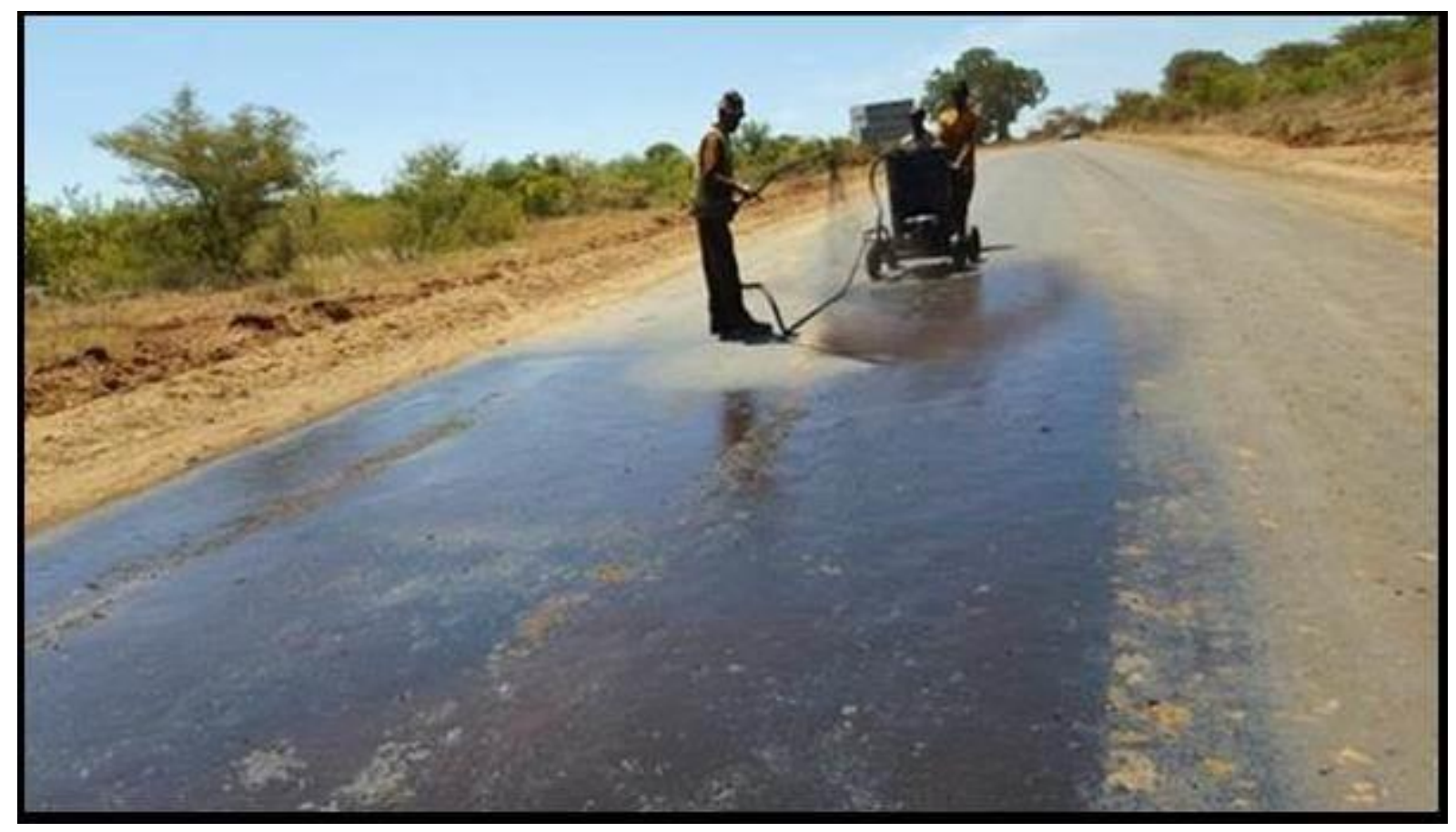

Figure 29. Hand application of a quick drying anionic diluted NME prime to protect the surfacing before application of the surfacing

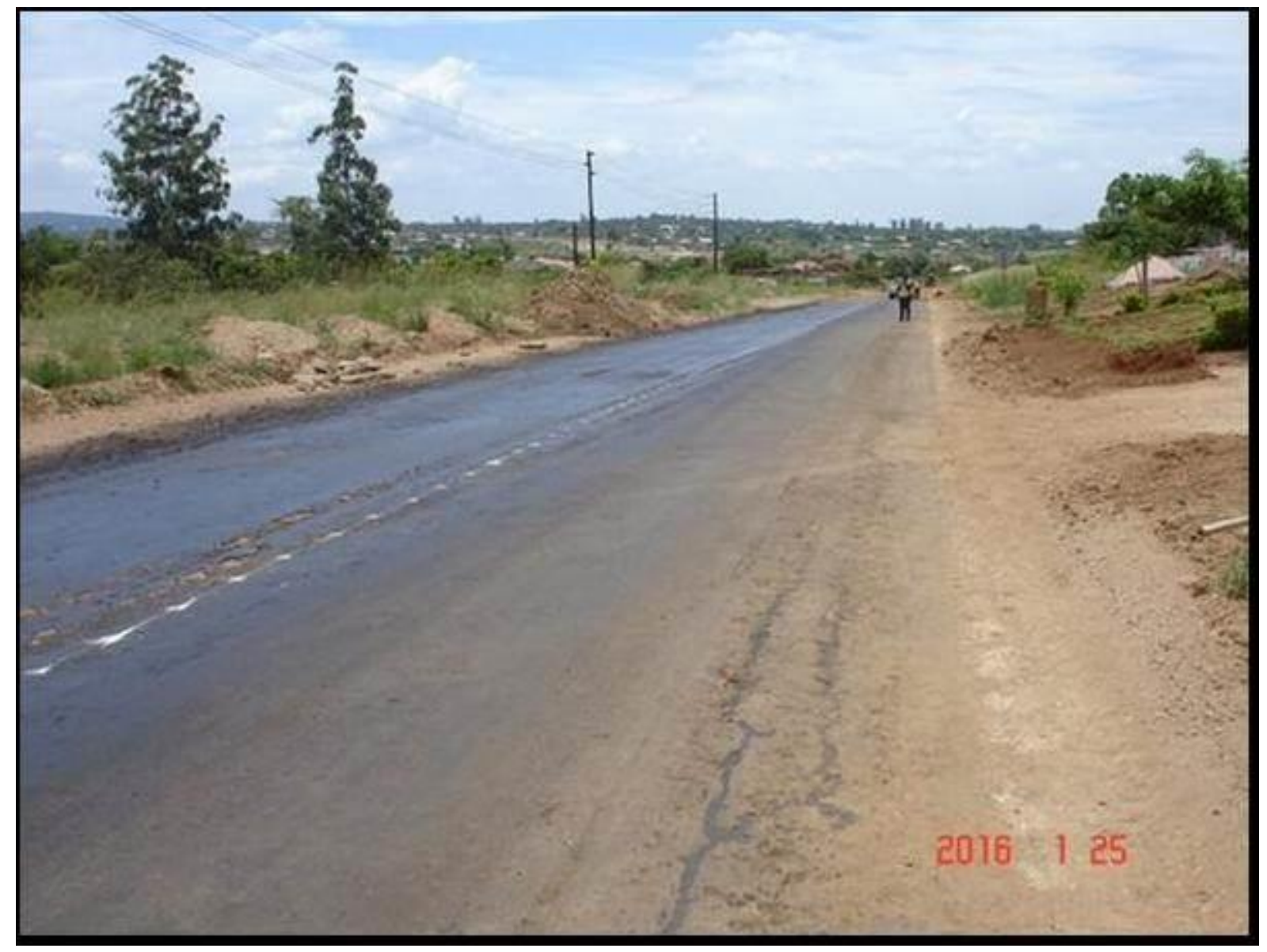

Figure 30. Condition of the base with prime after two months of trafficking during the summer holidays and applying of a tack-coat before surfacing 


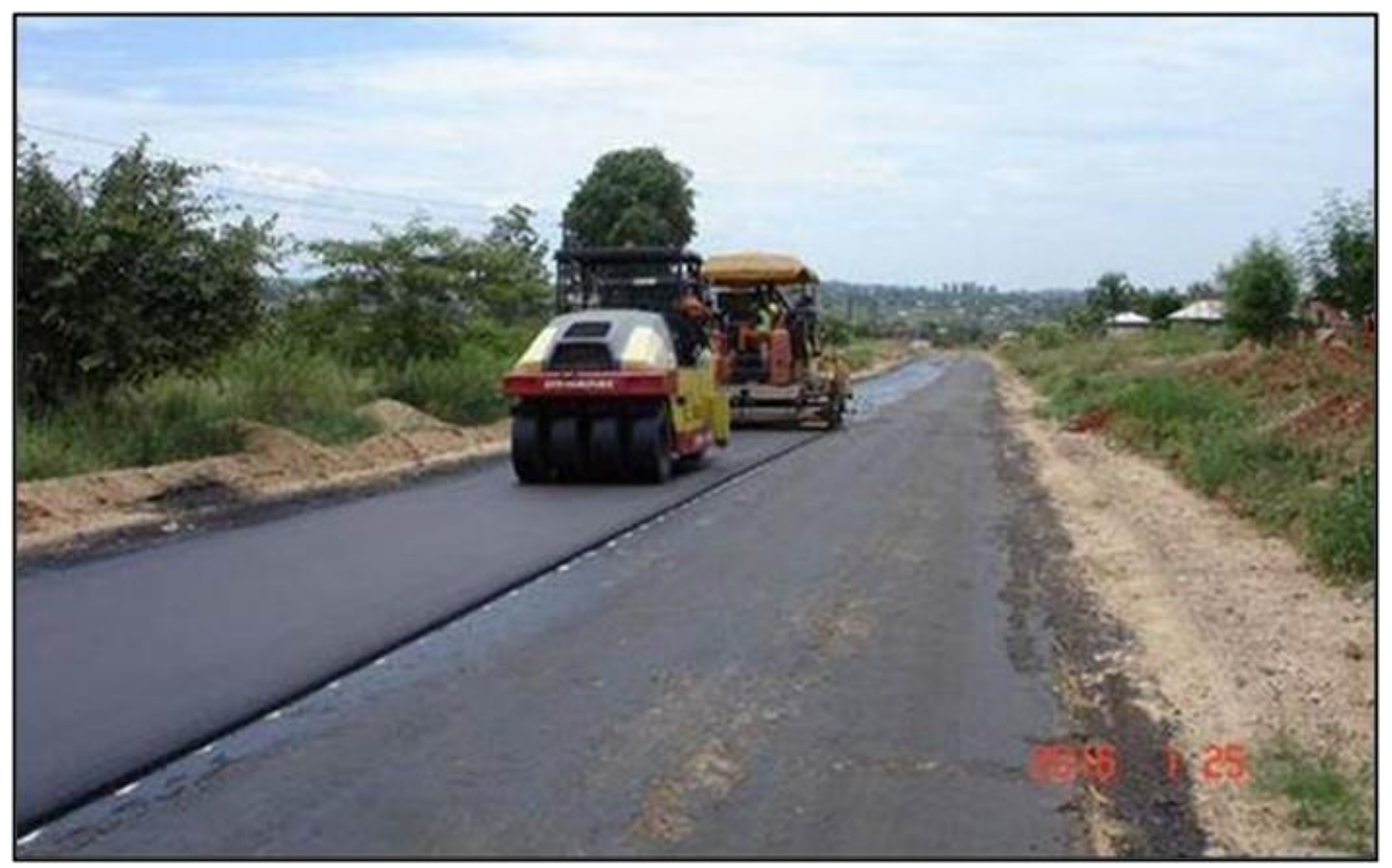

Figure 31. Surfacing of the rehabilitated urban road (Figures 24 to 29) after two months of trafficking during the summer holidays

6.4 NME stabilisation using conventional mixing equipment (water-bowser and grader) 6.4.1 General

In the absence of any centralised mixing equipment and recycling equipment, traditionally used construction equipment used for the construction of granular road pavement layers, are just as suitable for the NME stabilisation of naturally available materials. This traditional operations are equally applicable to the construction of highways, to secondary roads as well as the upgrading of gravel roads. No compromising of standards will be sacrificed by using traditional road construction equipment. As always, the final product delivered will be a function of the training and operational skills of the operators operating the various different pieces of equipment used to construct the road pavement layers. The use of conventional equipment on the various category of roads to the applicable standards is demonstrated through examples taken from highways to secondary roads to local access roads requiring a relatively low LOS.

6.4.2 Construction of multi-lane dual carriageway highways

Section of the highway shown in Figures 12 to 20 (using a centralised mixing plant) and Figure 22 (using a recycler, were constructed using conventional traditional road construction equipment, i.e. a:

- Water-bowser containing the anionic NME stabilising agent pre-mixed with the calculated construction water;

- Normal graders for the mixing and final cutting of the levels of the layer, and

- Conventional compaction equipment.

The construction of the sub-base layer of the dual carriageway with 0.7 per cent (about 0.4 per cent residual bitumen) of a G5/6 (refer Figure 1)-quality material, using conventional construction equipment is demonstrated in Figures 32 to 41. The anionic NME stabilising agent is pre-mixed with the calculated construction water as demonstrated in Figure 21. After construction the grader operators commenced that the process is nothing more than the construction of a normal granular layer using "dirty water". The sub-base was also subjected to the same rain conditions (Figure 39) as the base layer shown in Figures 19 and 20 and similarly, showed no damage. 


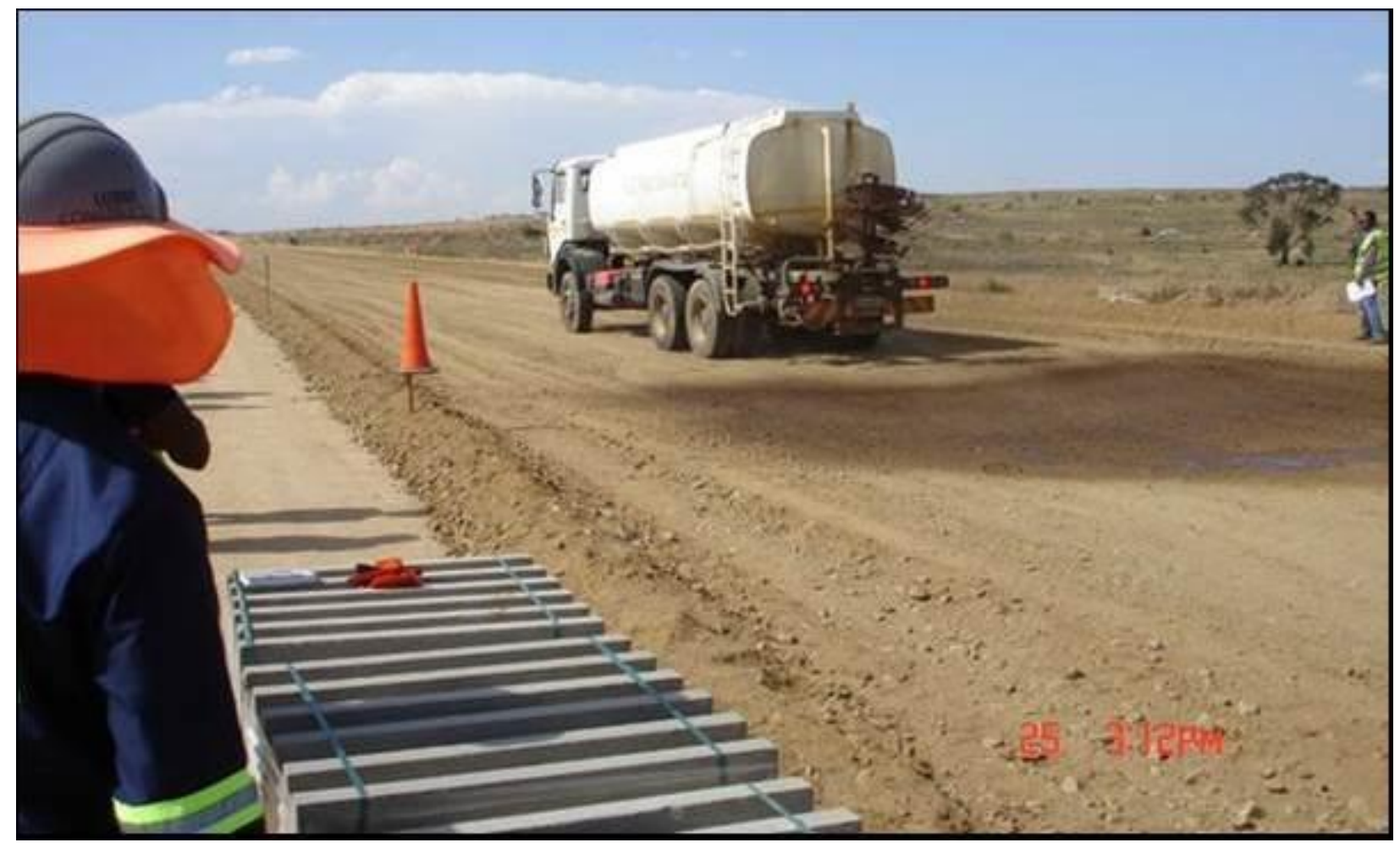

Figure 32. The sub-base granular material is spread along the section to be stabilised and compacted allowing for the compaction factor - the water-bowser containing the anionic NME pre-mixed with the required construction water is ready to start with the mixing process

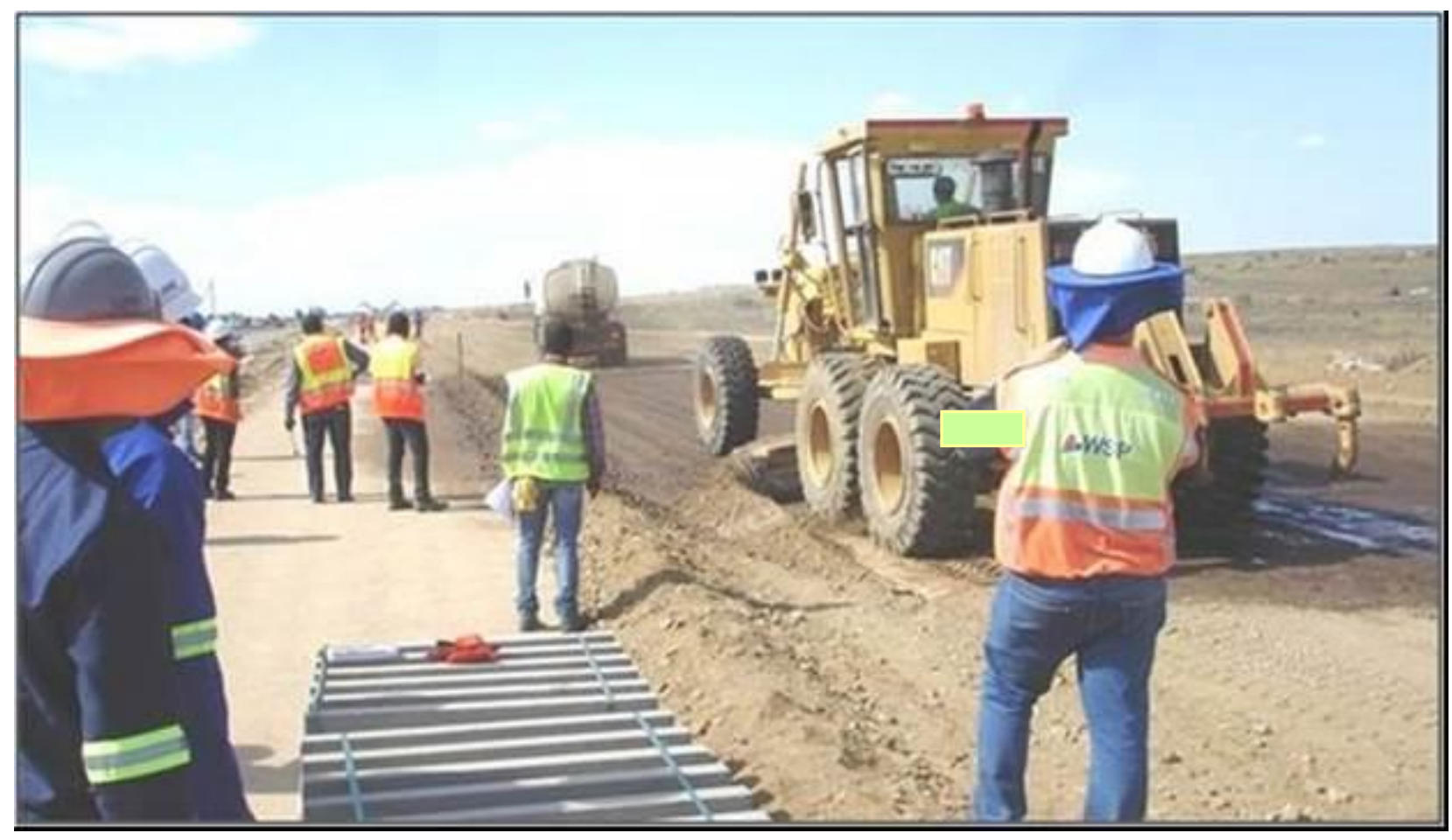

Figure 33. The water bowser is closely followed by graders that are mixing the NME stabilising agent dissolved in the construction water though the whole depth of the layer 


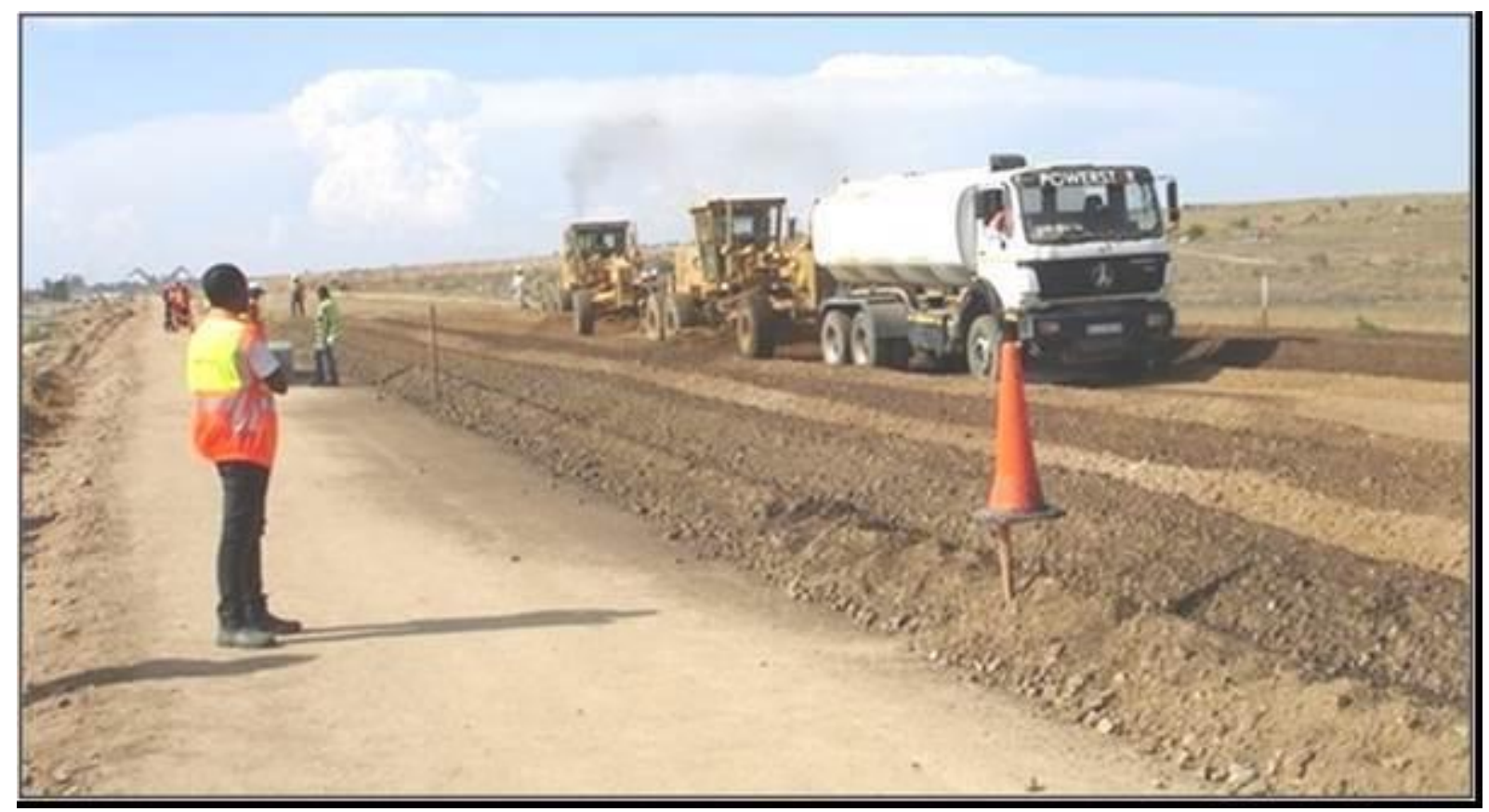

Figure 34. The spraying and mixing continue up and down over the whole width of the layer until the required stabilising agent is spread and mixed over the length, width and depth of the pavement layer

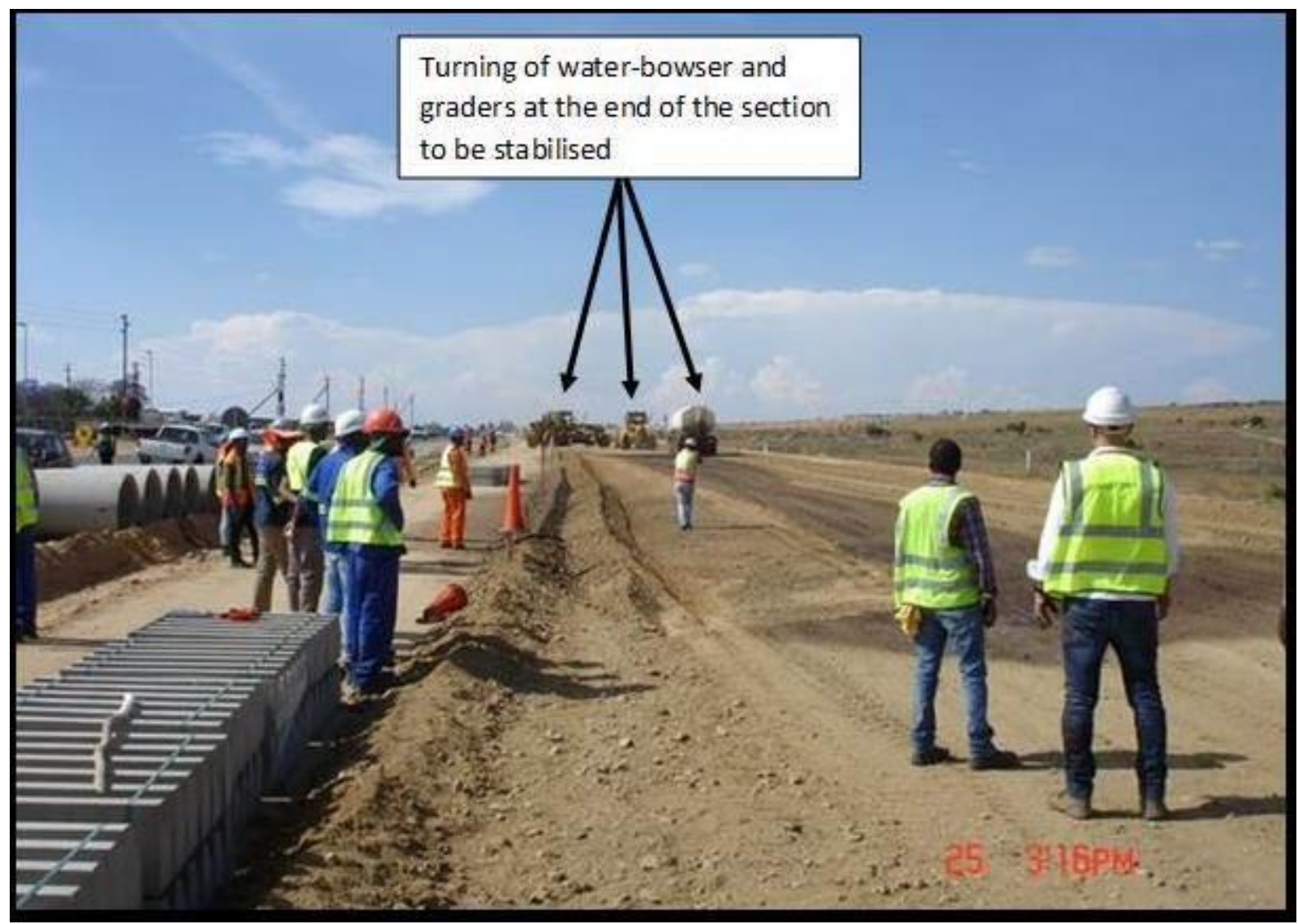

Figure 35. Turning of water-bowser and mixing graders at the end to the construction section, resulting in a longer construction time 


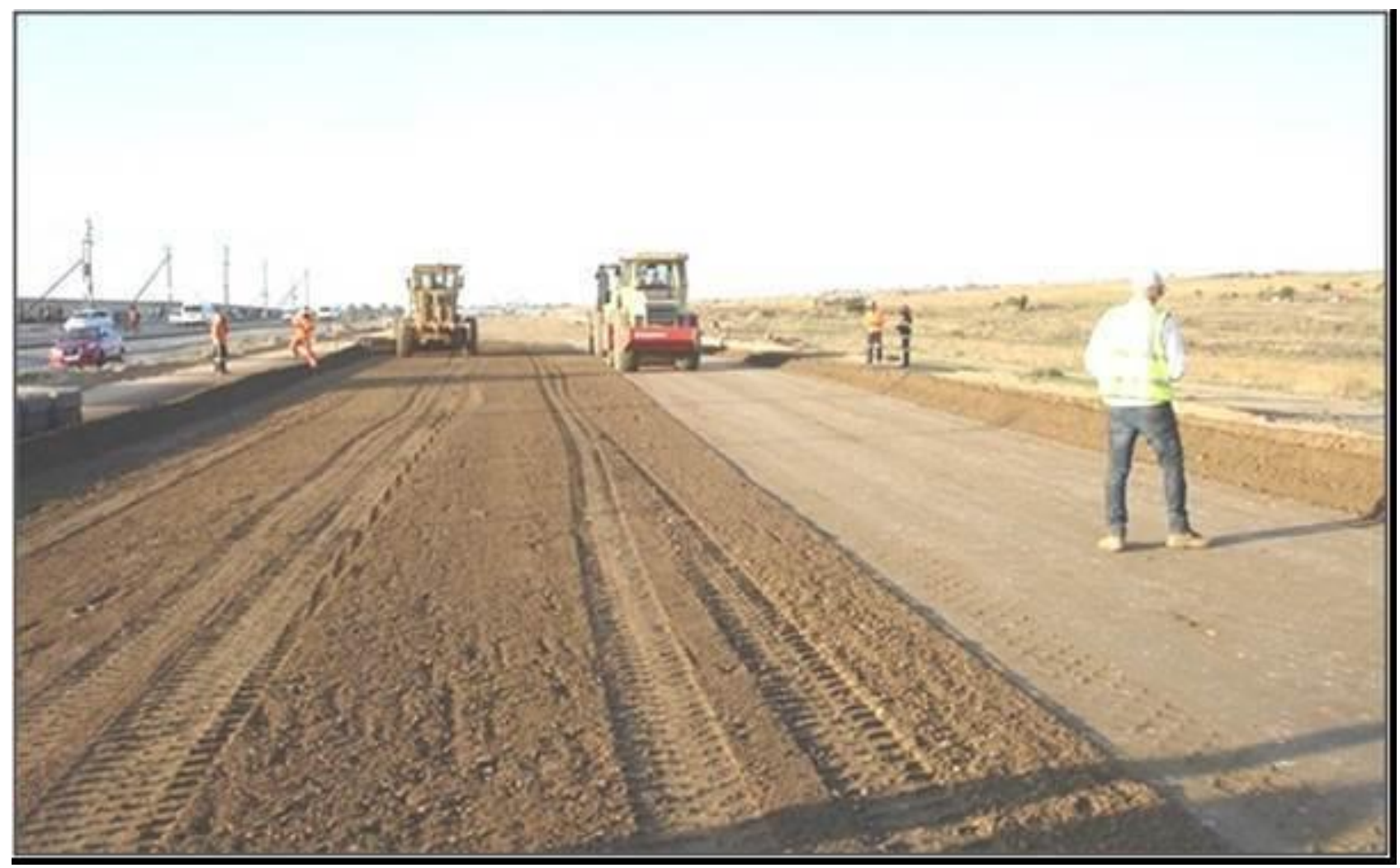

Figure 36. Shaping and compaction of the anionic NME stabilised layer $(0.7 \%$ NME with G5/6 quality granular material)

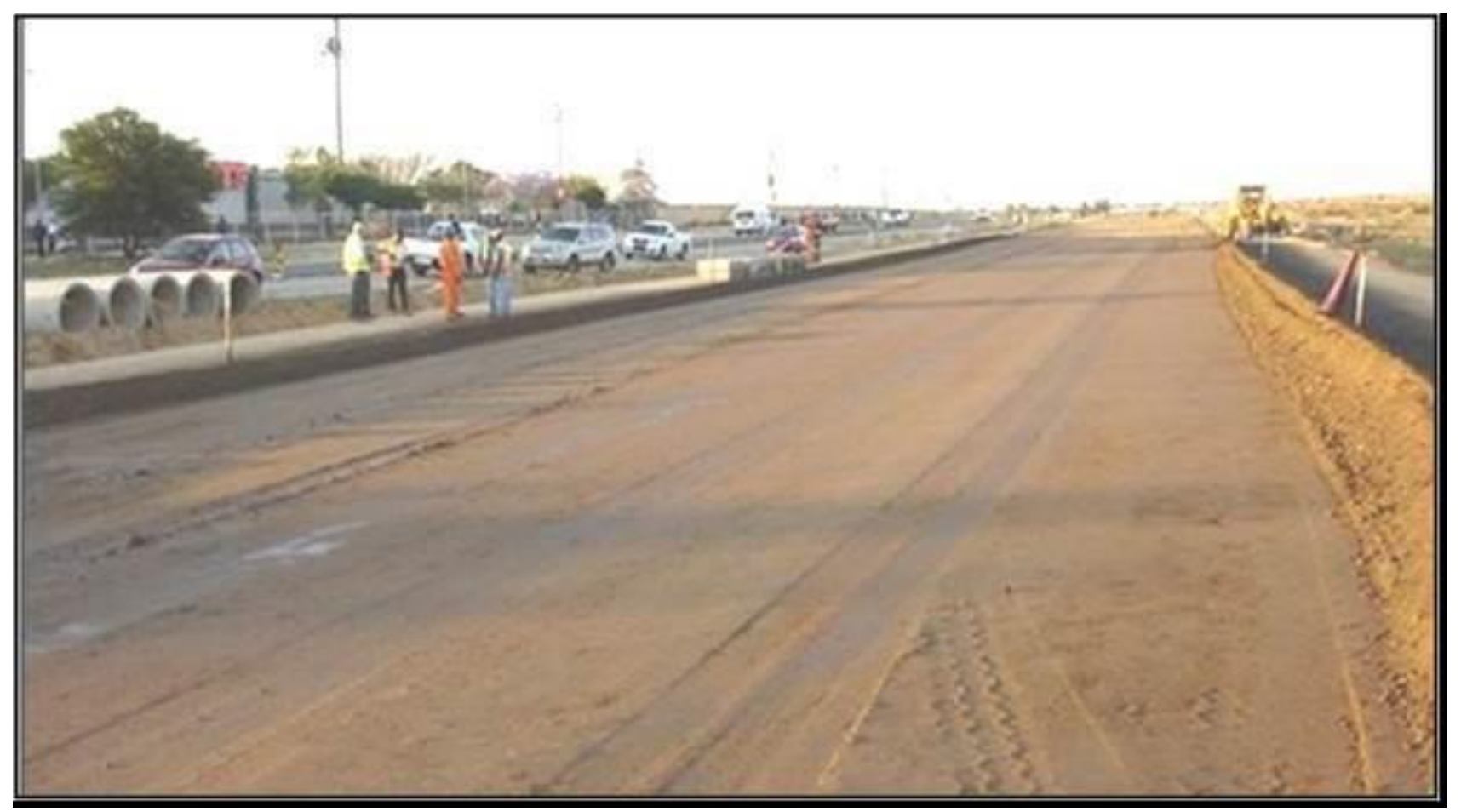

Figure 37. Enrichment of the top of the layer through spraying of the last of the diluted (with construction water) anionic NME stabilising agent before final compaction 


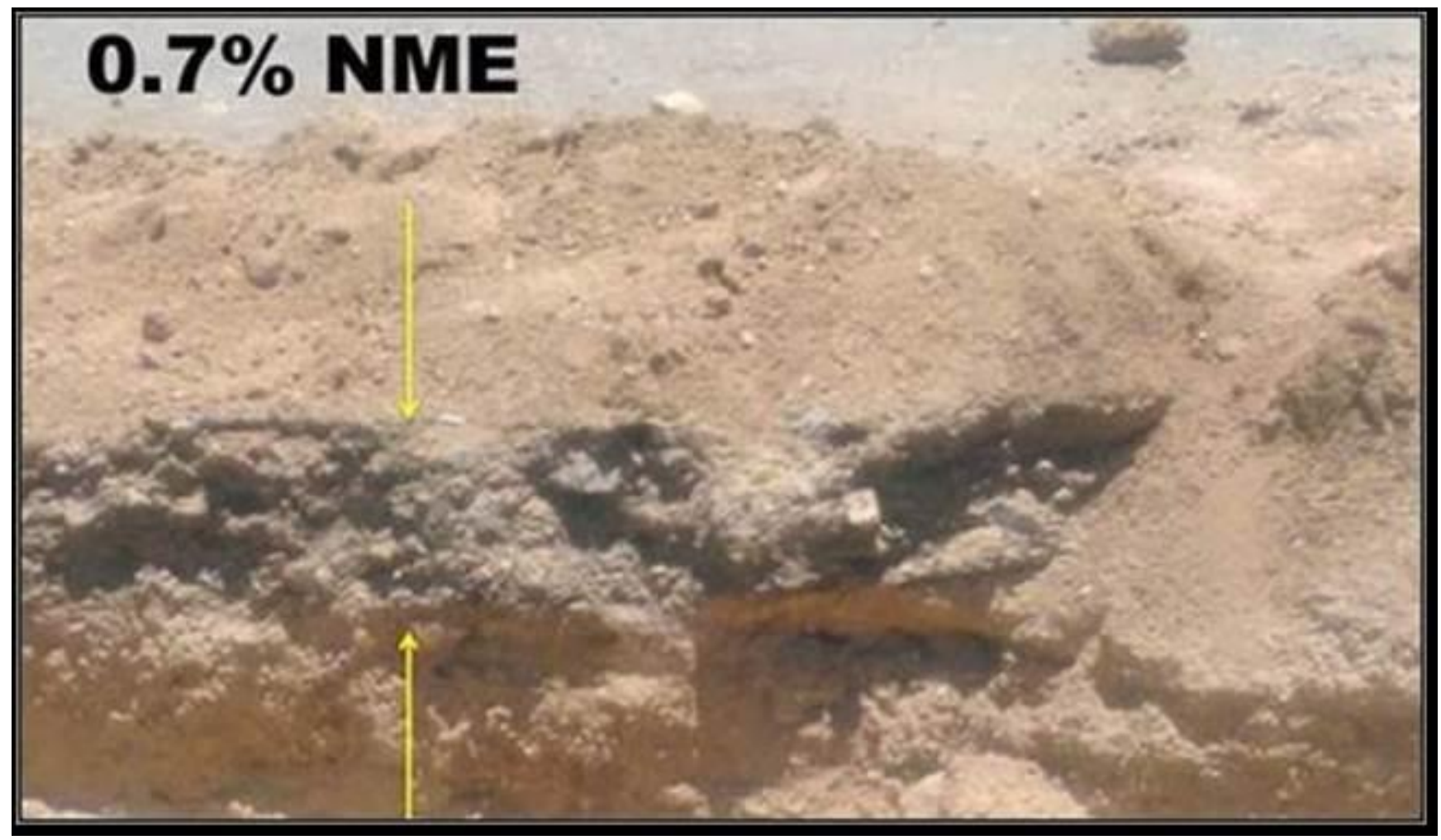

Figure 38. Cut through the stabilised sub-base constructed using a water-cart for distribution of the $0.7 \%$ anionic NME stabilising agent added to the construction water, mixed by grader and compacted

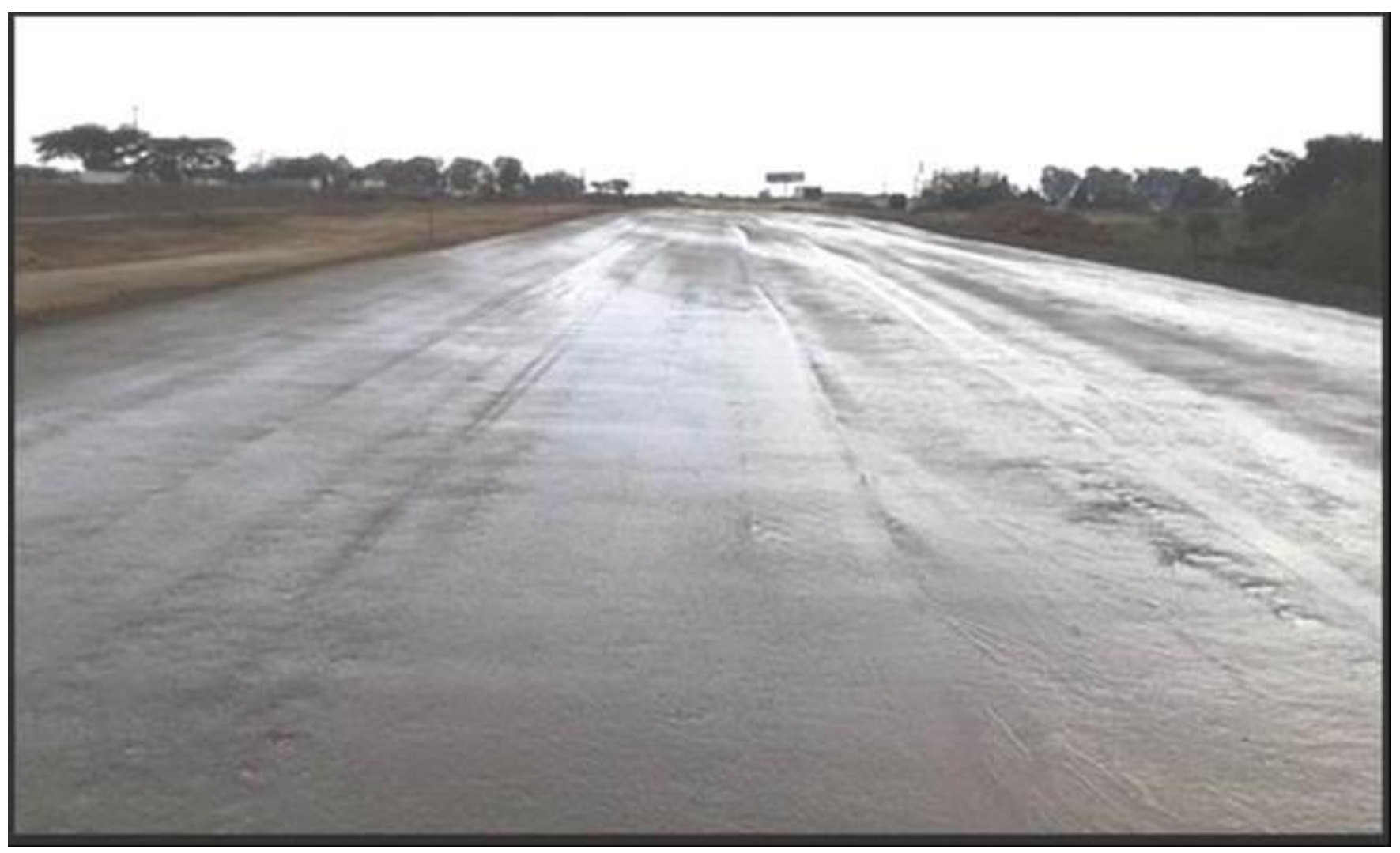

Figure 39. Similar to the exposed base layer (Figures 19 and 20), the sub-base was also subjected to $200 \mathrm{~mm}$ of rain in a single week soon after construction 


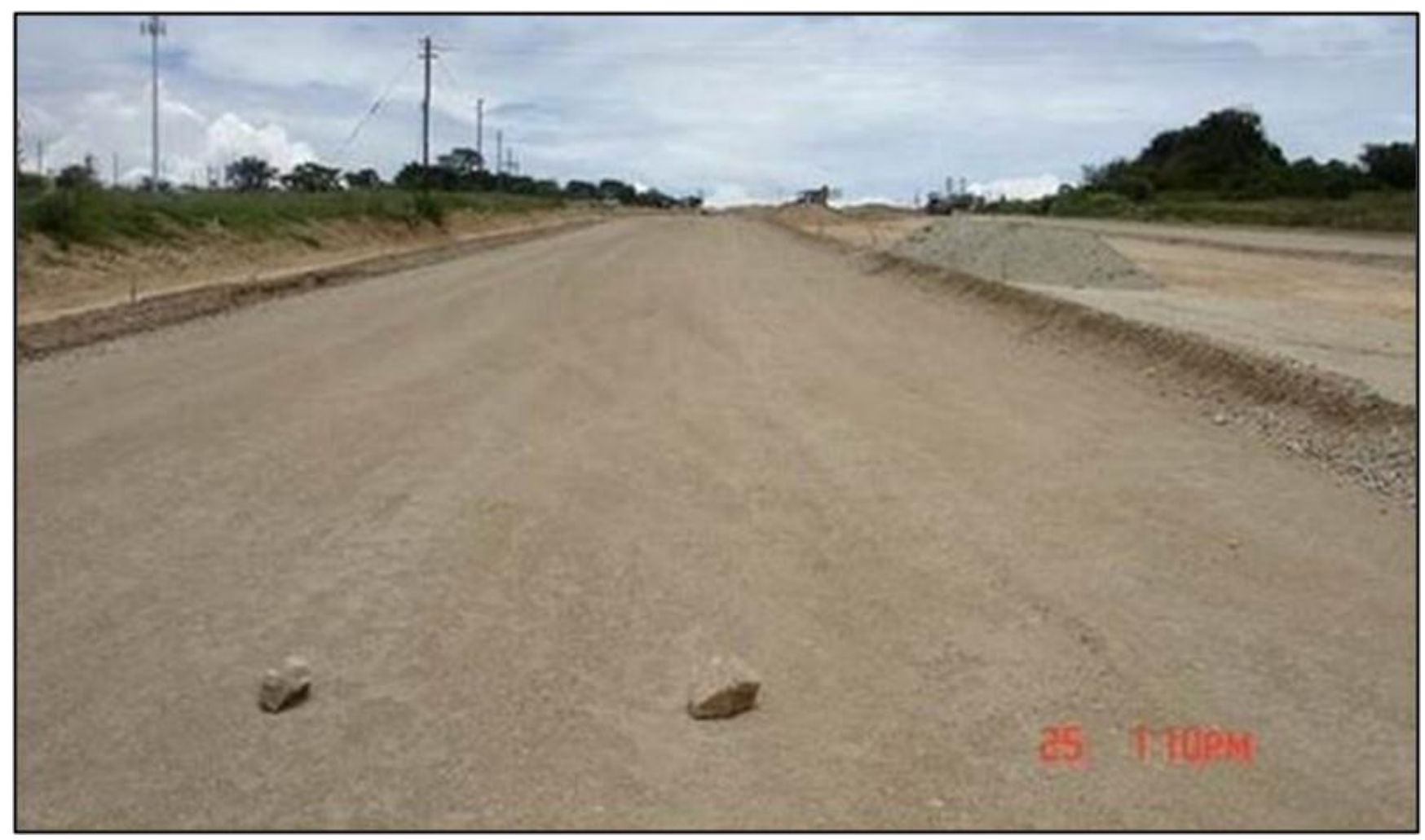

Figure 40. Condition of the sub-base after being subjected to the rain

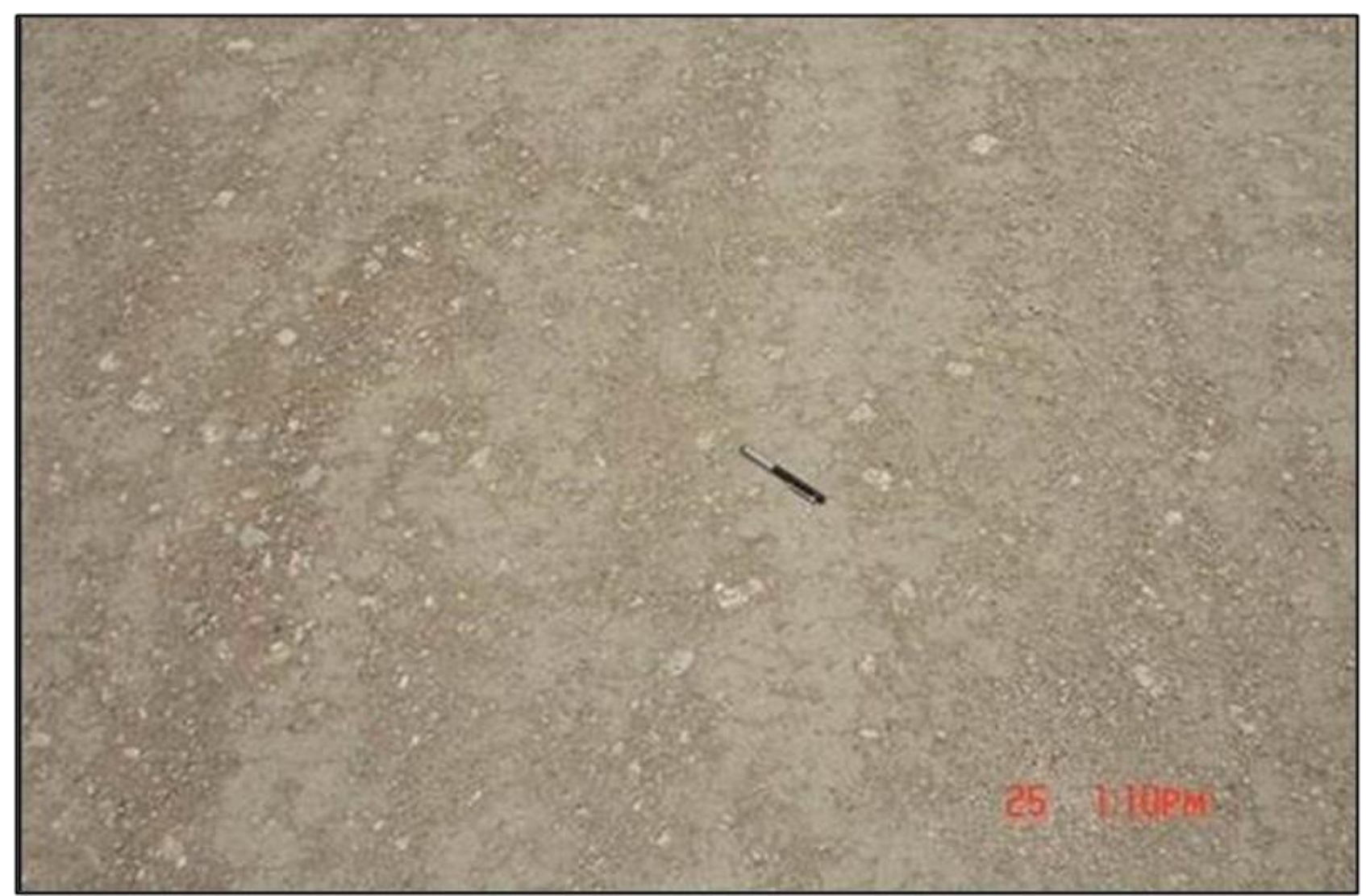

Figure 41. Close-up of the sub-base layer constructed with $0.7 \%$ anionic NME stabilising agent, using conventional construction equipment and after being subjected to a considerable amount of rain - the hydrophobic efficiency of the organofunctional silane modification of the bitumen emulsion modification has shown effective in practice 
The process for all category of roads using conventional equipment is similar in nature as described under the previous sections. In this example material was also imported on a compacted in-situ prepared road-bed. Material of a G7-quality (refer Figure 1) was used to construct a single $150 \mathrm{~mm}$ thick layer on top of the prepared base layer. Only one grader was used in the mixing of the material. The construction process and condition 6 years after completion of this secondary road are shown in Figures 42 to 46.

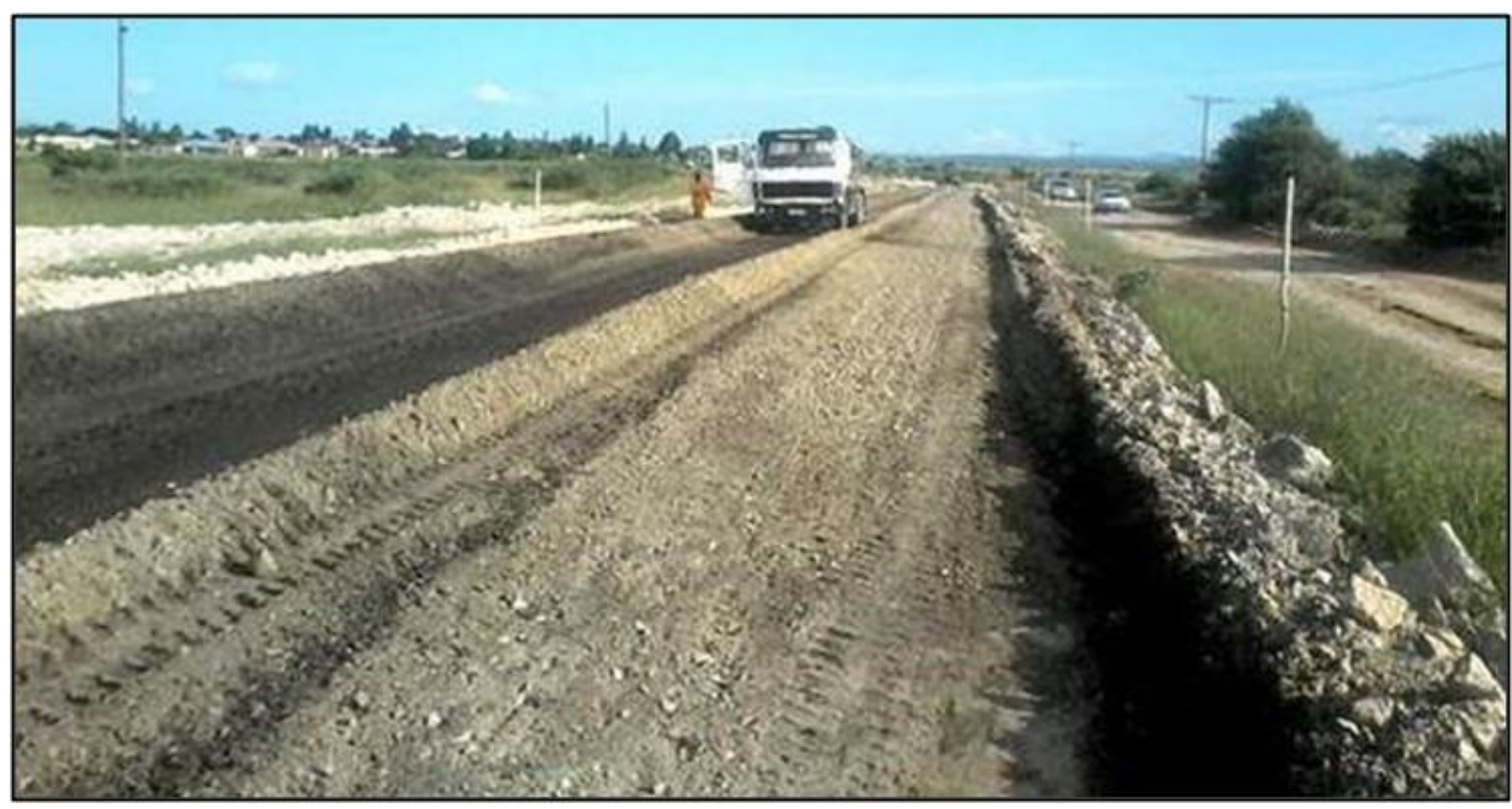

Figure 42. Water-bowser with construction water and anionic NME stabilising agent

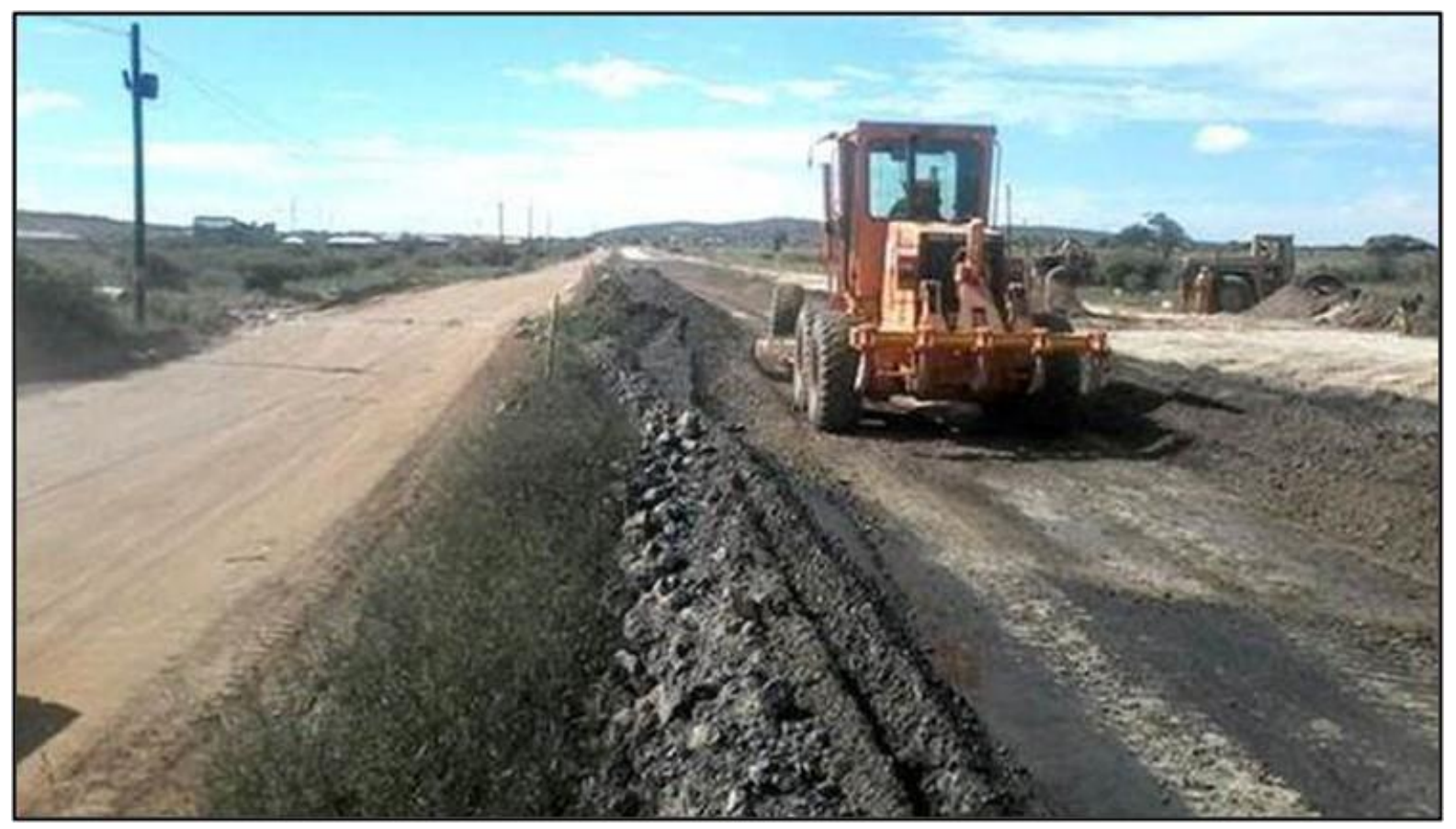

Figure 43. Single grader used for mixing of the anionic stabilising agent pre-mixed within the construction water 


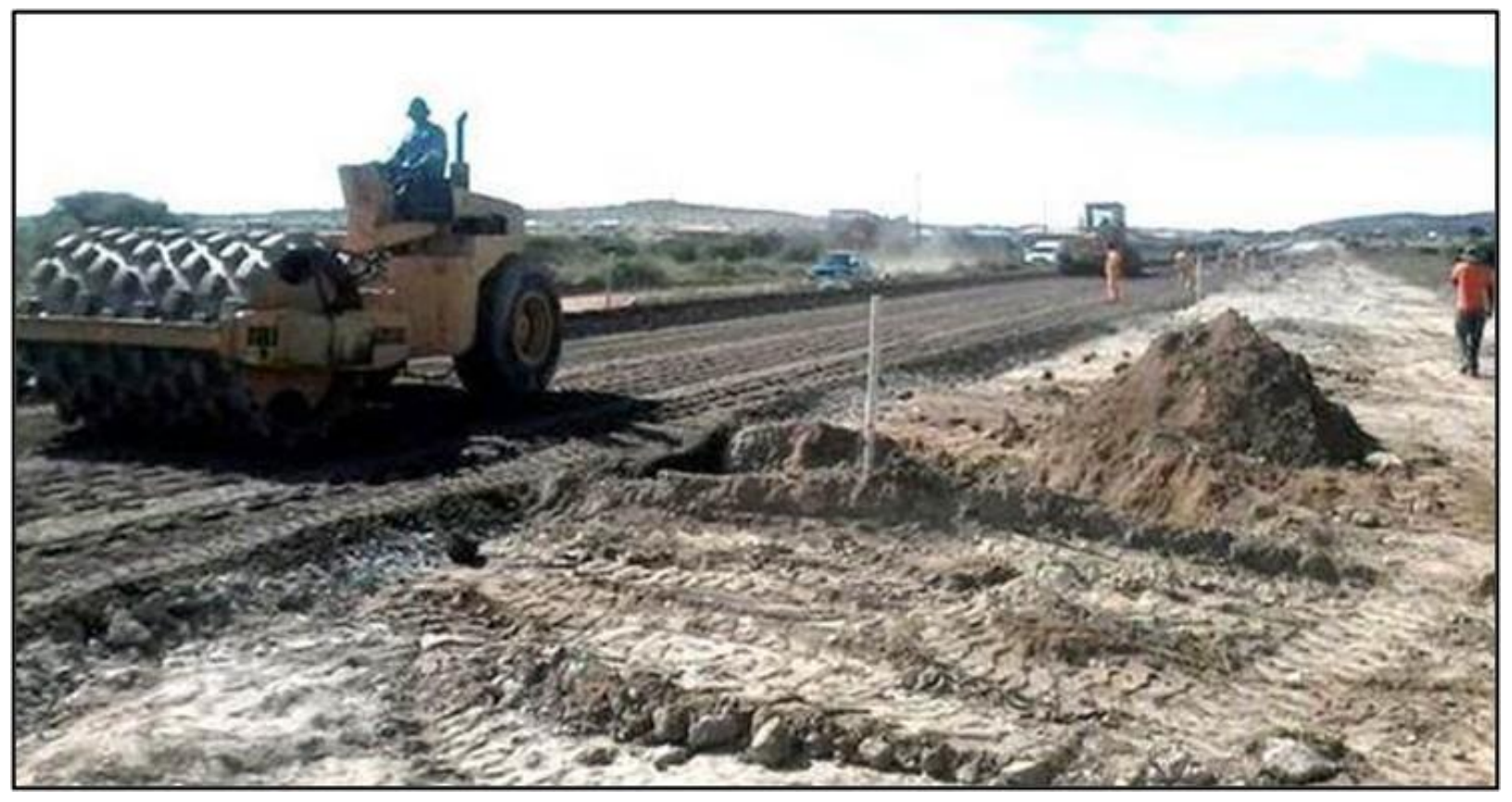

Figure 44. Compaction and cutting of final layer levels

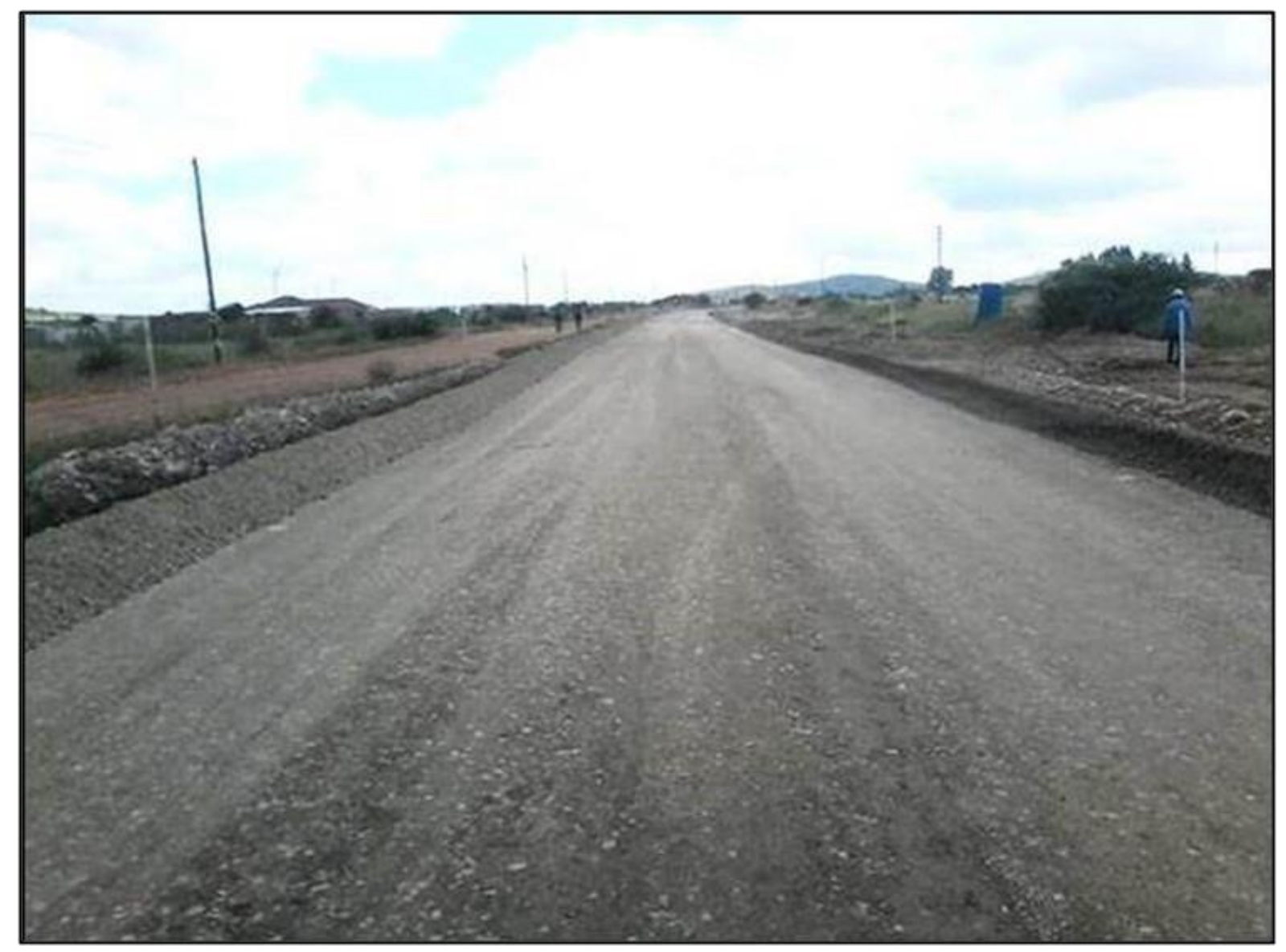

Figure 45. Condition of the compacted layer prior to applying a tack-coat and surfacing 


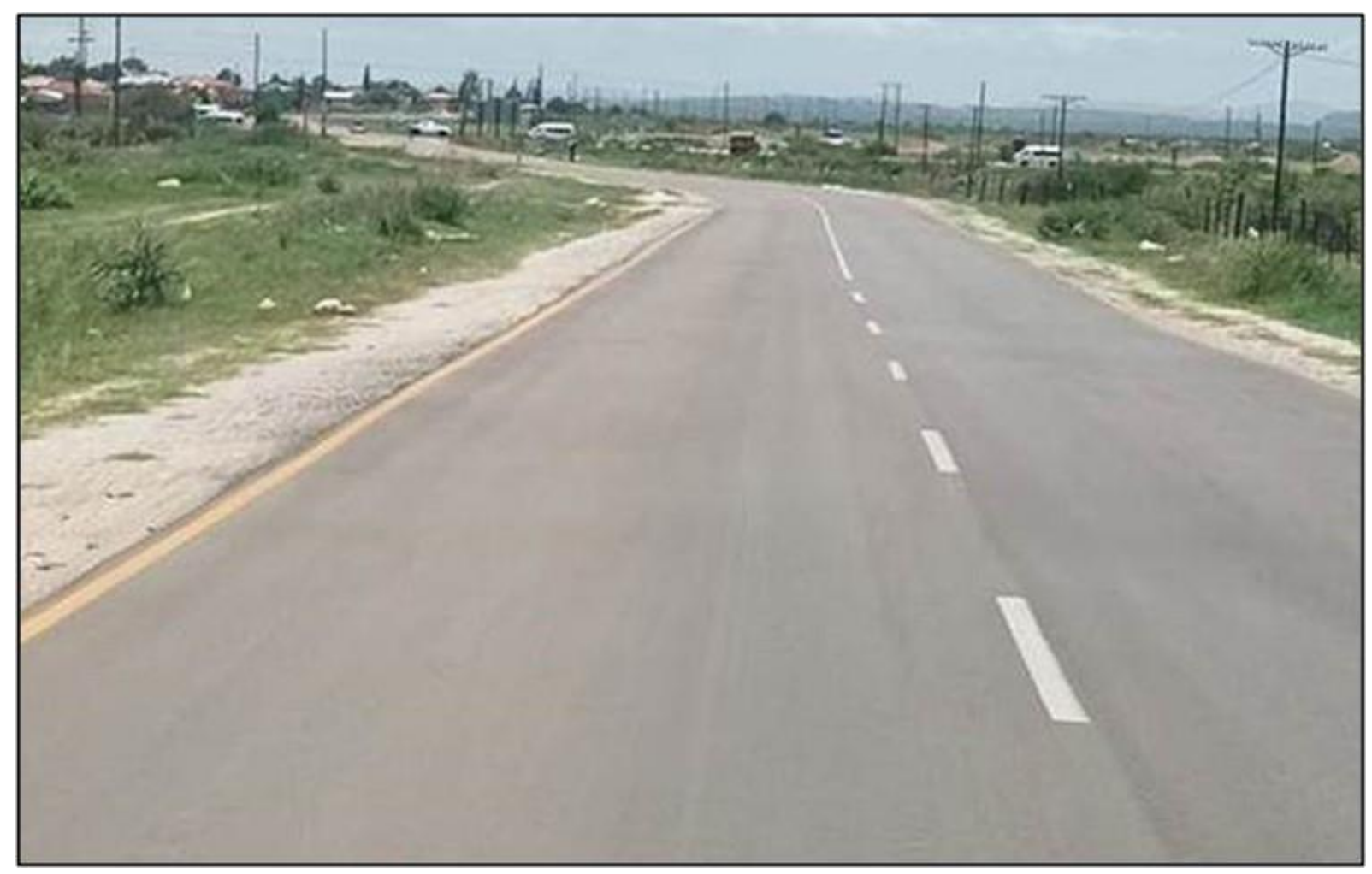

Figure 46. Condition of the surfaced road 6 years after completion

6.4.4 Construction and upgrading of a local access to farms and villages/townships using in-situ materials

The depth to which the in-situ materials need to be stabilised, is determined during the structural design process for the different material sections identified along the length of the road as per detailed design method [19]. Independent of the requirements and decisions with regard to the level of labour-intensive construction to be implemented, the following basic steps need to be followed:

- The in-situ material needs to be ripped to the required depth;

- Over-size material (usually more than $1 / 3$ of the thickness of the layer) needs to be removed - this can be done manually and the stone used for the protection of drainage facilities, if required;

- The ripped material needs to be windrowed, enabling the layer below to be compacted to the minimum required Dynamic Cone Penetrometer (DCP) penetration levels required for the layer at that depth within an applicable climatic zone (Appen$\operatorname{dix} C$ and D in Reference 19). This process will also ensure that the material to be stabilised is constructed to the correct thickness. DCP-DN values as per recommended design method [19], can be used for quick and easy quality control for the compacted layer on which the stabilised layer is to be constructed;

- The material can either be mixed with the stabilising agent by hand and transferred back onto the compacted layer or transferred back and mixed using conventional equipment such as a grader and water cart with compaction equipment. Compaction for Category D and E roads can be achieved using small pedestrian-type construction equipment to achieve the required densities. For Category D and E roads, the densities can quickly and easily be determined using the DCP equipment to evaluate the required DCP-DN values for that specific layer [19];

- The top of the base-layer should be treated with an anionic silane modified nano-polymer to ensure that a firm base-layer is achieved with a high-water resistance and protection against any possible damage, especially if it is to be opened to traffic before the surfacing is applied. For Implementing Agencies requiring a "natural" soil look to an upgraded gravel road, a second application of the anionic 
silane-modified nano-polymer is recommended. The anionic silane-modified nano-polymer can easily be applied by hand or sprayed by water-cart onto the finished base layer. Suitable application rates for the treatment of the base layer should be determined using trail sections. An application of $21 / \mathrm{m}^{2}$ of a diluted treatment (as per supplier recommendation) is suitable for the priming of an unstabilised base-layer. Stabilised base-layers will normally require a lesser application rate, and

- A suitable surfacing can be applied using mostly hand mixed materials such as slurries, sand seals and for a more durable surfacing, even a Cape seal [13].

Examples of the construction of pavement layers using an anionic NME stabilising agent for the upgrading of tertiary roads are shown in Figures 47 to 53. The slurry application by hand of a Cape seal is demonstrated in Figures 52 and 53. The surfacing of a similar access road in a semi-urban environment is shown in Figure 54.

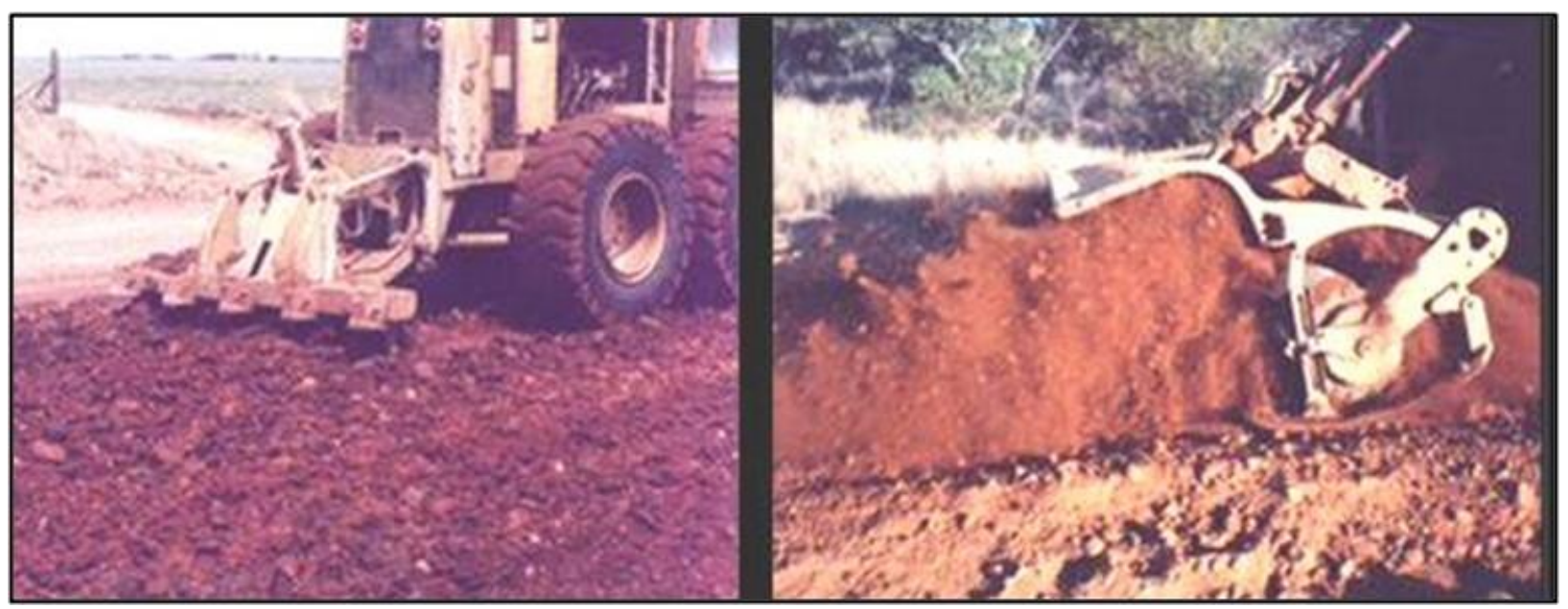

Figure 47. Ripping by grader and scarifying of in-situ material using a rotavator to loosen material to the required depth and expose oversized material for removal by hand

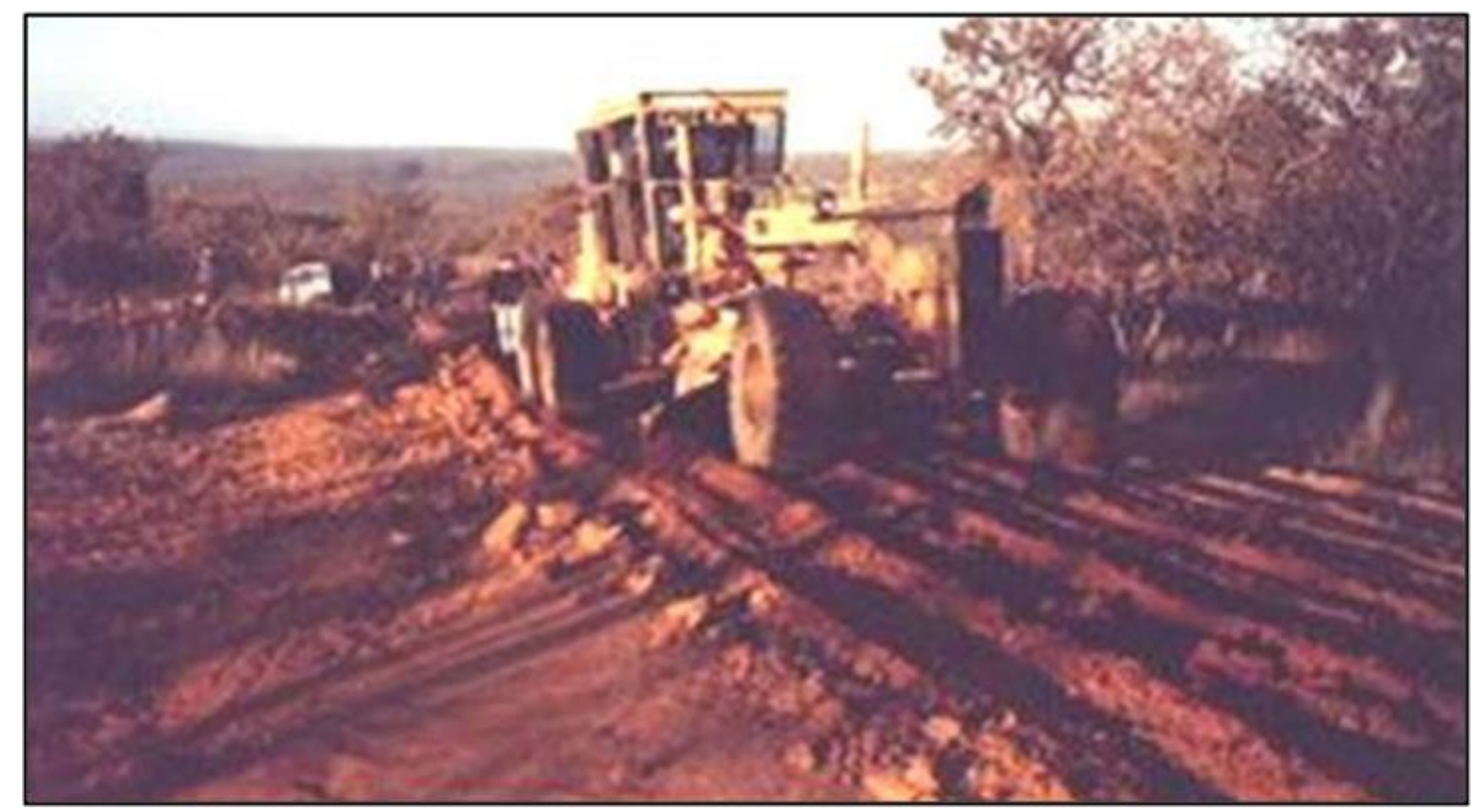

Figure 48. Ripping of layer to create layer depth exposure for ease of application of construction water diluted anionic NME stabilising agent 


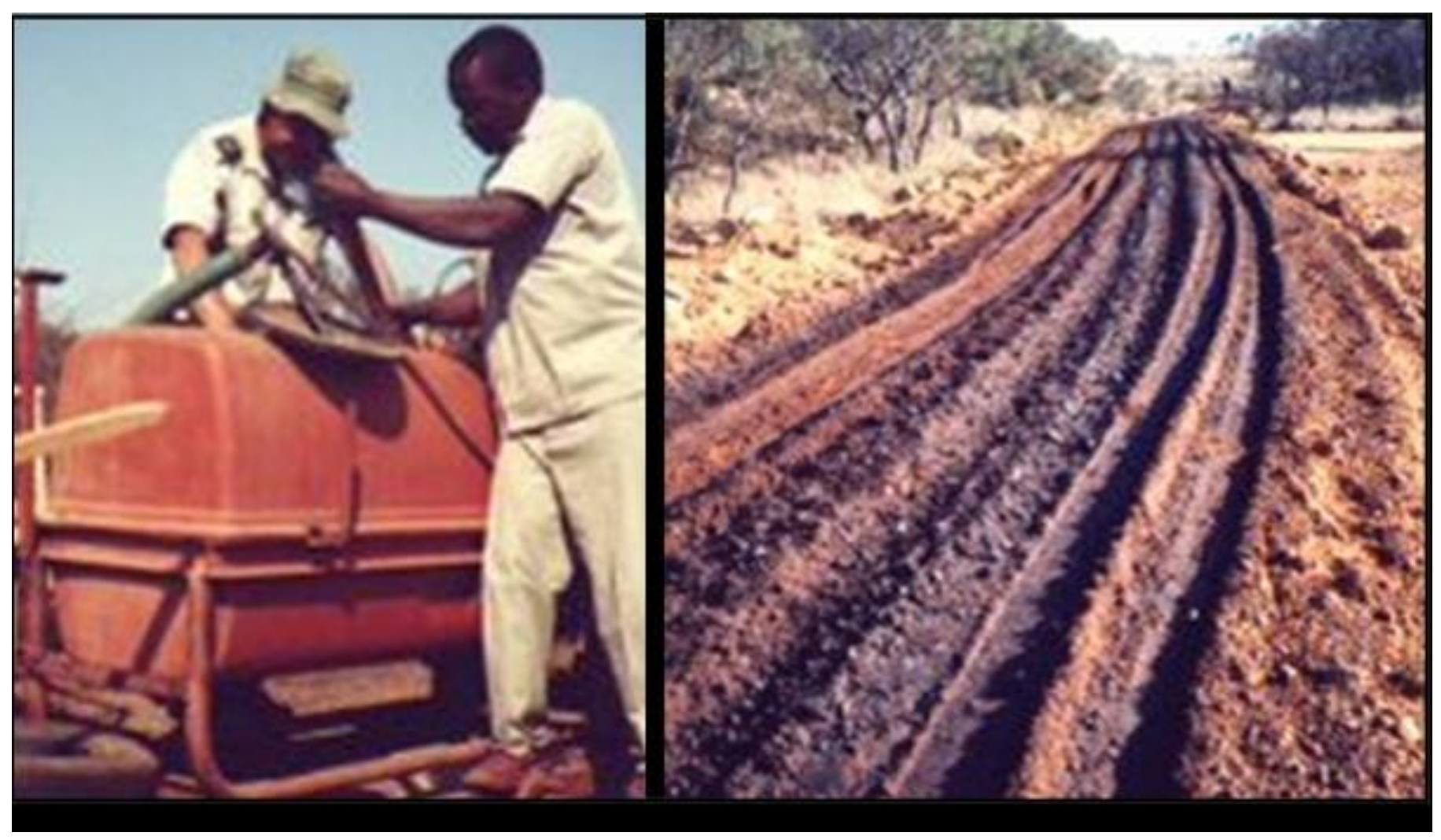

Figure 49. Addition of the material compatible anionic NME stabilising agent to a hand-operated sprayer and application of the anionic NME stabilising agent premixed with construction water on the ripped in-situ material

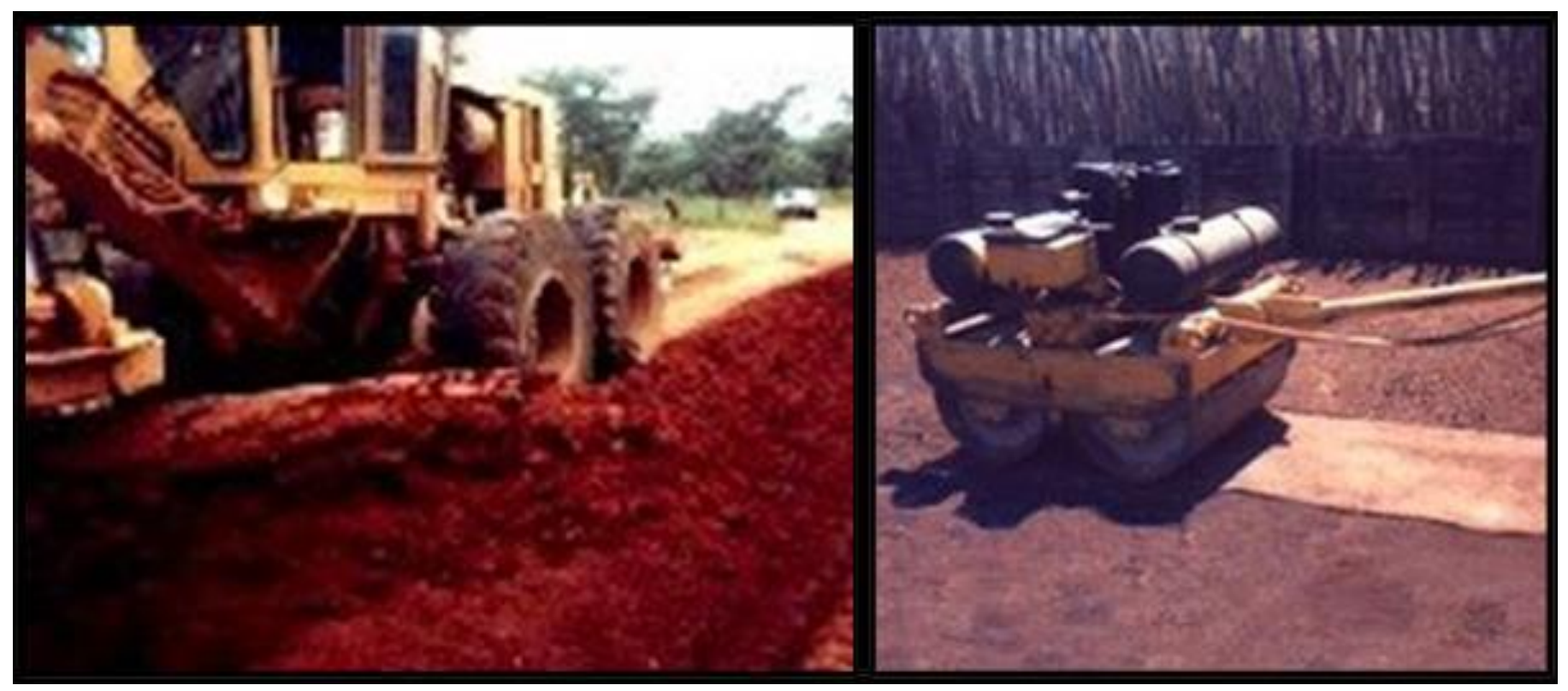

Figure 50. Mixing by grader and compaction using hand operating compaction equipment 


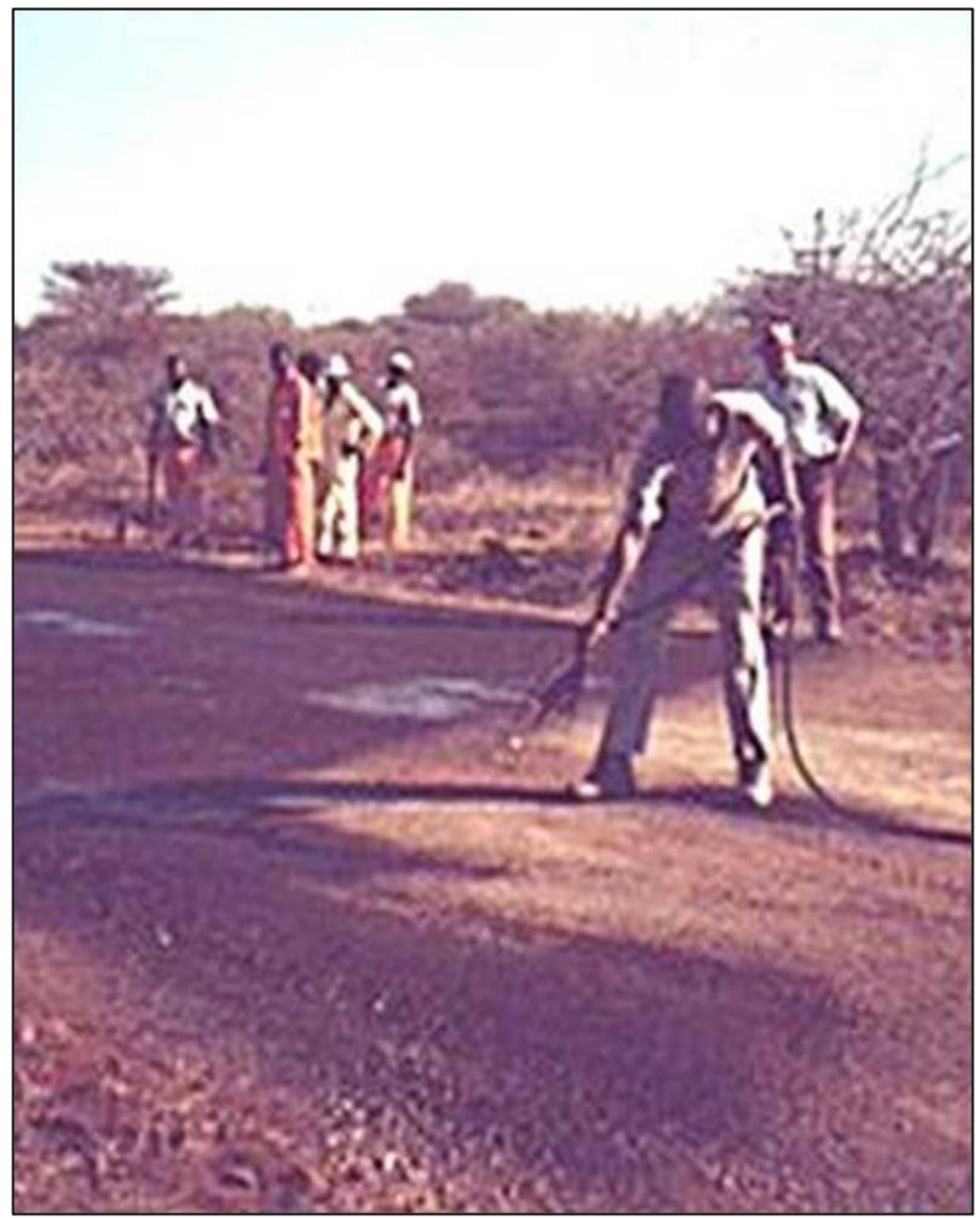

Figure 51. Application by hand of an enrichment layer 

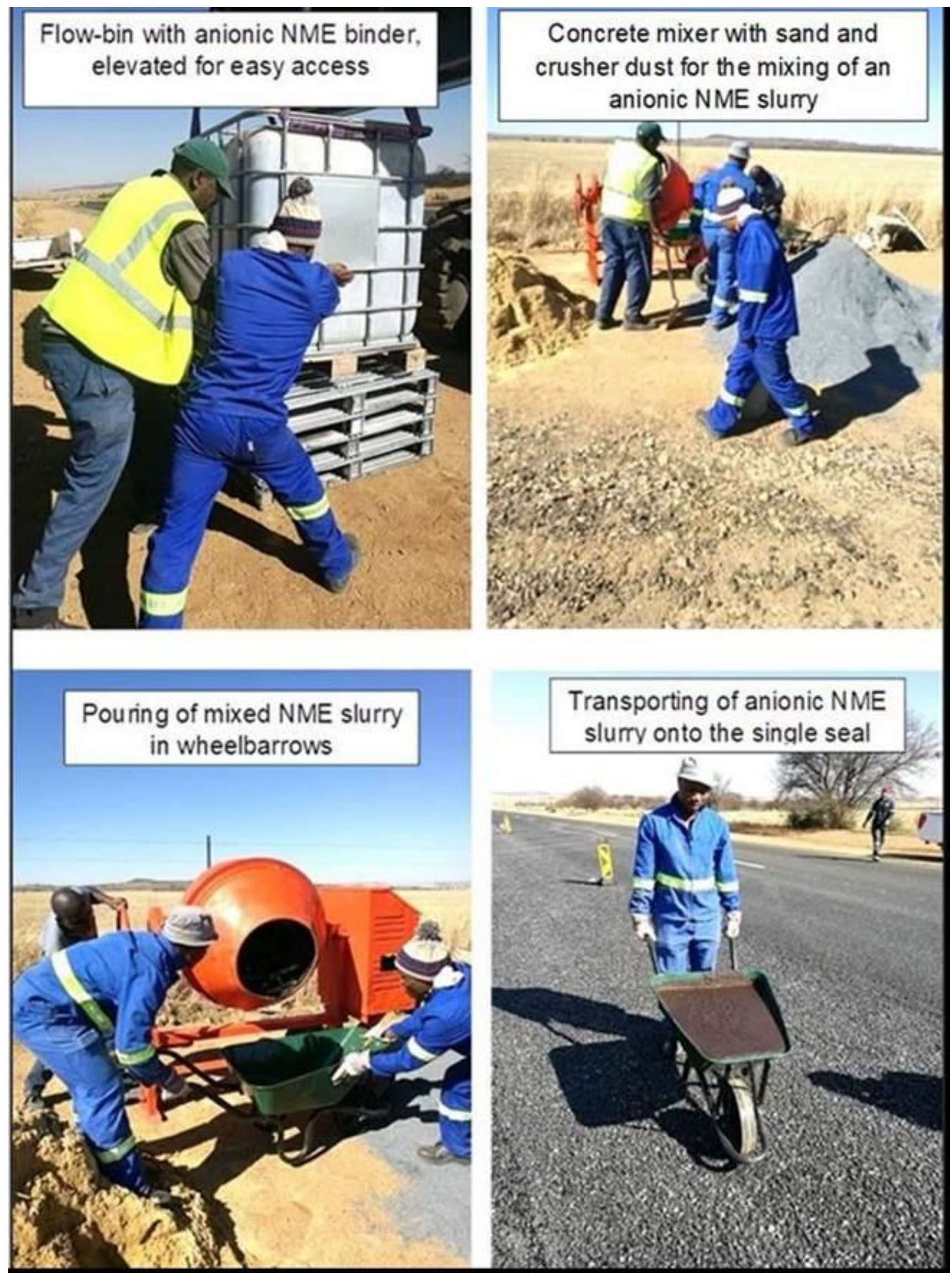

Figure 52. Labour-intensive road-side manufacturing of the slurry mix for a modified Cape seal using an anionic NME binder 


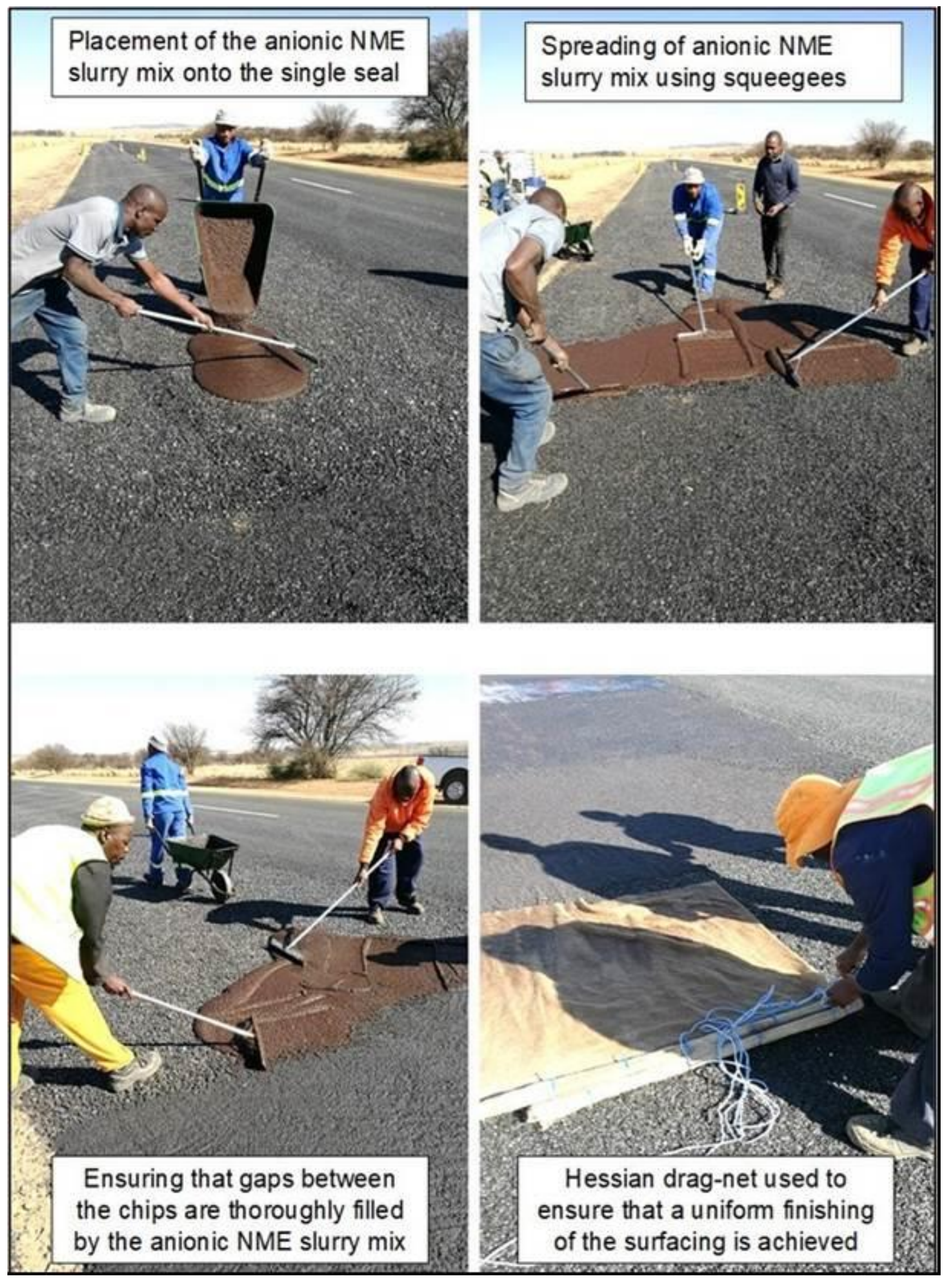

Figure 53. Labour-intensive construction of a modified Cape seal using an anionic NME binder with the slurry mixed on site next to the road 


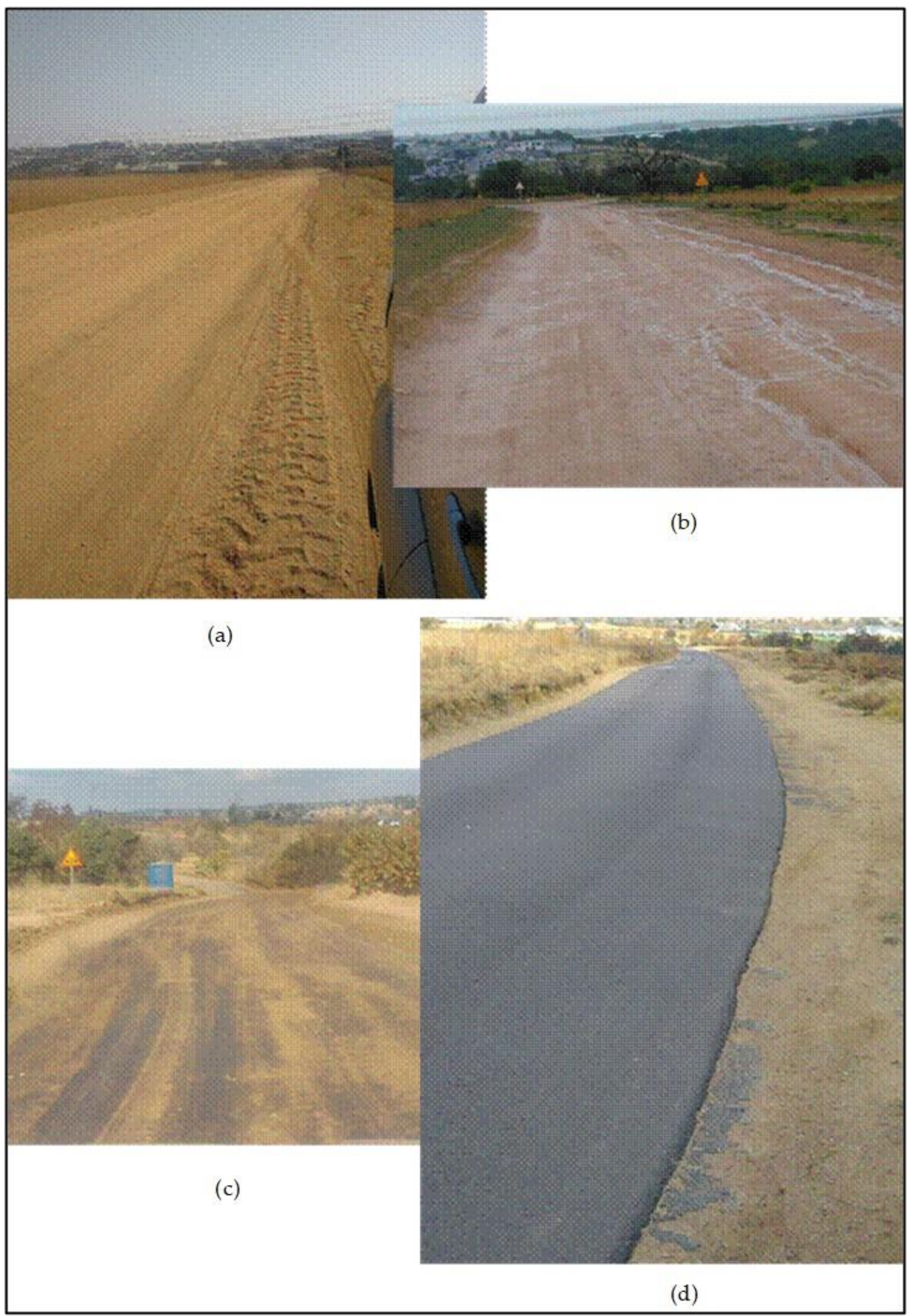

Figure 54. Upgrading of a local access road with (a) and (b) showing the sandy/slippery/muddy conditions prior to upgrading; (c) $100 \mathrm{~mm}$ in-situ stabilisation with an anionic NME stabilising agent and (d) with an ultra-thin finegraded asphalt surfacing 


\section{Resolving some Common Construction Related Problems experienced during the stabilisation of granular materials using New-age (Nano) Modified Emulsions (NME)}

\subsection{Compaction at moisture conditions too low or too high}

Compaction at moisture conditions that are too low are easily recognised in practice, noticing the formation of small cracks appearing after roller compaction. A typical example of such cracking is shown in Figure 55. It is always good practice to have on stand-by a water-bowser a=with a small percentage of diluted anionic NME in construction water. As soon as such cracking is noticed a light spray with the diluted NME solution will provide the necessary moisture to compact the layer as a solid unit. The additional NME solution will also enrich the surface of the layer providing additional strength in the top of the layer.

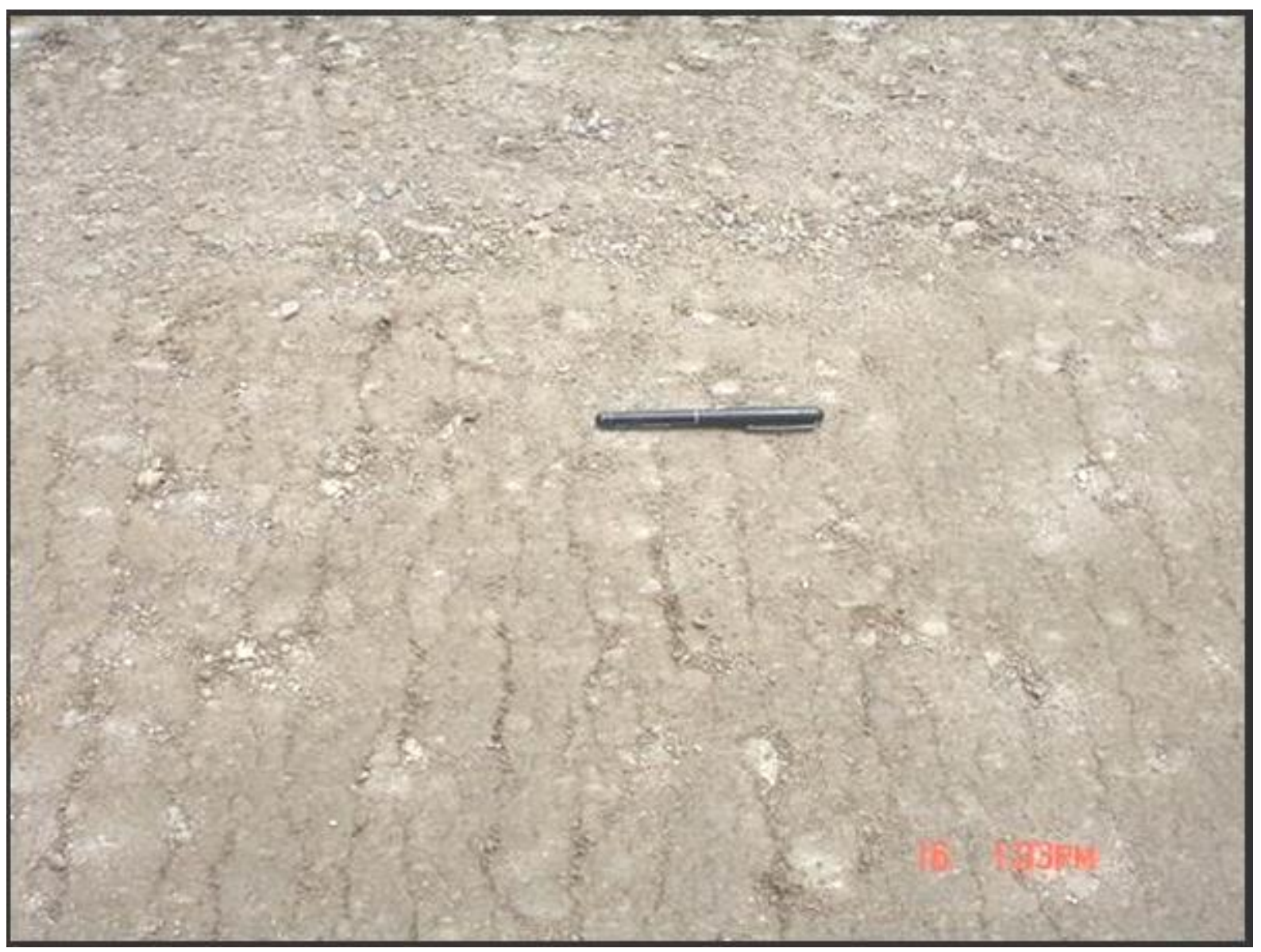

Figure 55. Appearance of small racking after roller compaction as an indication of moisture conditions that are too low for good compaction

Experience has shown that stabilisation of granular materials using construction water diluted NME stabilising agents are quite resilient and forgiving in nature. In contrast to compaction at too low moisture conditions, the opposite can also happen. It the case of too high moisture conditions, a small wave of material will be noticed to move in front of the smooth drum roller. In such cases no damage will be done by the ripping of the layer and allowing exposure to the sun for some of the moisture to evaporate. Recompact ion of the layer will have little impact on engineering strength requirements to be met.

In extreme cases, movement of the stabilised layer, even after some hours will be an indication of layer work that has been stabilised to the wrong depth with an oversupply of stabilising agent in a layer that that has been reworking to an inadequate depth with a concentration of the NME stabilising material in a layer that is too thin. An extreme ex- 
ample of such an occurrence is shown in Figure 56. Closer investigations have shown that the stabilisation was confined to a depth of $50 \mathrm{~mm}$ only instead of the specified $150 \mathrm{~mm}$. The depth of stabilisation is the responsibility of the contractor that must ensure that specifications are met. In this case a total rework of the layer to a depth of $150 \mathrm{~mm}$ is the required solution. Due to the resilient nature of the NME stabilising agent, the reworking can be achieved through the in-situ milling, mixing and windrowing of a $150 \mathrm{~mm}$ of material, followed by the reinstatement of the thoroughly mixed material and re-stabilisation by using 50 per cent of the original specified amount of NME stabilising agent. Care should be taken not to exceed the OMC of the reinstated materials. The organofunctional silane modifying agent (NME) already added to the material will have reduced the original $\mathrm{OMC}$ of the material by at least 10 per cent. Hence, compaction should be done at the drier side of OMC to avoid movement of the material during decompaction.

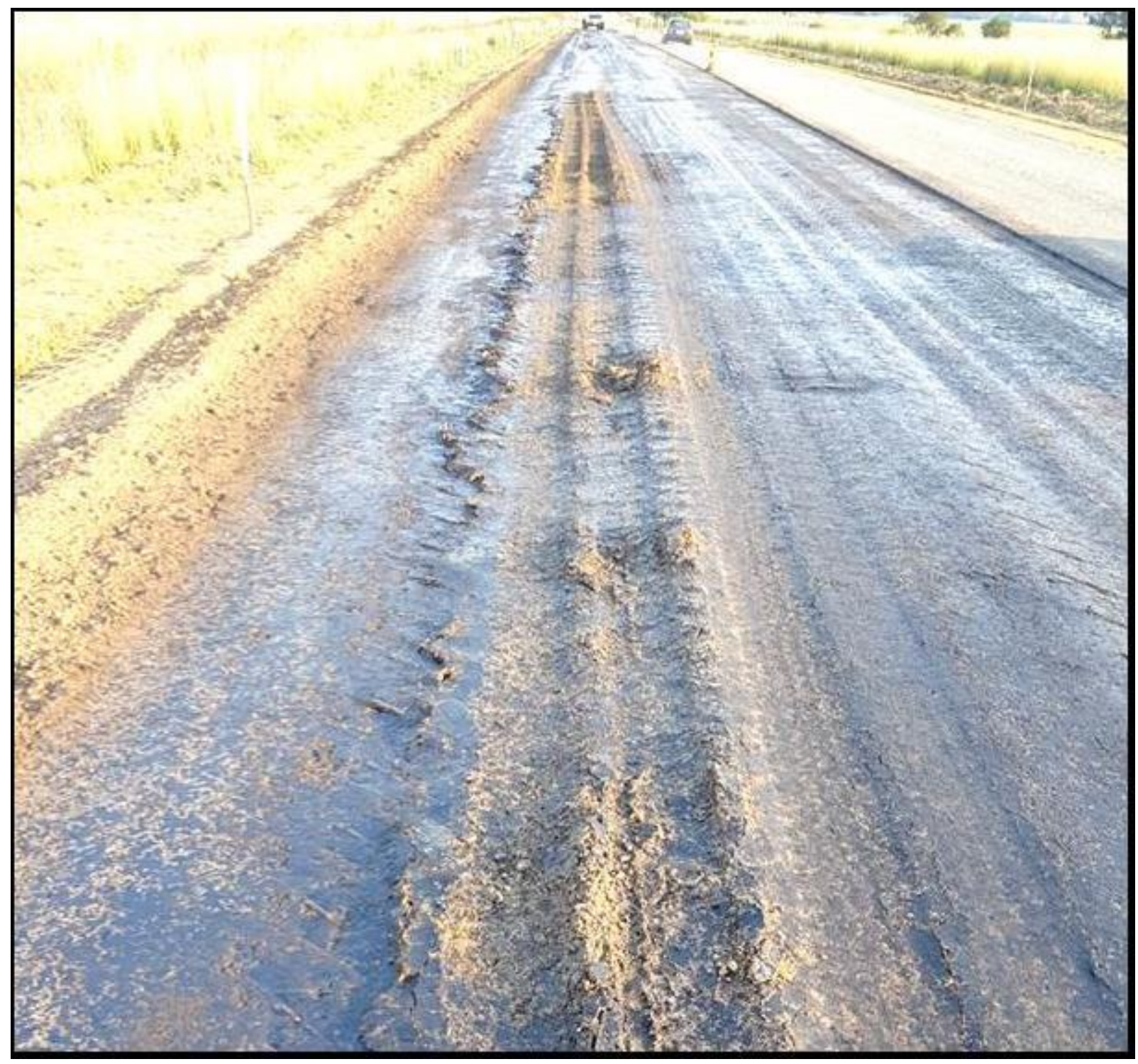

Figure 56. Severe movement of the NME stabilised layer indicative of layer thicknesses not complying to specifications with all the of the NME stabilising agent added to a very thin layer $(50 \mathrm{~mm})$ not meeting the specifications of a layer thickness of $150 \mathrm{~mm}$ 
7.2 Reworking of layer not meeting criteria and future rehabilitation of NME stabilised layers

7.2.1 Reworking of NME stabilised pavement layers

No construction contract is without any challenges. In all probability some problems will occur resulting in some NME stabilised sections not meeting the specified engineering criteria or, that some equipment failure result in a surfacing condition clearly indicating some problems with the equipment that are being used. A typical construction equipment related problem is shown in Figure 57.

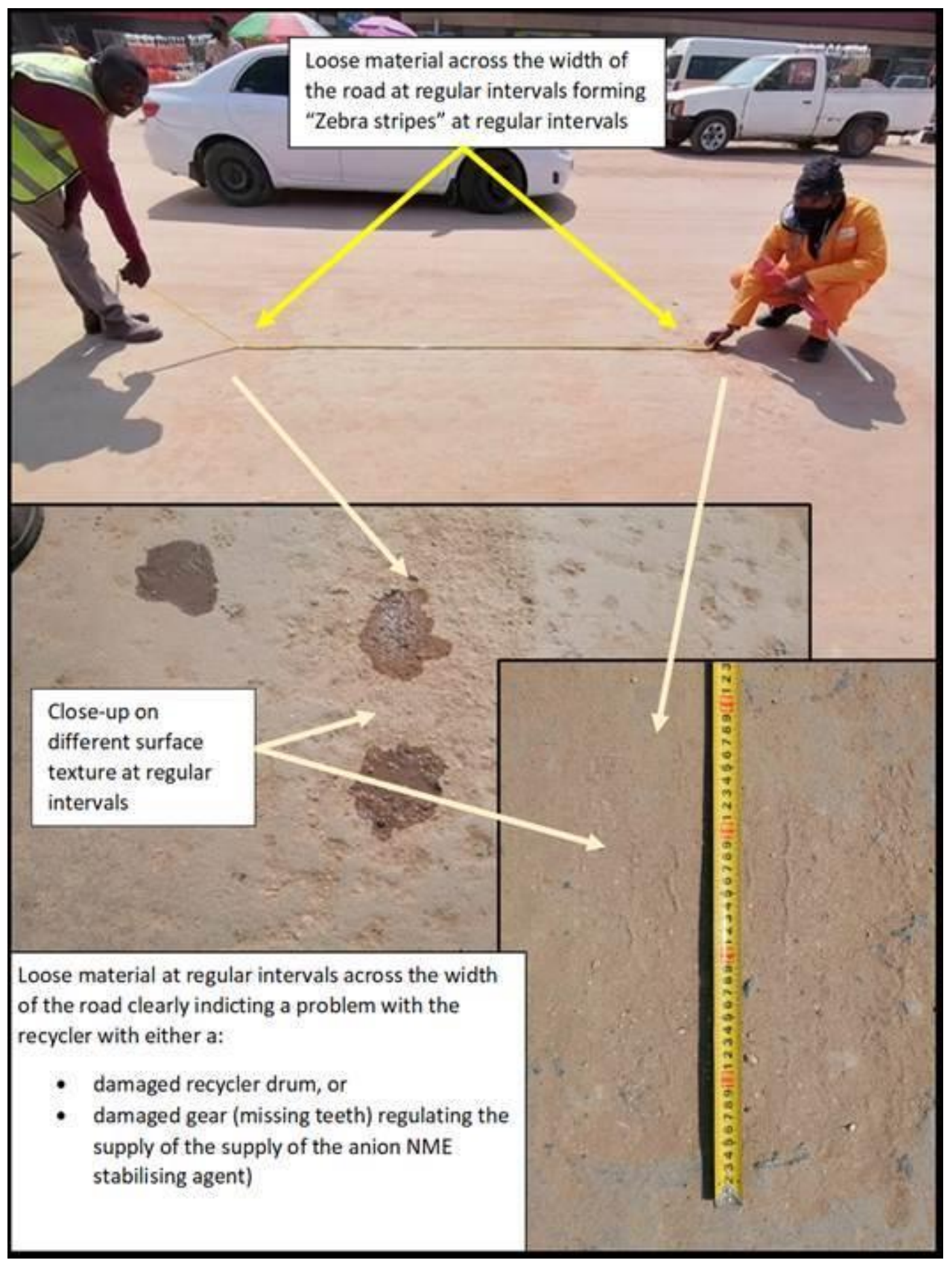

Figure 57. Construction equipment related surfacing problem, showing surface irregularities at regular intervals across the width of the stabilised section stabilised using recycling equipment (Photographs provided and permission for publication granted [20])

Due to the regular intervals of the visible surface irregularities, the problem had to be associated with the drum-mixer of the recycler (used on this project) and/or the supply 
of the construction water diluted NME stabilising agent. In this particular case a broken gear regulating the supply of the diluted NME stabilising agent, resulted in a regular undersupply of the diluted NME stabilising agent. The engineering specifications was exceeded by some margin throughout this constructed layer works. At his own risk, the contractor reworked the specific section without any addition of stabilising agent or construction water within 24 hours. Although a reduction in the original measurements were measured, the reworked road section still met the engineering requirements, the results of which are shown in Table 1 with a decrease in the wet US and ITS values of less 20 per cent. This example is testimony to the resilient, forgiving nature of the stabilisation of naturally available gravel material (in this case G7-quality material) stabilised with a material compatible NME stabilising agent.

Table 1: Results* of initial stabilisation and dry Reworking of the layer after 24 hours

\begin{tabular}{llll}
\hline & UCS (MPa) & ITS (kPa) & $\begin{array}{l}\text { Material classification } \\
\text { (Construction) }\end{array}$ \\
\hline Construction Specification & 0.70 & 140 & NME3 \\
\hline Initial Stabilisation & 2.95 & 232 & NME1 \\
\hline Dry reworking after 24 hours & 2.40 & 199 & NME2 \\
\hline Loss in strength measurement & $19 \%$ & $14 \%$ & \\
\hline
\end{tabular}

* Results provided and published with permission [20]

Reworking of layers not meeting specifications or the reworking of NME stabilised pavement layers in future rehabilitation works must be understood in the context of the science behind the anionic NME stabilising agent and the interaction thereof with the granular particles in a pavement layer $[4,5,8]$.

It is essential to understand that the organofunctional-silane modification to stabilising agent (anionic NME) enables:

- The ability to cover each particle of the granular material within a pavement layer to become water-repellent (hydrophobic) (provided a scientifically based design procedure is followed [8,13]; and

- $\quad$ To provide a strong chemical bond between the granular particles and the stabilising agent (i.e. bitumen emulsion or equivalent polymer).

Should a layer need to be reworked for whatever reason, the weakest link will be broken, which most probable will either be the bitumen stabilising agent (especially when it is relatively freshly stabilised) or the case of severely weathered materials, the granular particles itself will break. In the above example (Figure 57 and Table 1), the primary minerals measured contained a high percentage of Silicon in the form of quarzitic material that are relatively hard. These material particles did not break during reworking of the layer. The strong chemical bonds between the primary minerals and the nano-silane were also not broken. Hence, the bitumen stabilising agent (still relatively fresh and viscous) sheared during reworking and then bound together again during recompacting to generate adequate in-situ strength properties as confirmed by the test results. Off-cause not all bonds could be recreated, resulting in the measured reduction in UCS and ITS measurements (Table 1).

It could happen that during construction, design specifications are initially not met for whatever reason (e.g. compaction at moisture conditions either too low or too high (this is normally the case in most problems experienced on site) or breakage of construction equipment during the construction process). Experience has shown that the in-situ reworking of such layers with the addition of 50 per cent of the initial specified anionic NME stabilising agent, will ensure that the reworked layer will easily surpass the required specification (i.e. if the initial design required stabilisation of the granular materials using 0.7 per cent anionic NME - reworking with 0.35 per cent anionic NME (ap- 
proximately 0.2 per cent residual bitumen), will suffice for the reworking of the layer in order to meet the engineering specifications). In these cases the construction water together with the additional anionic NME stabilising agent will be considerably less than the initial required construction water. The water will now only be used as a distribution agent of the stabilising agent and act as a lubricant during construction. No absorption of the water by the aggregate (granular particles) will occur and the layer will become dry at a much-accelerated rate.

This characteristics are demonstrated in Figure 58 [10], showing the change in the characteristics of dolomite tested before and after stabilisation with a material compatible NME stabilising agent. It is seen that the density versus moisture content becomes less sensitive to changes in the compaction moisture content as a function of OMC. Hence, the required specified density could be achieved at lower moisture conditions. This aspect could be a significant factor for the construction of roads where construction water may be a scarcity. Should the layer be required reworking due to any problems (e.g. as shown in Figure 57), and the design criteria was exceeded by some considerable margin, dry reworking as shown in Table 1, could be a viable option.

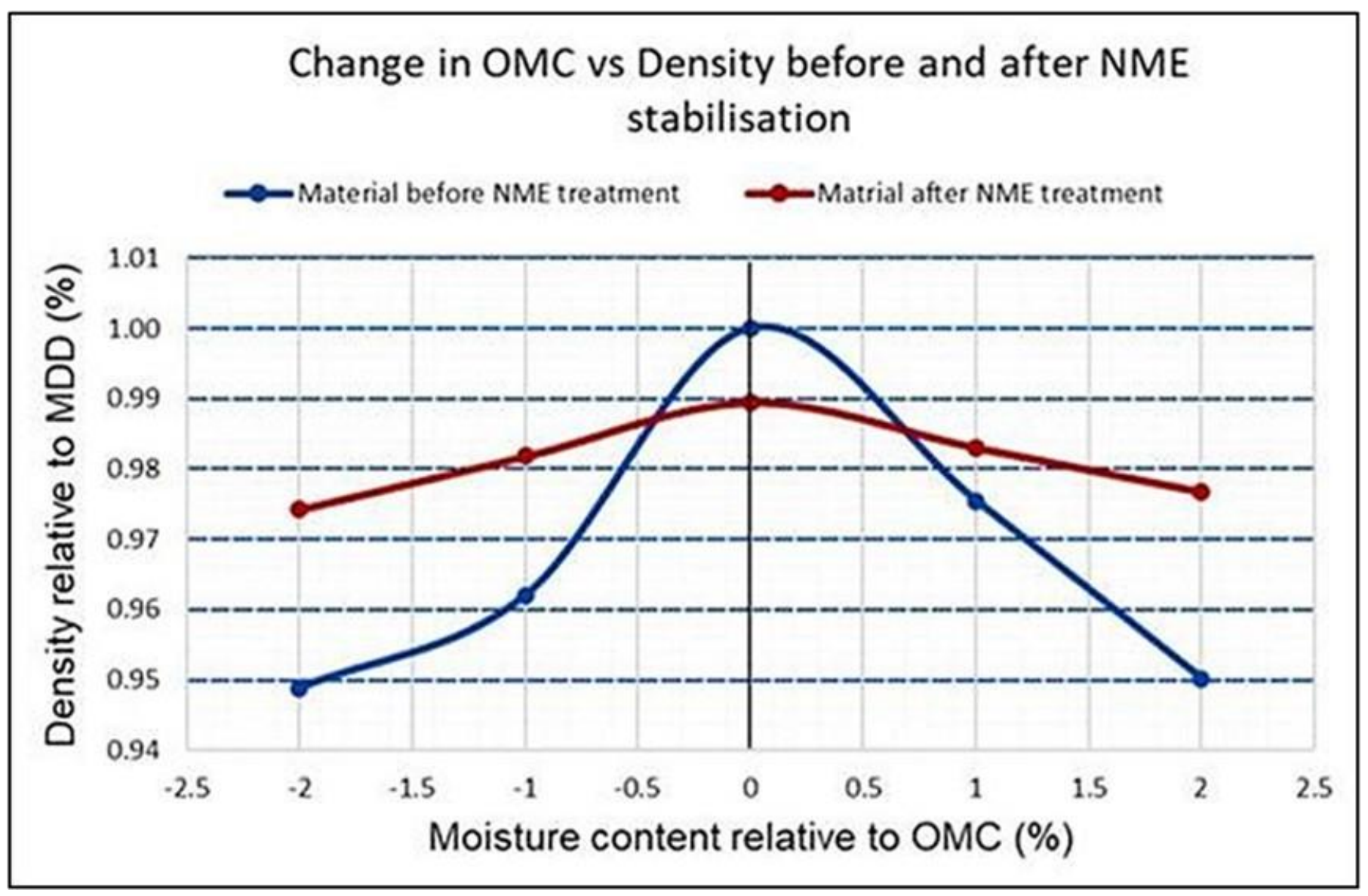

Figure 58 [10]. Change in material relative density as a function in the change of moisture relative to the OMC

\subsubsection{Concerns with regard to the future rehabilitation}

Future rehabilitation of pavement layers originally stabilised with a water-repellent NME stabilising agent will be exactly the same as discussed in the previous section. It should be realised that the material particles are rendered hydrophobic and that the stabilising agent is still an organic substance (bitumen or equivalent polymer of similar characteristics. The only change will be in the amount of water required to recompact or restabilize a previously NME stabilised layer - similar to the graph shown in Figure 58. Less water will be required to achieve the specify density - a considerable advantage in 
water-challenged regions of the world. With predictions of climate change and earth warming this factor could become more significant in future road construction projects.

\subsection{Uneven spray rates caused by blocked nozzles during construction using recyclers}

This is a common problem often related to poorly cleaned and or maintained equipment. The effect of blocked recycling nozzles or nozzles resulting in uneven distribution of the stabilising agent is easily noticed through the appearance of uneven coloured materials behind the recycler as shown in Figure 59.

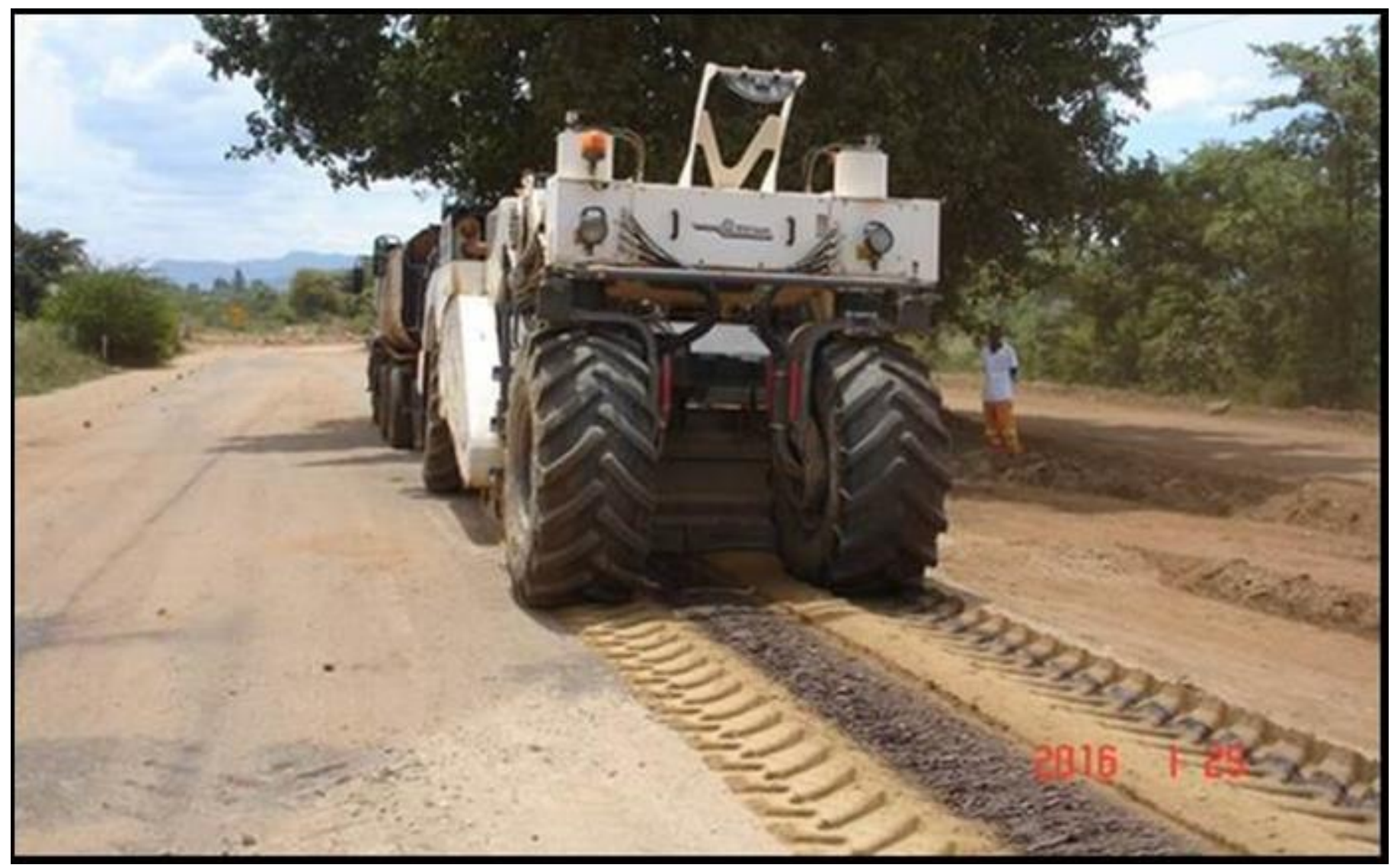

Figure 59. Uneven distribution of the stabilising agent behind the recycler caused by blocked spray-nozzles

The NME stabilising agent need to be evenly distributed through the width and depth of any layer during construction to achieve the required engineering properties, similarly to any other stabilising agent. Due to the resilient nature of the NME stabilising agent as discussed in the preceding sections, this particular problem can be resolved easily using conventional equipment to evenly distribute and mix the stabilising agent into the layer as demonstrated in Figures 60 to 


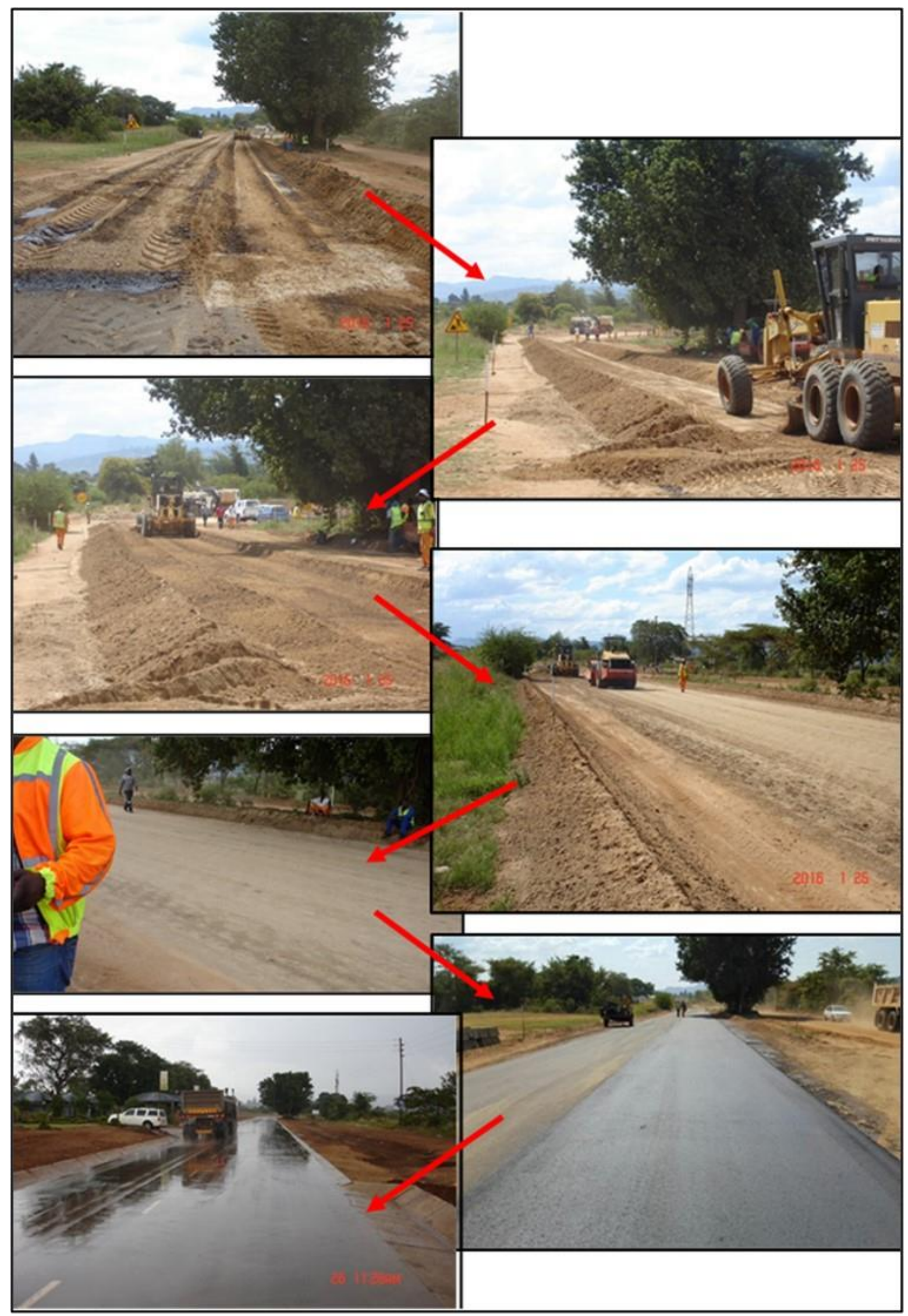

Figure 60. Resolving the uneven distribution of the NME stabilising agent trough the remixing of the road pavement layer using conventional equipment. 


\subsection{Incompatibility of materials.}

A problem generally applicable to pavement engineering is the use of incompatible materials together in the same design. These incompatibilities are not normally addressed in design documents and is a major problem associated with the general use of catalogue designs in combination with documents addressing available stabilising and binder modifications without emphasizing the basic principle of material compatibility. A first rule of thumb borrowed from basic chemistry is "likes prefer likes", i.e. similar binders prefer and works well with the same type of binder. Figure 61 show the application of two binders on the same NME stabilised sample. On the left, a similar NME modified binder was used in the seal. The seal could not be separated from the sample with a trowel resulting in the breaking of the stone chips without separating the applied seal. The binder of the seal on the right contained a sample of the right contained a latex modified binder which showed little adhesion to the NME stabilised sample. In fact the seal on the sample on the right could easily be removed by hand.

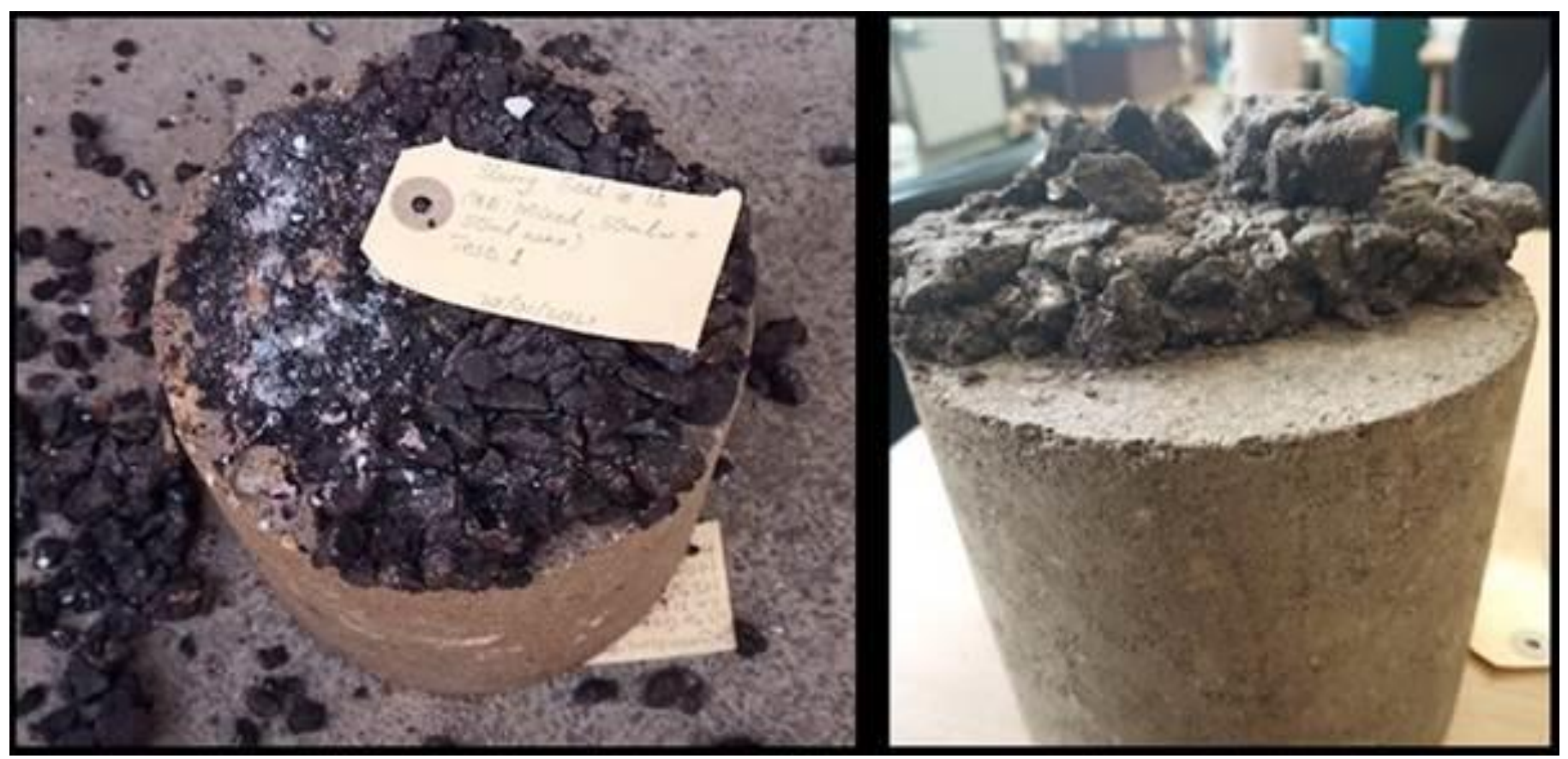

Figure 61. Application of different binders to the same NME stabilised samples showing the results of the use of compatible (left) and incompatible binders (right

Similar to Figure 61, the differences in the application of an applicable prime is shown in Figure 62. On the left is the application of a diluted anionic NME prime applied to the surfacing of an anionic NME stabilised sample. On the right is the consequences of the application of a diluted cationic prime to an anionic stabilised base layer, resulting in catastrophic failures. 


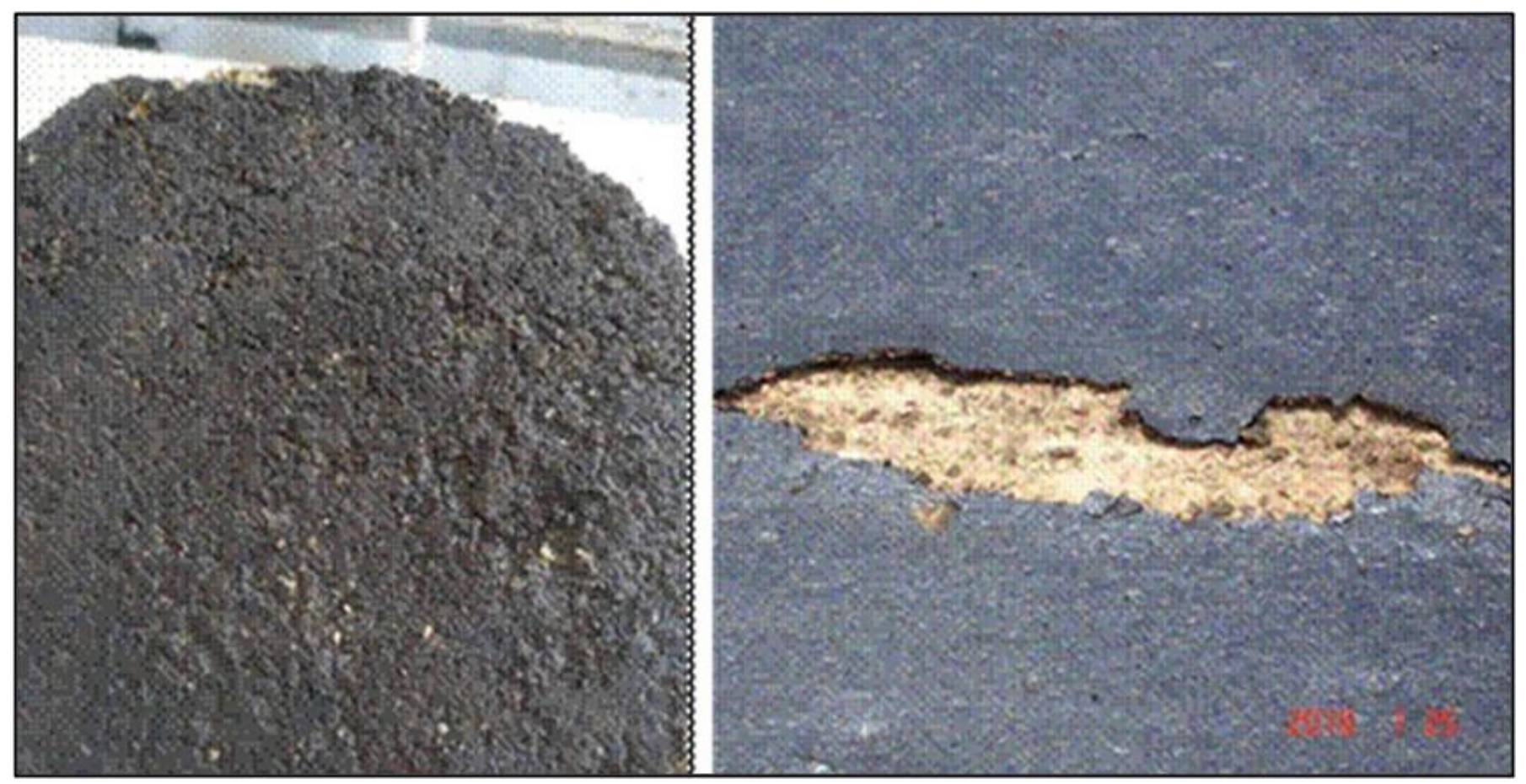

Figure 62. Material compatible prime of an anionic stabilised sample (left) versus a non-compatible prime applied to an anionic stabilised base layer (right)

7.5 Addressing and assuring depth of stabilisation for the rehabilitation construction of roads utilising in-situ materials

Many pre-mature failures have been investigated and could directly be associated with the depth of reworking and in-situ stabilisation not meeting the specified depths. Modern recyclers are easily programmed to change the depth of reworking which could result in considerable savings both in time and costs of the application of the stabilising agent. As a consequence, to counter these activities, it is often specified that pavement layers identified to be reworked and stabilised be pre-milled and windrowed to the specified depth. A new road-bed will then be recompacted before the milled material is reintroduced and stabilised. In the optimisation of designs layer thicknesses are also optimised and should be carefully monitored to prevent pre-mature failures. Figure 63 show the milling and windrowing of pavement layers before reintroduction and stabilisation using an anionic stabilising agent.

Modern construction equipment is able to easily rework layer up to a depth of at least $450 \mathrm{~mm}$ and successfully compact layers of these thicknesses to the specified densities. Before allowing contractors to deviate from the original design by combining layers, these practices should be verified with the design engineer. The reason for this is simple. The stress/strain distribution of a pavement structure containing, for example, two 150 $\mathrm{mm}$ stabilised layers may not necessarily be the same as the stress/strain distribution of a single $300 \mathrm{~mm}$ stabilised layer. It follows, that the combination of layers within a pavement structure may have an influence on the bearing capacity of the pavement structure. This example is especially relevant for the stabilisation of layers creating a semi-ridged structure with a low tolerance toward flexure (tensile) strength [/]. Pavement engineering has experienced a strong movement away from empirically based design methods towards Mechanistic-Empirical (ME) design methods. ME design methods enables a detailed analysis of stress/strain distributions through complex pavement structures. These abilities and associated proven failure theories should be fully utilised to prevent uninformed decisions to be verified before any deviation of the specified design is approved by site personnel not familiar with the original design. 


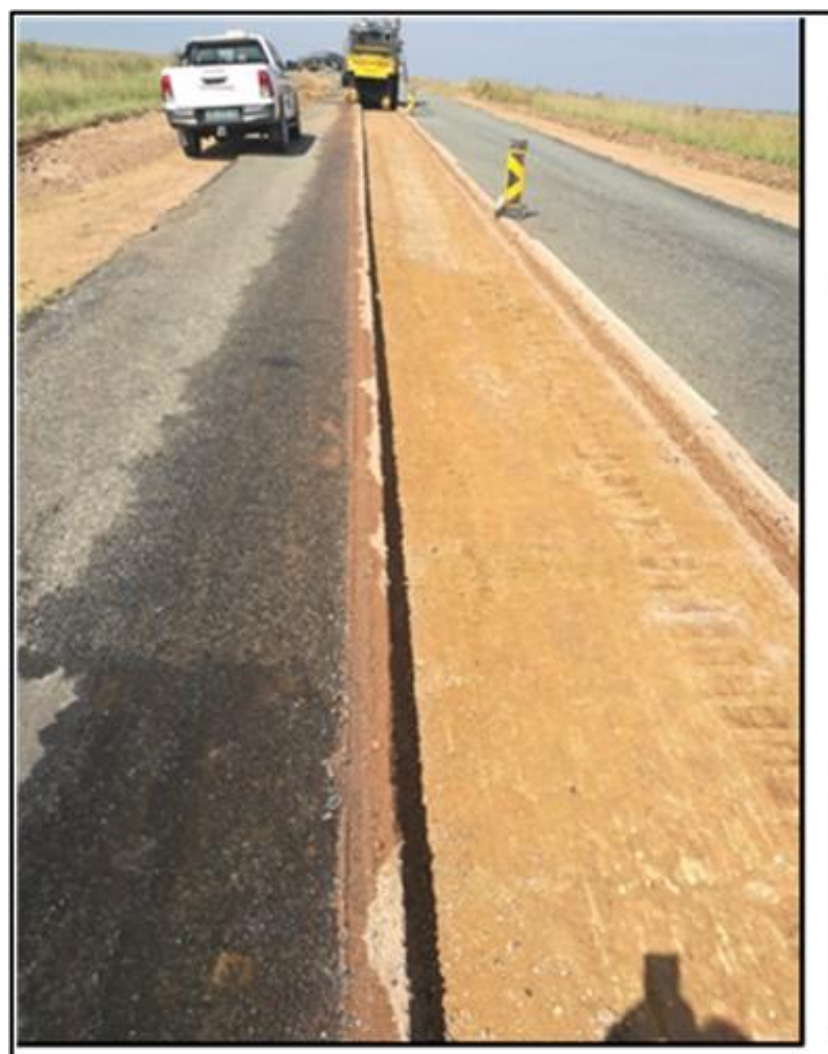

(a)

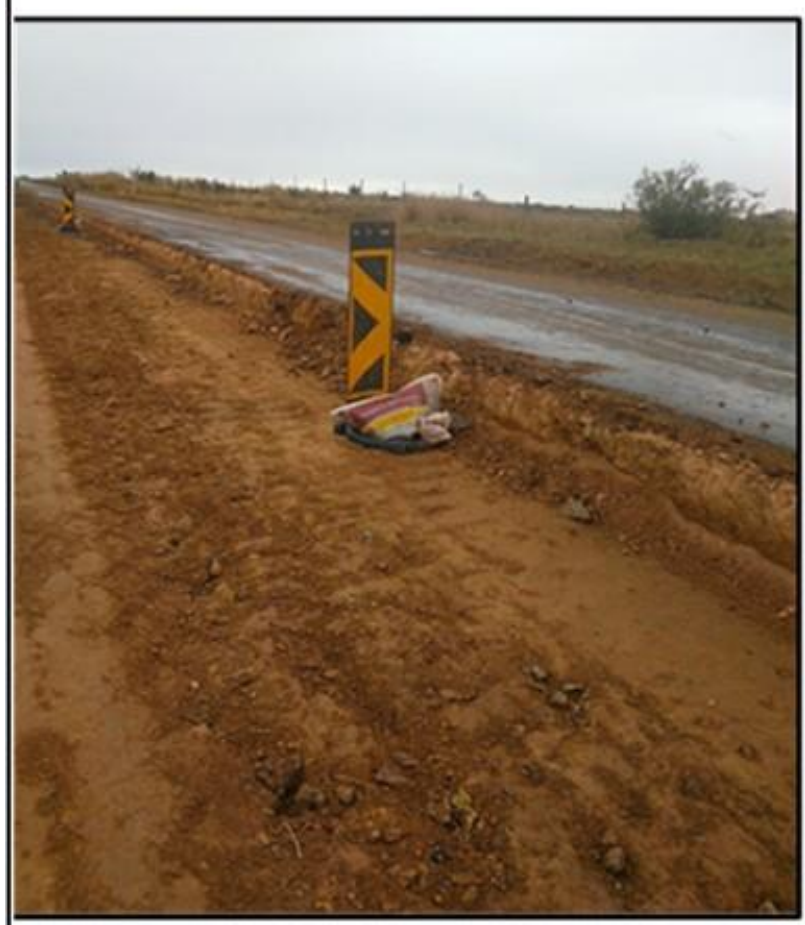

(c)

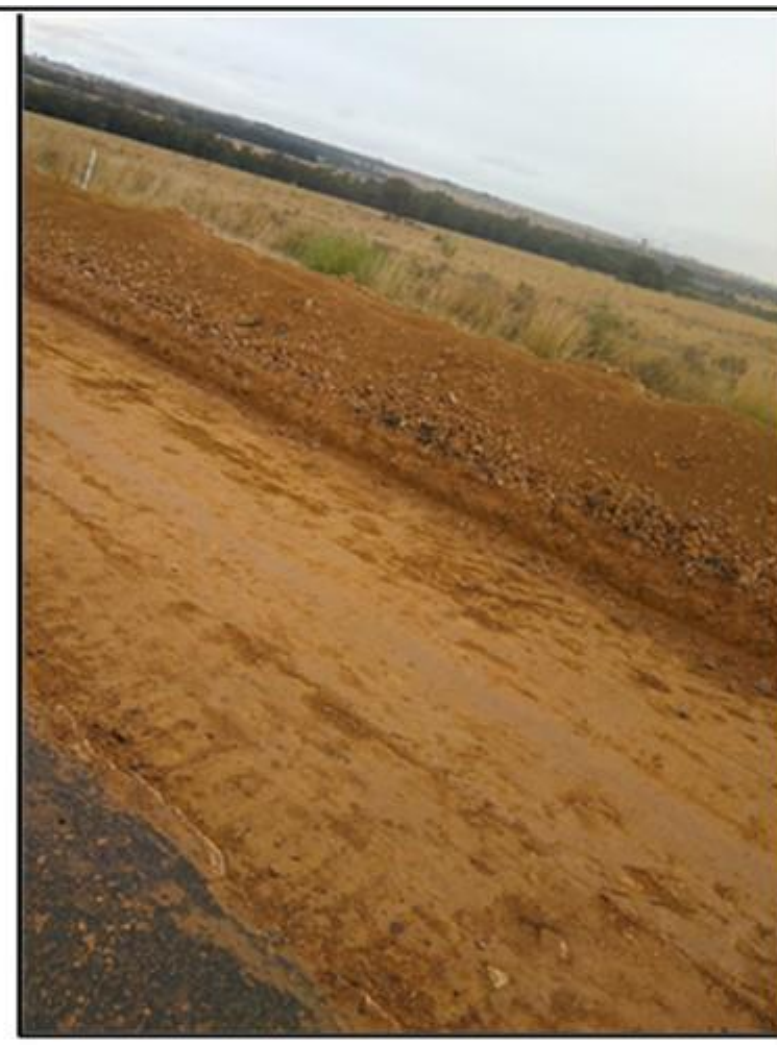

(b)

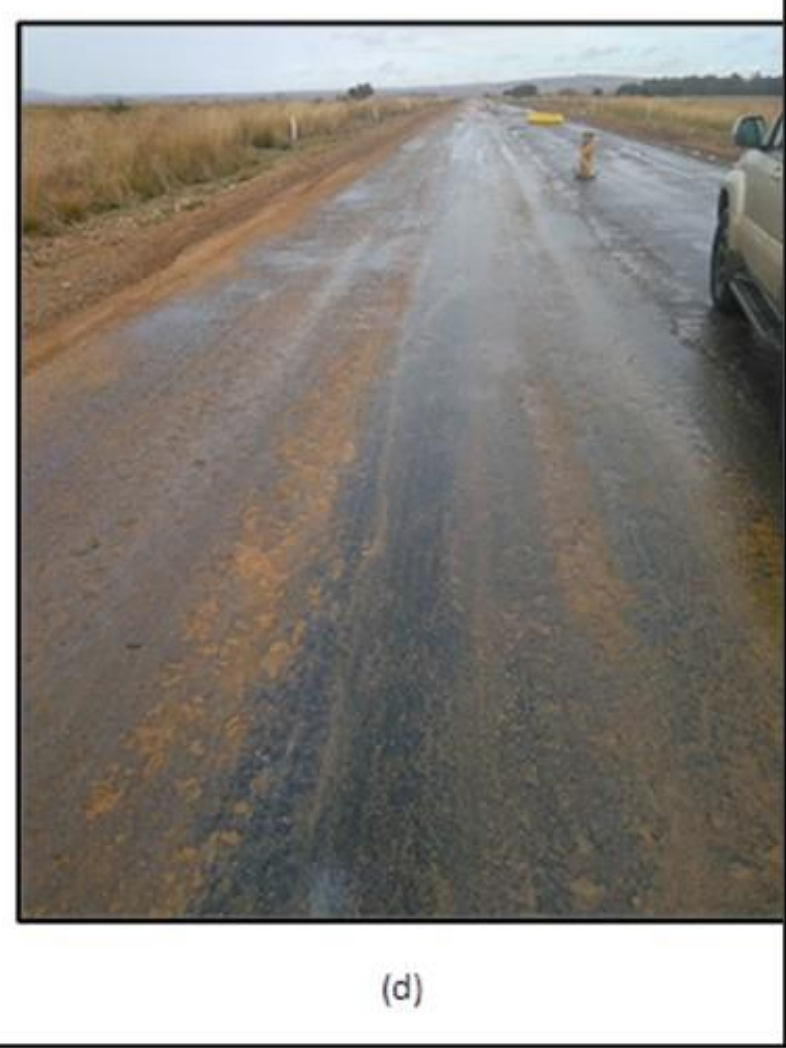

Figure 63. (a) Milling of existing base and sub-base layers to be stabilised using an anionic NME stabilising agent (b) stockpiling of material next to the road (c) showing depth of milling and new road-bed to be compacted and (d) showing the reintroduced sub-base and base separately stabilised using an anionic stabilising agent 


\section{Nanotechnology solutions to road maintenance needs}

Failures on existing surfaced road infrastructure are often associated with the aging and associated cracking of the surface materials that are not able to provide distress free protection to the pavement structure over the design period. These failures are especially pertinent in regions not associated with institutionalised Maintenance Management Systems (MMS's). Periodic maintenance needs to be performed on roads at regular intervals to ensure that the surfacing will continue to provide the required protection to the pavement structure underneath the surfacing. Unfortunately, MMS's are often not prioritised, resulting in pre-mature (before the end of the original design period) cracking followed by the appearance of pot-holes that continue to expand as a result of the natural variation in the material properties.

Applicable and proven nanotechnologies can also play a considerable role in the protection of the existing surfaced road infrastructure due to the inherent properties of the organofunctional silanes in terms of e.g.:

- Water-repellent (hydrophobic) characteristics that will render surfacings to repel water and prevent the ingress thereof, and

- Nano-scale particle size that enables deep penetration into the existing surfacing and restore the water-resistant characteristics of existing surfacings.

The application of maintenance activities incorporating suitable nanotechnology solutions can be highly effective towards labour-intensive operations. These actions could include the manufacturing and hand application of anionic NME modified slurry seals to the application of nano-silane nano-polymer clear-seals that would restore the protective characteristics of existing surfacings. Anionic NME slurries are ideally suited for routine maintenance of existing road surfacings through the application of a NME modified slurry seal, the basics of which is illustrated in Figures 64. Prior to the application of the NME Modified slurry, it is recommended that the old, distressed surfacing be pre-treated with a deep penetrating waterproofing spray that is applied through a labour-intensive treatment of the old surfacings with a Nano-silane Modified Graded Nano-Polymer clear-seal, the application of which is shown in Figure 65. This pre-treatment will provide deep protection throughout the old-open surfacing which will prevent future ingress of water into an open surfacing and the formation of potholes.

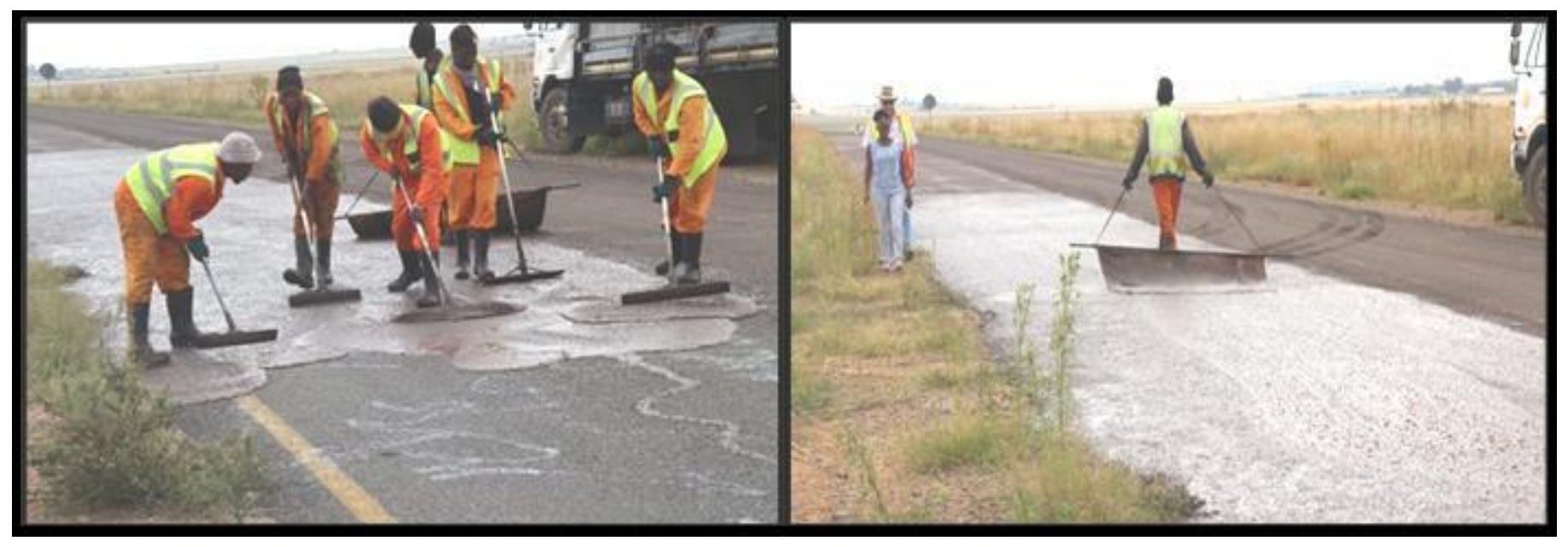

Figure 64. Application of a labour-intensive anionic NME slurry seal to effectively provide a water-repellent new surfacing, preventing water-ingress into the pavement structure on as severely cracked surfacing without disturbing the existing surfacing and restoring some riding quality - this surfacing will dry within 6 hours due to the water-repellent addition of the nano-silane - a six hour working envelope is created by dilution the anionic NME modified normal slurry mix by 50:50 with water, reducing the bitumen content by about 50\% while creating a permanent bonding to the old surfacing and a water-resistant surfacing 


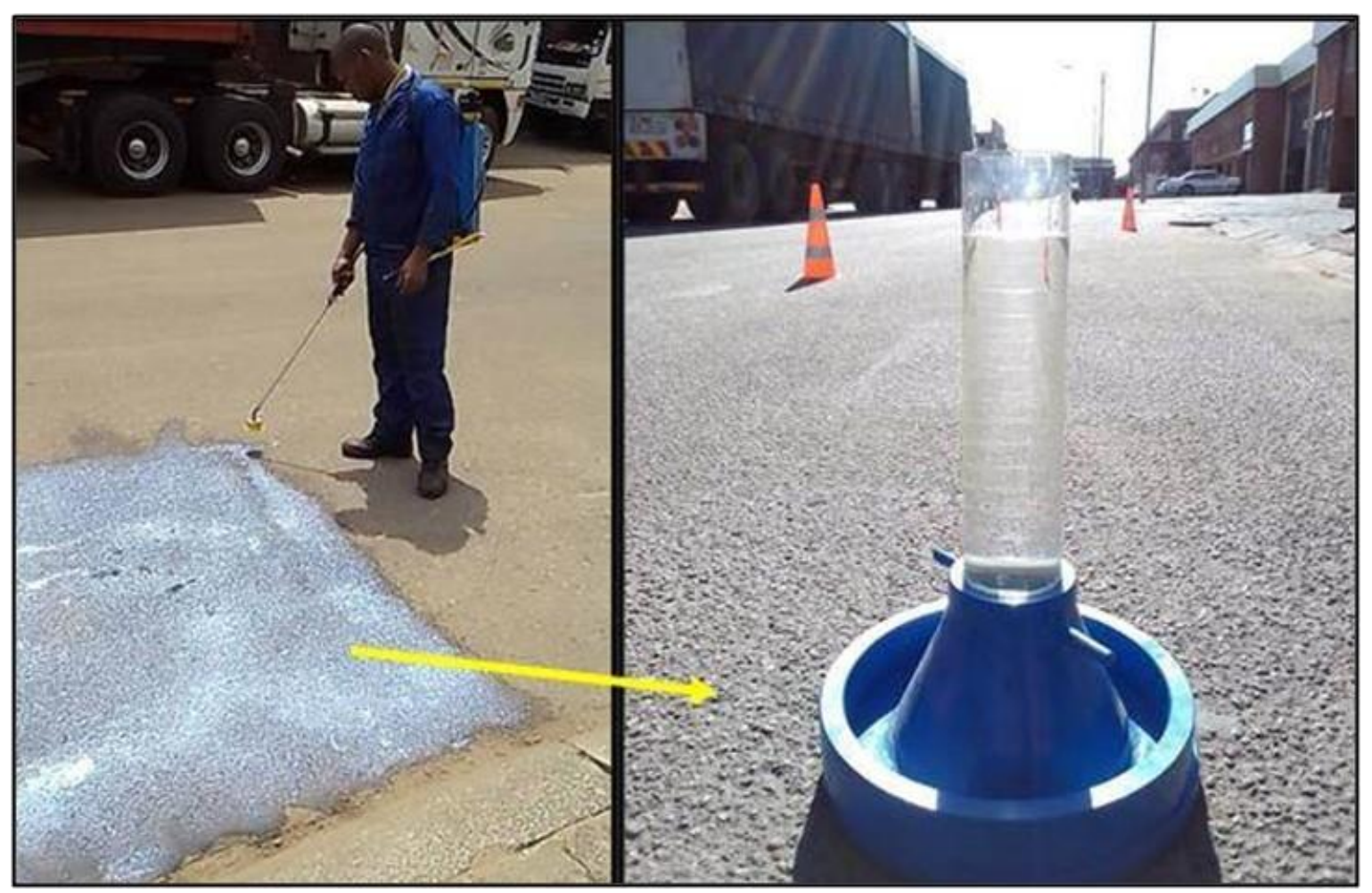

Figure 65. Labour-intensive application of a Nano-Silane Nano-Polymer (NSNP) clear-seal to provide a deep penetrating water-repellent surfacing to protect against the ingress of water into the pavement structure, preventing the formation of potholes (Photographs provided and published with permission [21]

The effect of the application of a NSNP clear- seal application of an unprotected crushed-stone base-layer is demonstrated in Figure 66 at the University of Pretoria at the Engineering 4 facility. The effect of clear-seal is demonstrated in Figure $x x$, showing the difference between the treated and untreated sections of the crushed stone layer. The penetration rates of the G1 layer after being exposed to elements for more than 6 months with some vehicle movement on some sections are summarized in Table 2.

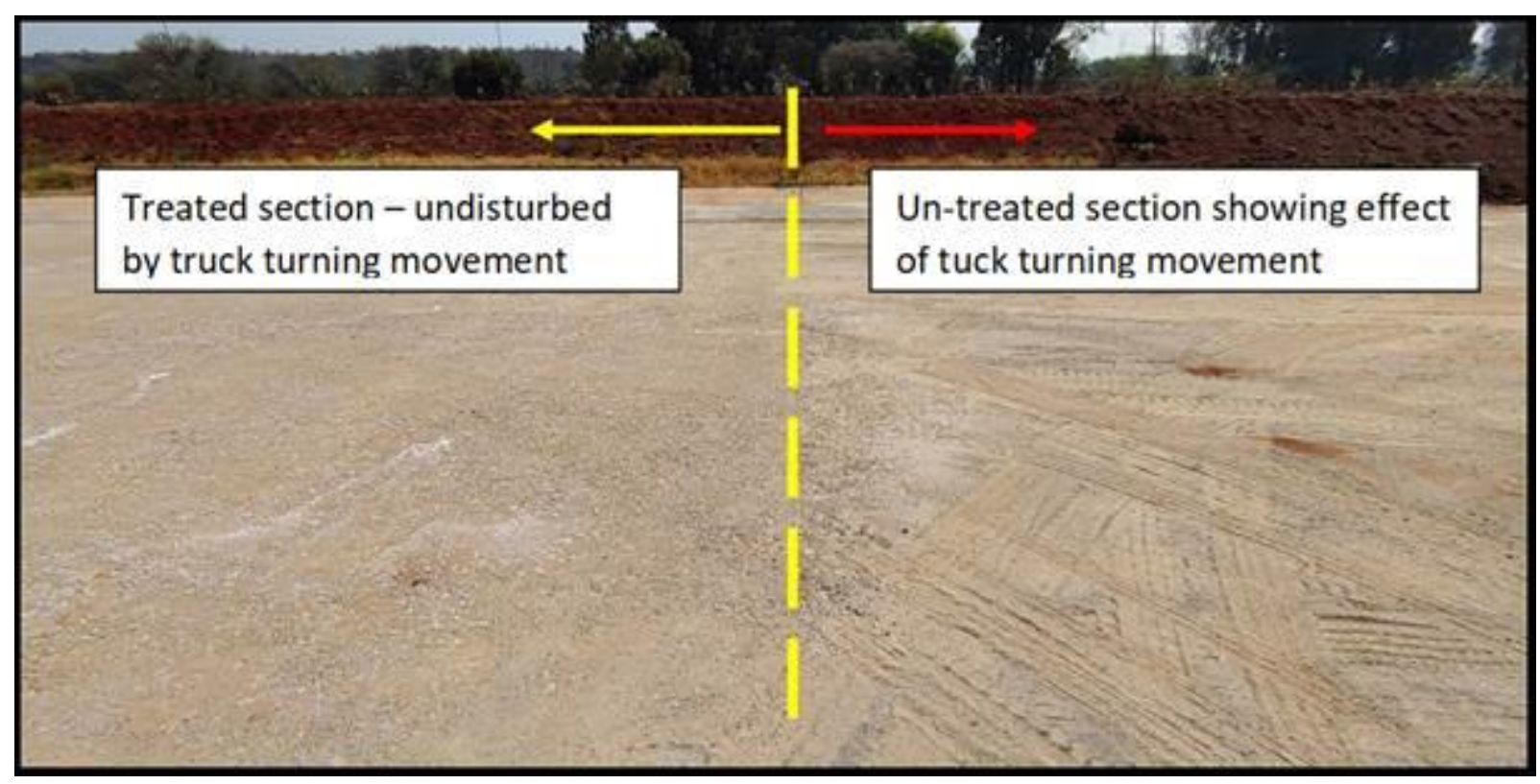

Figure 66. NSNP clear-seal application on an unprotected G1 layer at the Engineering 4 facility at the University of Pretoria showing the effect of truck movements on sections treated versus untreated sections 
Table 2*: Penetration rates tested using Marvil apparatus of the application of a NSNP clear-seal on an exposed G1 layer at the Engineering 4 facility at the University of Pretoria ( date applied - 21-08-2020; date tested - 20 -05-2021) test duration on each section $=1$ hour

\begin{tabular}{|c|c|c|c|}
\hline $\begin{array}{l}\text { Permeability measured on } \\
\text { the G1 layer per volume of } \\
\text { water }\end{array}$ & G1 layer - Untreated & $\begin{array}{l}\text { G1 layer - Treated with } \\
\text { a NSNP Clear-seal ap- } \\
\text { plied at } 21 / \mathrm{m}^{2}-\text { no } \\
\text { traffic }\end{array}$ & $\begin{array}{l}\text { G1 layer - Treated with a } \\
\text { NSNP clear-seal applied at } \\
21 / \mathrm{m}^{2} \text { - with } 9 \text { months of } \\
\text { light vehicle travelling and } \\
\text { some surface damage }\end{array}$ \\
\hline @ 50 ml & $0.370 \mathrm{l} /$ hour & $0.035 \mathrm{l} /$ hour & $0.059 \mathrm{I} /$ hour \\
\hline @ 100 ml & $0.260 \mathrm{l} /$ hour & - & - \\
\hline @ 150 ml & $0.207 \mathrm{I} /$ hour & - & - \\
\hline \multicolumn{4}{|l|}{$\begin{array}{l}\text { Permeability at different } \\
\text { intervals }\end{array}$} \\
\hline $20 \mathrm{ml}$ & - & $0.030 \mathrm{l} /$ hour & - \\
\hline $25 \mathrm{ml}$ & - & - & $0.061 \mathrm{l} /$ hour \\
\hline $75 \mathrm{ml}$ & $0.279 \mathrm{l} /$ hour & - & \\
\hline Average Permeability & $0.279 \mathrm{l} /$ hour & $0.030 \mathrm{l} /$ hour & $0.061 \mathrm{l} /$ hour \\
\hline
\end{tabular}

${ }^{*}$ Data gathered, provided and published with permission [21]

Clear-seal treatments are relatively inexpensive and can easily be performed by maintenance teams and sprayed (applied) by hand (refer Figure 65), providing a deep penetrating, waterproof protective layer with no "pickup" by vehicles and no-repainting of road signs. In cases where no severe cracking is as yet present, the application will provide a waterproof layer, bind the existing surface together and will provide an extended pot-hole free surfacing. Where damaged in terms of pot-holes have already occurred the surfacing can quickly be fixed with an anionic NME gravel mix (Figure 67[/]), which will dry within an hour, an applied at a fraction of the costs of traditional cold-mix, providing a waterproof foundation for the application of an anionic NME clear-seal followed by an anionic slurry to restore the water-proof the surfacing layer. In the presence of extensive existing crocodile cracking, these actions can be followed by the application of a labour-intensive anionic NME slurry, providing a maintenance free flexible, ultra-violet (UV) resistant, new surfacing with an expected surfacing life in the order off 6 to 10 years, depending on traffic and climatic conditions. These actions can all be applied at ambient temperatures, requiring no extensive dangerous heating processes and creating numerous employment opportunities while protecting one of the most precious existing assets (transport infrastructure) of a country. Existing available and proven new-age nanotechnology solutions are available to immediately impact on employment, while providing the required maintenance actions desperately needed to protect one of the cornerstones needed for economic development. The anionic NME pot-hole kit is designed to adhere to granular material and handling by hand will cause minimum contamination with no bitumen sticking to exposed skin as demonstrated in Figure 68 where the material was purposely handled by hand to demonstrate the effect of the organofunctional modification of the bitumen emulsion used to fill the pot-hole. 


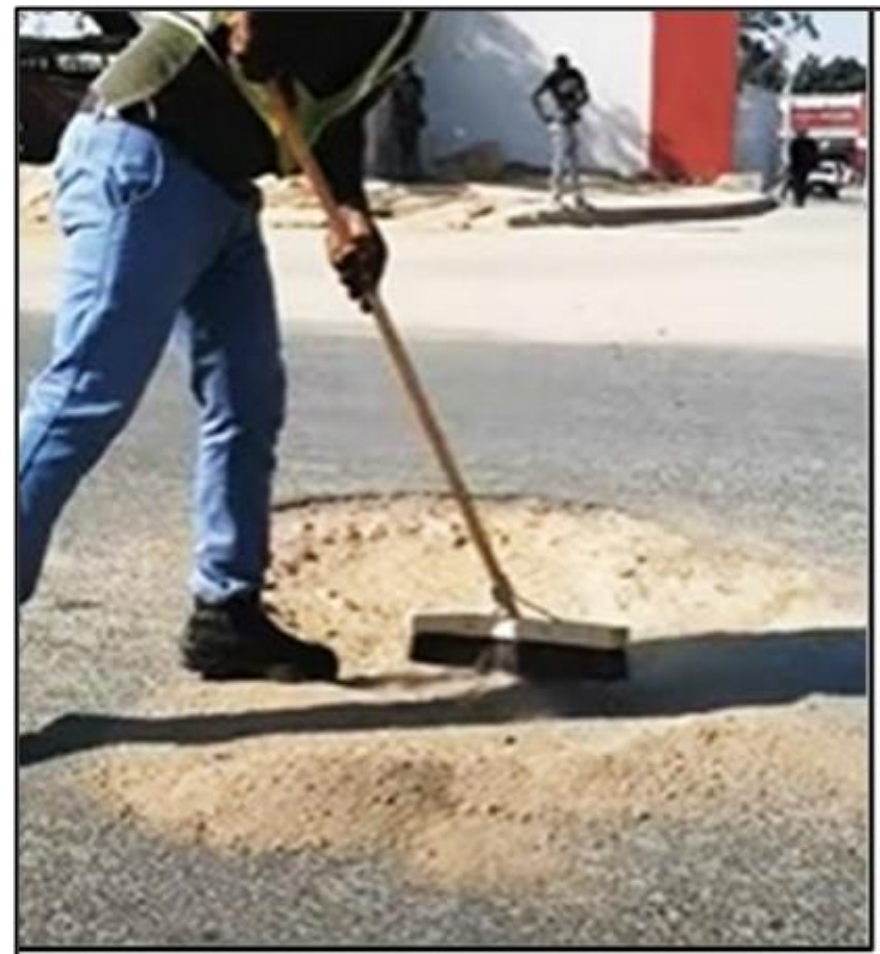

(a)

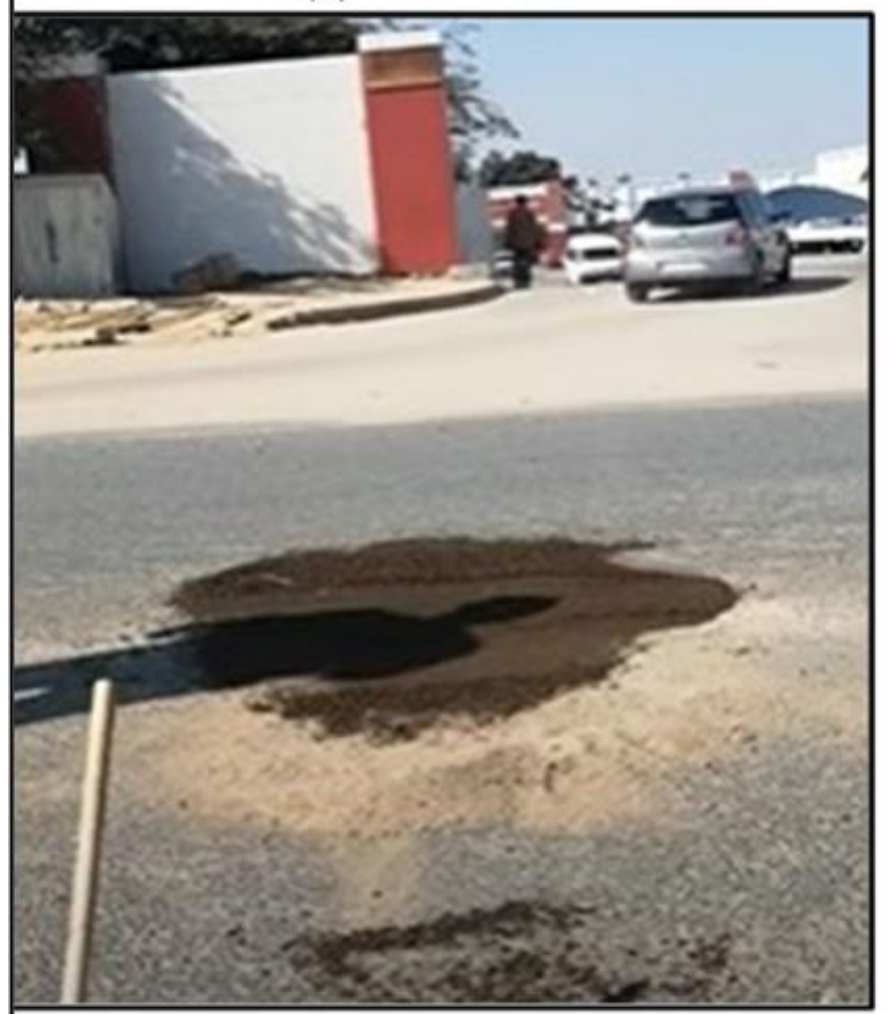

(c)

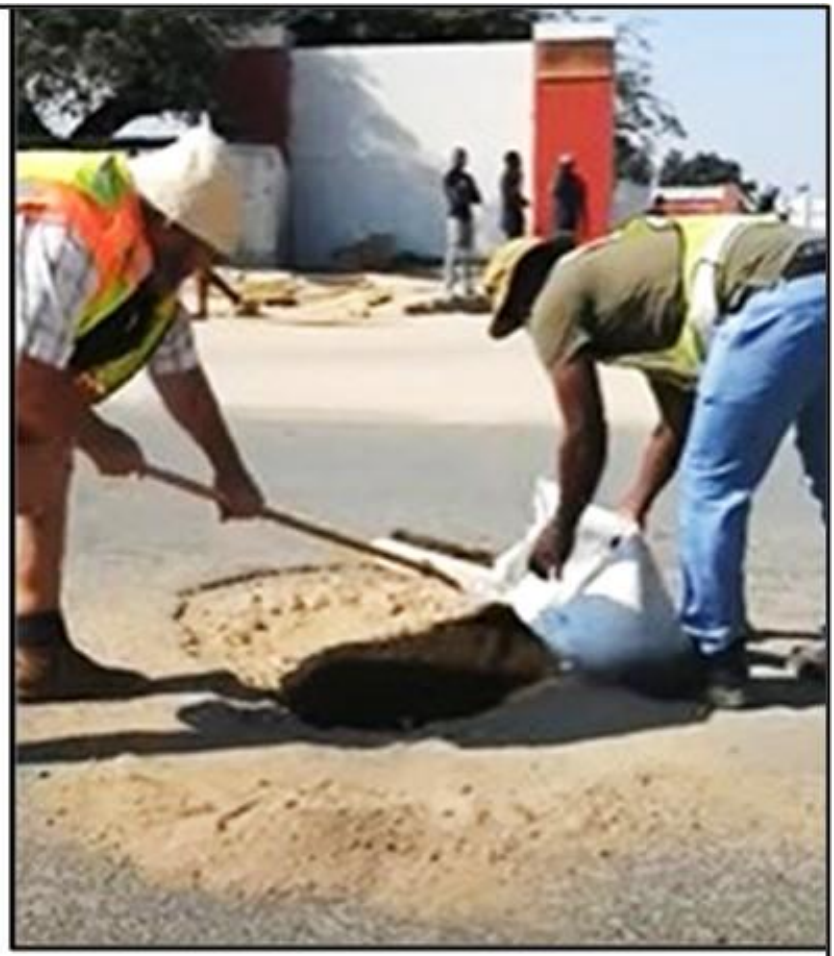

(b)

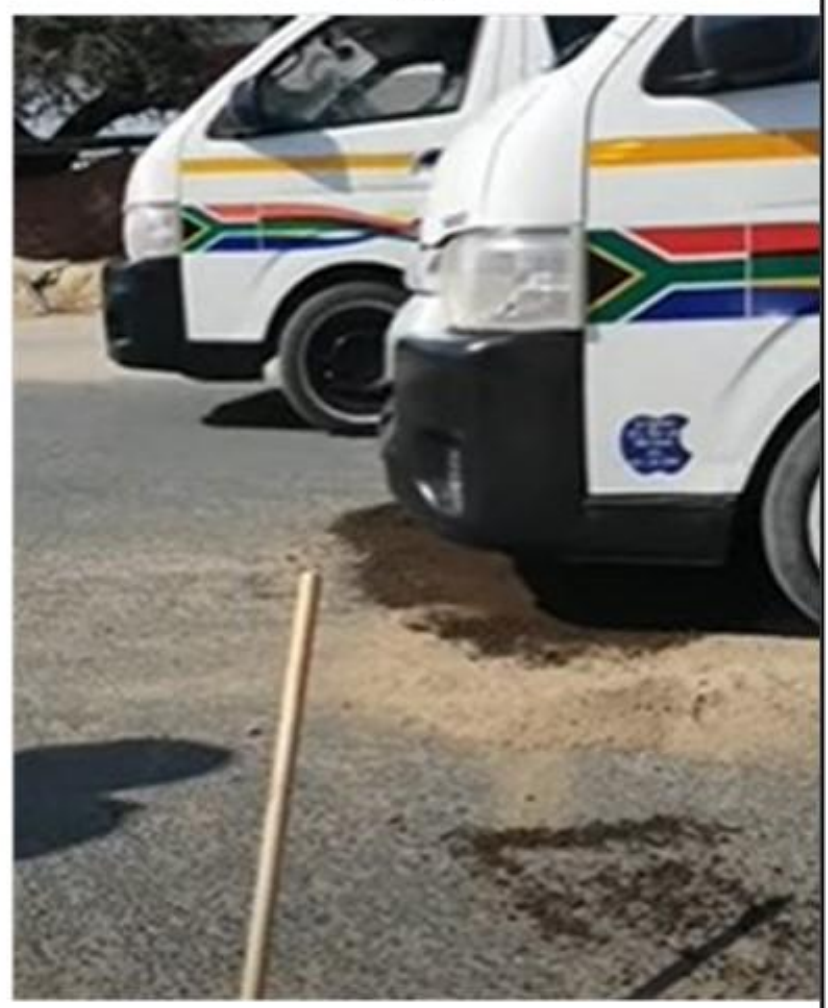

(d)

Figure 67. (a) Cleaning of pot-hole; (b) filling pot-hole with a water-resistant anionic NME gravel; (c) hot-hole filled and partially compacted by hand, and $(\mathrm{d})$ vehicles driving over filled pot-hole and increase compaction (Photographs provided and published with permission [20]) 


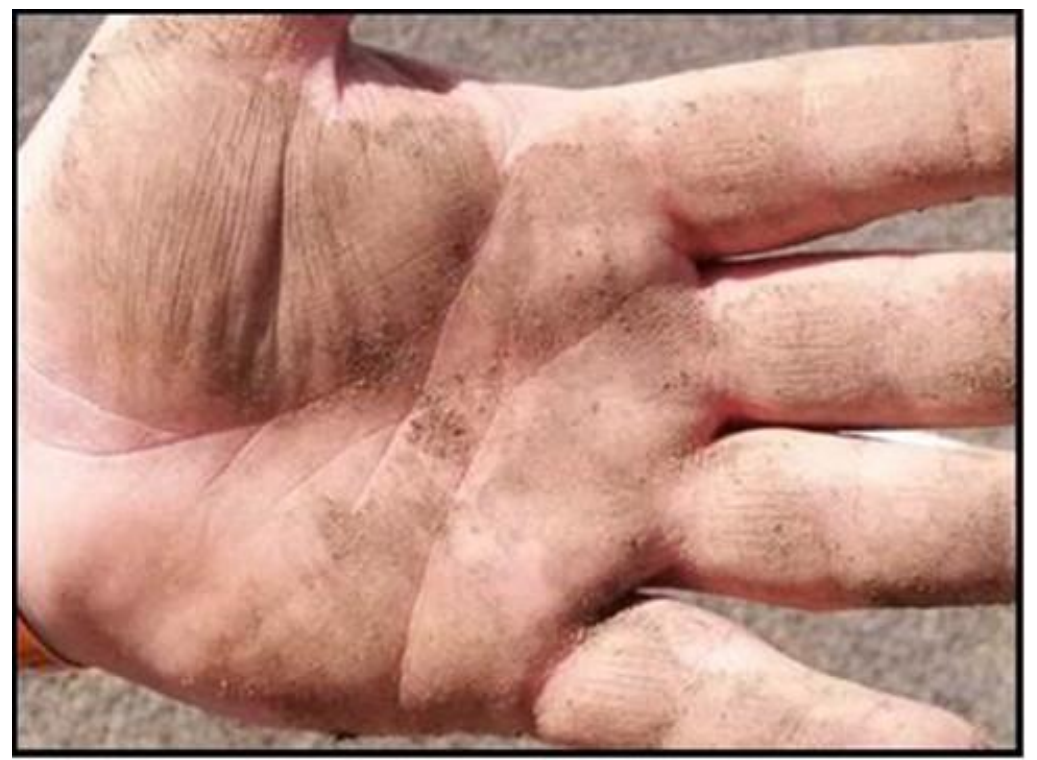

Figure 68. Demonstration of the effect of the organofunctional modification of the bitumen emulsion that is designed to adhere to granular material not contaminating the bare hand with bitumen

\section{Conclusions}

Granular materials traditionally classified as marginal in terms of use on various road categories, stabilised and improved by using material compatible nanotechnologies in the form of New-age (Nano) Modified Emulsions (NME), have been tested and evaluated over a number of years in laboratories and in practice using Accelerated Pavement Tests (ATP). Scientifically based material design methods, based on the mineralogy of the granular materials, have been developed to ensure that potential risks associated with the introduction of new technologies are minimised, if not eliminated. From all the evidence produced, there is little doubt that the introduction of the NME nanotechnology products can considerably reduce the unit costs of the construction of road infrastructure. The implementation of these available and proven technologies can contribute significantly towards the cost-effective delivery of much needed road infrastructure without compromising the quality of the end product. In-fact, from the available results, it is evident that the durability of the roads will be improved through the use of these nanotechnologies that introduce water-repellent characteristics which inhibits in-situ chemical weathering of granular materials..

However, the acceptance and roll-out of new technologies in the provision of bulk infrastructure need to be accepted by the construction industry. Any new technology introduced into the construction industry must be shown to be reliable, be used at an acceptable risk without considerable advanced capital investments in new equipment and be resilient in the face of unforeseen problems. No construction site is without problems and the introduction of new technologies need to have the ability to be user-friendly in the face of these problems. These principles apply to the construction of any road from multi-lane highways to Low Volume Roads (LVR).

The practical implementation of NME technologies for the stabilisation of granular materials for use on all road categories have been demonstrated. Adhering to basic sound construction processes, it is shown that NME stabilised granular materials are suitable for use in combination with the most sophisticated equipment to the most basic. Addressing a number of possible problematic construction challenges, it is shown that the NME characteristics is such that problems can be rectified with little additional costs and effort. In fact, construction tempos proven in practice and generally achievable, will be matched by few (if any) other available road construction materials, even at considerably higher costs. 
The water-resistant characteristics introduced through the NME nanotechnologies as tested in laboratories and during ATP testing, has shown its effectiveness in practice under severe (unplanned - as a normal risk associated with road construction projects) weather conditions. Unprotected pavement layers survived, without damage, cyclone rain conditions which normally would have required reconstruction of these exposed layer-works. Concerns in terms of the reworking of NME stabilised granular material pavement layers have been thoroughly addressed in practice. Pavement layers have successfully been re-worked without any additional water or stabilising agent and with the addition of a small percentage of NME. The impact on the construction moisture content to achieve the specified densities is especially of note in water-scarce regions of the world and the predicted impact of climate change.

Over and above the use of NME nanotechnologies (which incorporates nano-silane technologies) for the construction or rehabilitation of roads, the significant potential of these technologies in terms of the maintenance of the existing road infrastructure is demonstrated. The implementation of these maintenance activities can be done with little training, requiring no sophisticated equipment and incorporate the water-resistant characteristics of the organofunctional silanes. With little layout, numerous employment opportunities can be created which will provide effective protection to existing surfaced roads from the detrimental effect of water-ingress and the resultant formation of pot-holes. These activities can effectively contribute to the protection of existing surfaced roads and positively address some of the well-documented, existing back-logs, in the maintenance of surfaced road networks throughout the world.

Author Contributions: G.J.J. under the directive of the Head of Department of Civil Engineering, W.J.vdM.S., has been leading the research into the provision of affordable road infrastructure at the faculty of Engineering, University of Pretoria. He has been instrumental in the design, implementation and construction supervision of roads using nanotechnologies. W.J.vdM.S. recognized the potential of nanotechnology solution in the field of pavement engineering more than a decade ago. G.J.J., through involvement in the private sector, has been responsible for the development of scientific principles, ensuring that implementation can be achieved at a minimum risk. All authors have read and agreed to the published version of the manuscript.

Funding: This research received no external funding.

Institutional Review Board Statement: Not applicable.

Informed Consent Statement: Not applicable.

Data Availability Statement: Not applicable.

Acknowledgments: The support of GeoNANO Technologies (Pty) Ltd., 18 Davies road, Wychwood, Germiston, 1401, South Africa, Tel: +27844078489, www.geonano.co.za, info@geonano.co.za, in support of students in the Department of Civil Engineering, University of Pretoria, Pretoria, South Africa, to test a wide variety of materials as part of final year projects and post-graduate theses, testing the various principles identified in this paper, is acknowledged.

Conflicts of Interest: The authors declare no conflict of interest.

\section{References}

1. Steyn, W.J.vdM.; The upside of disruptive 4IR technology and innovation, University World News - Africa Edition, 2021.

2. Jordaan, G.J.; Kilian, A. The cost-effective upgrading, preservation and rehabilitation of roads-Optimising the use of available technologies. In Proceedings of the 2016 Southern Africa Transportation Conference (SATC 2016), Pretoria, South Africa, 4-7 July 2016.

3. Jordaan, G.J.; Kilian, A.; Du Plessis, L.; Murphy, M. The development of cost-effective pavement design approaches using mineralogy tests with new nano-technology modifications of materials. In Proceedings of the 2017 Southern Africa Transportation Conference (SATC 2017), Pretoria, South Africa, 10-13 July 2017.

4. Jordaan, G.J.; Steyn, W.J.vdM. A Comprehensive guide to the Use of Applicable and Proven Nano-Technologies in the Field of Road Pavement Engineering Design and Construction; Department of Civil Engineering, University of Pretoria: Pretoria, South Africa, 2019; ISBN 978-0-620-83022-5. 
5. Jordaan, G.J.; Steyn, W.J.vdM. Testing of granular/soil characteristics for the optimisation of pavement designs using reactive stabilising agents including "new-age" nano-technologies. In Proceedings of the 12th Conference of Asphalt Pavements for Southern Africa (CAPSA 2019), Sun City, South Africa, 13-16 October 2019.

6. Jordaan, G.J.; Steyn, W.J.vdM. Fundamental principles ensuring successful implementation of new-age (nano) modified emulsions (NME) for the stabilisation of naturally available materials in pavement engineering. Appl. Sci. 2021, 11, 1745. doi:10.3390/app11041745.

7. Jordaan, G.; Steyn, W.J. Basic chemistry explaining engineering properties of new-age (nano) modified emulsion (NME) stabilised naturally available road pavement materials. Preprints 2021, 2021070627. doi:10.20944/preprints202107.0627.v1.Von Ebelman, J.J. Untersuchungen über die Verbinddungender Borsäure mit Aetther. Ann. Chem. Pharm. 1846, 57, 319-353.

8. Jordaan, G.J.; Steyn, W.J.vdM. Nanotechnology Incorporation into Road Pavement Design Based on Scientific Principles of Materials Chemistry and Engineering Physics Using New-Age (Nano) Modified Emulsion (NME) Stabilisation/Enhancement of Granular Materials. Appl. Sci. 2021, 11, 8525. https://doi.org/10.3390/app11188525Von Hoffman, W. Stone-preserving processes: Royal Institute of British Architects. Build. 1861, 19, 103-105.

9. Akhalwaya, I.; Rust, C.F. Laboratory evaluation of road construction materials enhanced with nano-modified emulsions (NME). In Proceedings of the Southern African Transportation Conference (SATC'18), Pretoria, South Africa, 9-12 July 2018.

10. Kidgell, M.M.; Steyn, W.J.vdM.; Jordaan, G.J. Effect of Nano-Modified Emulsions (NME) (nano-silanes) stabilisers on the properties of Dolomite, Proceedings of the 2019 Southern African Transportation Conference (SATC'19), Pretoria, South Africa, 2019.

11. Rust, F.C.; Akhalwaya, I.; Jordaan, G.J.; Du Plessis, L. Evaluation of a nano-silane-modified emulsion stabilised base and subbase under HVS traffic. In Proceedings of the 12th Conference on Asphalt Pavements for Southern Africa (CAPSA 2019), Sun City, South Africa, 13-16 October 2019.

12. Rust, F.C.; Smit, M.A.; Akhalwaya, I.; Jordaan, G.J.; Du Plessis, L. Evaluation of two nano-silane-modified emulsion stabilised pavements using accelerated pavement testing. Int. J. Pavement Eng. 2020, doi:10.1080/10298436.2020.1799210.

13. Jordaan, G.J.; Steyn, W.J.; Broekman, A. Evaluation of cost-effective modified binder thin chip and cape seal surfacings on an anionic nano-modified emulsion (NME)-stabilised base layer using accelerated pavement testing (APT). Appl. Sci. 2021, 11, 2514. doi:10.3390/app11062514.

14. Jordaan, G.J.; Kilian, A.; Machiavelli, N.; Dlamini, D. Practical Application of Nano-Technology in Roads in Southern Africa. In Proceedings of the 8th Transportation Technology Transfer (T2) Conference, Lusaka, Zambia, 4-8 March 2017.

15. Committee of Land Transport Officials (COLTO); Draft TRH14: Guidelines for Road Construction Materials; National Institute for Transport and Road Research (NITRR), CSIR: Pretoria, South Africa, 1985.

16. American Association of State and Highway Transportation Officials (AASHTO). M145-91: Standard Specification for Classification of Soils and Soil-Aggregate Mixtures for Highway Construction Purposes; AASHTO: Washington, DC, USA; 1995.

17. American Society for Testing Materials (ASTM). D3282-09: Standard Practice for Classification of Soils and Soil-Aggregate Mixtures for Highway Construction Purposes; ASTM: Pennsylvania, PA, USA, 2009.

18. Jordaan, G.J. Optimisation of Flexible Road Pavement Rehabilitation Investigations and Design; Department of Civil Engineering, University of Pretoria: Pretoria, South Africa, 2013., Distributed through www.lulu.com, ISBN 978-1-77592-036-6.

19. Jordaan, G.J.; Steyn, W.J. Cost-Effective Upgrading of Gravel Roads Using Naturally Available Materials with New-Age Modified Emulsion (NME) Stabilisation; Department of Civil Engineering, University of Pretoria: Pretoria, South Africa, 2020; ISBN 978-0-620-91415-4.

20. Photographs and data supplied by Mr. H. Swart, Published with permission, 2021.

21. Photographs and data supplied by GeoNANO Technologies (Pty) Ltd), Published with permission, 2021. 